The copyright of this thesis vests in the author. No quotation from it or information derived from it is to be published without full acknowledgement of the source. The thesis is to be used for private study or noncommercial research purposes only.

Published by the University of Cape Town (UCT) in terms of the non-exclusive license granted to UCT by the author. 


\section{Pollen digestion in flower-feeding Scarabaeidae: protea beetles (Cetoniini) and monkey beetles (Hopliini)}

\section{Shelley Johnson}

Thesis submitted in fulfillment of the requirements for the degree Master of Science

Zoology Department University of Cape Town

2000

Supervisor: Assoc. Prof. Sue W. Nicolson Co-supervisor: Dr Ian G. van Tets 


\section{Declaration}

I the undersigned, hereby declare that the work contained in this thesis is my own original work and that any technical assistance received is fully acknowledged. I have not previously submitted this thesis or any part of it at a university for a degree.

\section{Signed by candidate}

Shelley Johnson

Date $08 / 2000 \ldots$ 


\section{Acknowledgements}

My sincere thanks to my supervisor Assoc. Prof. Sue Nicolson for her time, assistance and guidance throughout the study.

I thank Dr. Ian van Tets for his time and comments on the manuscript.

I thank Miranda Waldron and Mohammed Jaffer of the Electron Microscope Unit (EMU), University of Cape Town, for their time and assistance in scanning electron microscopy and cryosectioning, and the EMU for access to their computing and printing facilities.

I gratefully acknowledge Wendy Sutton and Patricia Papier of the Postmortem Histology Laboratory in the Anatomical Pathology Department, University of Cape Town Medical School for assistance in sectioning material for staining purposes.

Bursaries for study towards obtaining a MSc degree were awarded to me by the National Research Foundation.

Finally, I thank Bevil Spence for his photography during fieldwork, comments on the manuscript and its presentation, but most importantly, his support and encouragement. 


\section{Abstract}

Beetles pollinate over $80 \%$ of all flowering plants and feed on the two most common floral rewards, nectar and pollen. Pollen is nutritionally very valuable, being a rich protein and carbohydrate source. However, the hard and highly resistant outer wall (exine) of the grain is an obstacle that pollen-feeders must overcome in order to benefit from the pollen's nutritious protoplasm.

There are a variety of mechanisms that pollen-feeders may use to deal with the exine. Collembolans secrete exinase that breaks down the wall, but other pollen-feeders do not produce this enzyme. Pollen-feeders that are unable to ingest grains may either pierce the grain and suck out the contents (thrips and biting-flies) or cause the grain contents to leach out and imbibe the leachate (butterflies and the eucalypt nectar fly). Pollen-feeders that can ingest the grains (bees, syrphid flies, rodents, marsupials, bats and birds) may use osmotic shock, pseudo-germination, exudation, microbial digestion or enzyme penetration to gain access to the protoplasmic contents. Further study is needed to define the details of these methods and whether they are all in use.

Very little is known about pollen-feeding in beetles and no previous work has been done on the digestion of specific pollen grain nutrients by beetles. The present study considers three pollen-eating scarab beetle species endemic to South Africa. The green protea beetle Trichostetha fascicularis is a cetoniine pollinator of Proteaceae in the southwestern Cape. Monkey beetles (Hopliini) pollinate mainly Asteraceae and Mesembryanthaceae, also in the southwestern Cape as well as Namaqualand. Two monkey beetle species, Peritrichia cinerea and Pachycnema flavolineata, belonging to two different monkey beetle pollinator guilds, were selected for the study.

The mouthparts and alimentary canals of beetles were examined by light microscopy, as well as scanning electron microscopy. Brushes of setae were present on all the mouthparts, but were most dense on the tips of the maxillae. Observations of feeding beetles showed that these brushes are well suited for mopping up nectar, as well as sweeping up pollen, a mechanism previously described for other flower-visiting beetles with similar brushes on their maxillae. The general structure of the alimentary canal and differences from the generalised insect gut were noted. Different gut regions were embedded in wax, sectioned and stained for the presence of amyloid and cellulose carbohydrates, proteins and lipids. Measurements of the intensity of stain uptake by each nutrient type and examination of stained material under a light microscope were used to determine the progression of digestion of pollen grains and their nutrients as pollen passed along the gut. Pollen in the gut was identified by comparison against reference pollen collected in the field. Stain uptake intensity in the gut was compared against fresh pollen stained in the laboratory as controls to determine the effect of digestion. Grains were ingested intact and there was no evidence of germination inside the gut. Each nutrient was digested at varying rates along the gut and by the time grains reached the hindgut the majority of the grains were empty so that only the undigested exine was excreted. Of all the above mentioned methods used by pollen-feeders to gain access to protoplasmic contents of pollen, the most likely one used by these beetles is enzyme penetration and exudation of the products of digestion from the grain. 


\section{Contents}

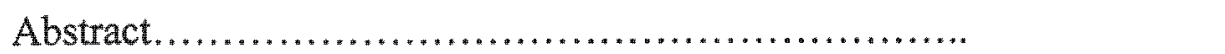

Introduction.............................................. 1

Pollination syndromes............................. 1

Beetle pollination - ancestral or not ?............. 14

Pollen-feeding..................................... 18

Piercing and sucking...................... 21

Leaching and imbibing................... 22

Osmotic shock............................. 23

Pseudo-germination and exudation

from ingested grains...................... 24

Microbial digestion...................... 29

Enzyme penetration........................ 29

Pollen-feeding in beetles - what methods

do beetles use to break

through the exine?........................ 30

Beetle pollination in the Cape flora................ 32

Materials and methods.................................. 38

Specimen collection and preparation.............. $\quad 38$

Morphological examinations..................... 40

Embedding and sectioning.................... 40

Staining...................................... 42

Pollen digestion................................ 43

Results................................................ 46

Head and mouthparts........................... 46

Alimentary canal............................... 48 
Pollen digestion................................ 51

The protea beetle, $T$. fascicularis............ 53

Monkey beetles, $P$. cinerea and

P. flavolineata

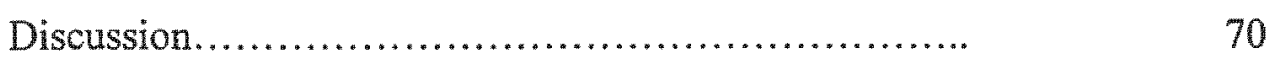

Head and mouthparts............................

Protection of sensory structures........... 71

Feeding mechanism...................... 72

Alimentary canal.............................. $\quad 75$

Regenerative cells....................... 75

Peritrophic membrane..................... 76

Gregarines.............................. 78

Hindgut structure ....................... $\quad 80$

Musculature............................ 81

Pollen digestion.............................. 81

Dealing with the exine.....................

Digestion of different nutrient types........ 87

Digestion efficiency........................ $\quad 89$

The flowers and the beetles: a

close relationship............................... 91

Conclusion...................................... 92

Appendix 1

Fixative solutions.............................. 94

References.......................................... 


\section{Introduction}

The beetles (order Coleoptera) are just one group among a variety of insects that visit, feed on and pollinate an enormous variety of flowers. Apart from the insects, some vertebrates also feed on and pollinate many plant species, creating a diversity of pollination systems that is quite remarkable. This diversity is recognised in a wide range of pollination syndromes. These syndromes require some discussion before concentrating on the topic of beetle pollination and pollen digestion among pollenfeeders.

\section{Pollination syndromes}

A pollination syndrome is characterised by a set of interacting plant and animal attributes that form a consistent pattern, where flower form, colour and scent are compatible with the respective flower visitor's morphology, physiology and ethology.

The German pollination biologist Stefan Vogel defined pollination syndromes in which certain groups of animals were strongly associated with particular floral classes, in an essay published in 1954 (Buchmann \& Nabhan 1996). Biologists tumed these "classical relationships" into stereotypes. The "harmonious" relationship between flower and flower visitor as described by Faegri and van der Pijl (1966) was believed to be truly representative of, and the norm in, the natural world. Pollination syndromes became the paradigm for studying the interactions between flowers and their pollinators. Certain flowers became known as "beetle flowers" or "hummingbird flowers" because they were visited by beetles or hummingbirds, but other animals have also been recorded as visiting and feeding on these same flowers. It is natural for 
humans to group things together and to look for patterns, but the natural world is not quite so simple. Today we realise that the idea of the pollination syndrome is inaccurate. It underestimates the complexity and variability of relationships in nature (Buchmann \& Nabhan 1996). Some authors suggest that a more generalised approach to pollination systems may be more suitable (Waser et al. 1996).

Nevertheless, the concept of pollination syndromes is still a useful tool in biology, and the methodology used in defining them is invaluable to students. The following sections describe the various pollination syndromes with an emphasis on insects. Pollen feeding has been observed in a majority of the insects and vertebrates that define these syndromes.

The apterygote and the exopterygote insects include incidental flower visitors, for most of them, the importance as pollinators is negligible (Proctor et al. 1996). One exception among the Exopterygota is the order Thysanoptera. Thrips have bristles on their bodies in which pollen grains get trapped (Lewis 1973). The number of bristles varies between species and some have been found to be significant pollinators of certain plant species. Some species of thrips are specialised pollen feeders with piercing and sucking mouthparts (Kirk 1984; 1987), but this will be dealt with in greater detail later. With the exception of Thysanoptera (Exopterygota), regular specialised flower visiting is restricted to four major orders of Endopterygota: Diptera (flies), Lepidoptera (butterflies and moths), Hymenoptera (bees, wasps and ants) and Coleoptera (beetles). It is in each of these orders that insect pollination syndromes have been recognised. 


\section{Myophily: flies and fly-pollinated flowers}

Due to their variation in size and habit, there is a wide range of methods of pollination amongst flies (Diptera). Myophily includes all flies except long-proboscid flies, carrion flies and bee flies (these are dealt with as separate syndromes, or in the case of bee flies (Bombyliidae), as a subsyndrome of mellitophily - bee pollination). Most flies have suctorial mouthparts that can either penetrate tissues and imbibe internal fluids or, more commonly, are adapted for mopping up exposed fluids. Small flies (e.g. Bibionidae and Tipulidae) with short probosci (1-2 $\mathrm{mm}$ in length) generally visit flowers with open, well-exposed nectar or very short floral tubes (Proctor et al. 1996). The nectar of these flowers is generally rich in hexose sugars (Baker \& Baker 1982). Fly blossoms are characterised by small flowers with a short stigma to nectar distance. Blossoms occur in large numbers and are regular, simple flowers with no depth effect. Flower colour is light and dull, and odour is usually imperceptible in fly-pollinated flowers. If a slight odour is present it may be aminic or spermatic. Umbellifers (Apiaceae) are prime examples of fly flowers (Proctor et al. 1996), others examples include Silene (Caryophyllaceae), Crassula (Crassulaceae), Erica (Ericaceae), Brabejum (Proteaceae), Myrica (Myricaceae) and Selago (Scrophulariaceae) (Whitehead et al. 1987). Fly blossoms have been described as "open house" flowers as they are visited by many other insect species as well, such as small hymenopterans, lepidopterans and coleopterans.

\section{Rhinomyophily: long-proboscid flies and their flowers}

This syndrome is typified by long-proboscid hovering flies. The flowers are characterised by long narrow straight tubes with a small opening at the top, surrounded by a nectar guide. Flowers are generally light in colour, often pink or 
white with a red nectar guide (Whitehead et al. 1987). The nectar is hidden and in these groups of flies the proboscis has become elongated as an adaptation to feeding from longer-tubed flowers. Tabanidae and Nemestrinidae have probosci that are approximately $47 \mathrm{~mm}$ and $70 \mathrm{~mm}$ long respectively (Proctor et al. 1996). Hovering fly blossoms include Pelargonium (Geraniaceae); Lapeirousia (Iridaceae); Sonderothammus (Peneaceae) and the Erica section Euryloma (Ericaeae) (Whitehead et al. 1987).

\section{Sapromyophily: carrion flies and carrion beetles and their flowers}

Sapromyophilous flowers are dull, dark, red-mauve/brown/purple/greenish in colour, generally have no nectar and emit an odour that resembles that of decaying protein (Buchmann \& Nabhan 1996). The flowers may be lantern-shaped and have filiform appendages that emit the odour. Sapromyophily is based on deceitful attraction and mimicry. The odour attracts flies and beetles that lay their eggs in carrion or dung, and sapromyophilous flowers offer no real reward. An appropriate texture and warts or spotted patterns on the flowers acting as imitation flies are additional lures. Asclepiadaceae, Aristolochiaceae, Hydnoracea, Araceae and Orchidaceae contain numerous members that conform to the classical sapromyophilous syndrome (Whitehead et al. 1987; Proctor et al. 1996). Some examples of orchids that lure flies in by brood-site imitation but offer no reward, are Masdevallia fractiflexa (Dodson 1962) and Bulbophyllum macranthum (Proctor et al. 1996). 
Psychophily, phalaenophily and sphingophily: butterflies, small settling moths

\section{and hovering hawkmoths and their flowers}

The behaviours of butterflies and moths (Lepidoptera) correspond very well to butterfly and moth blossoms, respectively. Butterflies are diurnal, so butterflypollinated flowers exhibit diurnal anthesis. The odour of the flower is weak, but vivid colouring stimulates the well-developed visual sense of the insects. Nectar located at the bottom of long floral tubes and spurs can be reached with the long thin proboscis of a butterfly, and is usually sucrose-rich or sucrose-dominant (Baker \& Baker 1982). Butterflies are lighter than moths and can land on flowers, so blossoms are borne erect. A typical butterfly blossom is one with a narrow tube and flat rim (for landing) such as Disa uniflora (Orchidaceae), which is pollinated by the mountain pride butterfly Meneris tulbaghia (Satyridae). Other examples include Ixia, Morea, Gynandriris (Iridaceae); Satyrium (Orchidaceae); Impatiens (Balsaminaceae); Hibicus (Malvaceae) and Lobelia (Campanulaceae) (Whitehead et al. 1987).

In contrast, moths are nocturnal, so moth-pollinated flowers exhibit nocturnal anthesis. Heavily scented sweet-smelling flowers attract moths by stimulating their strong olfactory sense. Moths are visually sensitive to colours that can be seen at night. Therefore moth-pollinated flowers are mostly white or pale coloured. In comparison to butterflies, moths have longer probosci, corresponding to longer floral tubes than in the butterfly-pollinated flowers. The majority of the features of settling moth pollination parallels those of hovering moth pollination, except settling moths need a landing platform and do not require as large an energy source as hovering moths. The hovering sphingid moths have a high metabolic rate and as a result they visit flowers that produce larger quantities of nectar. The nectars of both 
phalaenophilous and sphingophilous pollination syndromes are characteristically sucrose-rich or sucrose-dominant (Baker \& Baker 1982). Settling moth flowers are similar in floral structure to butterfly flowers (Whitehead et al. 1987). Some examples are Hesperantha, Ixia, Morea (Iridaceae); Bartholina, Habenaria, Holothrix, Mystacidium (Orchidaceae); Olenlandia (Rubiaceae) and Buchnera (Scrophulariaceae) (Whitehead et al. 1987)

Some flowers are suitable for both butterflies and moths, e.g. the pyramidal orchid Anacamptis pyramidalis is visited during the day by butterflies and at night by moths (Proctor et al. 1996).

\section{Melittophily: bees and bee-pollinated flowers}

Bees (Hymenoptera) visit a wide range of flowers to collect nectar and pollen. There is no single pollination syndrome for bees, but several, to suit the particular characteristics of different types of bees (Proctor et al. 1996). Bees, especially social bees, will visit any blossom type that yields sufficient nectar, as long as the nectar is not too deeply hidden. An extremely efficient generalist, the honeybee, has no distinctive syndrome of flower characteristics associated with it. Generally, a bee blossom has to be a mechanically strong flower with space for landing and a surface that gives a good foothold. Yellow, blue or purple flowers with fresh smelling scents usually attract bees, and the flower shape is one of two categories: tubular or bellshaped corollas and brush-blossoms. Flowers visited by long-tongued bees usually produce nectar rich in sucrose, and those visited by short-tongued bees produce nectar rich in hexose (Baker \& Baker 1982). The purpose of the bee's visit also influences the shape of the flower, since some bees visit to collect nectar and pollen, some just 
collect nectar and others just pollen. Bee blossoms that are nectar providers are found in families such as Labiatae, Scrophulariaceae, Papilionaceae, Orchidaceae (Faegri \& van der Pijl 1966; Whitehead et al. 1987). Rosaceae, Rutaceae and Papaveraceae best typify pollen providers (Whitehead et al. 1987).

Some of the flowers that offer only pollen to visiting bees belong to the poricidally dehiscent angiosperms. This taxonomically diverse group of angiosperms comprises $6-8 \%$ of flowering plants (19 000 species of all dicotyledons and 1150 species of all monocotyledons) (Buchmann 1983). The anthers in these flowers dehisce pollen by means of short apical slits, valves or apical pores. Since access to the pollen is severely limited by these pores, bees have evolved a behavioural repertoire to release the pollen. Hanging from the anther cone, bees rapidly vibrate their thoracic muscles, causing pollen grains to be released from pores at the tips of the anthers. This behaviour has, for obvious reasons, become known as buzz or vibratile pollination. Bumblebees visiting Solanum dulcamara, bittersweet, exhibit buzz pollination as they hang from the anther cone (Proctor et al. 1996). Not all poricidal plants are buzz pollinated. Of the total number of porose species, $5-10 \%$ are nonvibratile (Buchmann 1983). Examples of nonvibratile porose species are found in Araceae. The anthers of such plants have apical slits or pores, but their pollen is sticky due to an excess of pollenkitt on the exine surface, rendering buzz pollination ineffective.

\section{Vespidophily: wasps and their flowers}

Wasps (Hymenoptera) have flat tongues only suitable for lapping nectar. For this reason wasp flowers are characterised by having exposed nectar and no morphological adaptations for guiding of restricting visitors (Whitehead et al. 1987). 
As a result wasp flowers can be exploited by a wide variety of insects apart from wasps alone, and this makes some biologists reluctant to recognise a syndrome of wasp pollination. However, there are some flowers that, despite their accessibility to other insects, are visited only by wasps. An example is Hedera colchicha (Whitehead et al. 1987). A typical wasp flower is radially symmetrical, simple and has dull, brown colours. The exposed nectar is usually rich in sucrose (Baker \& Baker 1982). As pollinators, parasitic wasps are not very effective, as they are almost completely naked, whereas the social wasps have hairier thoraxes that traps pollen easily (Brackenbury 1995).

\section{Myrmecophily: ants and their flowers}

Ant flowers are small and inconspicuous and produce both minute quantities of nectar and sticky pollen. Flowers are sessile and borne in an exposed position close to the stem. Ants are efficient exploiters of nectar and each flower produces only a small amount, with the result that the pollinators move between flowers bringing about successful pollination. Further efforts to ensure outbreeding include each individual plant producing only a few blooms at a time, and plants growing in intertwined mats close to the ground, which allows ants to move easily between plants without having to leave the plants (Whitehead et al. 1987). Examples of ant flowers are contained in the plant family Euphorbiaceae, and possibly also Chenopodiaceae and Crassulaceae (Whitehead et al. 1987). 


\section{Cantharophily: beetles and beetle-pollinated flowers}

Beetles (Coleoptera) form one of the oldest and the most diverse group of insects. They were visiting flowers long before the appearance of butterflies and bees. However, compared to butterflies and bees very little has been studied on beetle pollination.

Pollen was probably the original attractant for beetles, with nectar-feeding developing later (Faegri \& van der Pijl 1966). Being large, awkward and often heavy insects on the flowers they visited, beetles became known as "mess and soil" pollinators (Kevan and Baker 1983). Chewing on floral parts and consuming pollen and nectar as they went along, beetles were destructive, and flowers had to develop means of protecting their ovules. This was done by sinking ovules into the receptacle or by the close massing together of floral parts so that the ovaries could not be reached. For example, in Asteraceae, the anthers are stiffened and united to form a mass in the centre of the flower.

There are two types of beetle-pollinated flowers: the primitive type with large, flat, cylindrical or shallow bowl-shaped flowers, and the more advanced type with small flowers condensed in inflorescences, which is visited by small beetles such as Nitidulidae and Staphylinidae (Gottsberger 1977). The colour of beetle-pollinated flowers covers a wide range: flowers are frequently greenish or off-white (Proctor et al. 1996), however, Dafni et al. (1990) found that species of Amphicoma (Scarabaeidae) in the eastern Mediterranean region are strongly associated with red bowl-shaped pollen flowers. Also, monkey beetles (Scarabaeidae) in the south westem Cape region visit flowers which range in colour from white and yellow to 
blue and purple to red, orange and pink (Picker \& Midgley 1996). The odour of beetle flowers is often strong and can be fruity like spicy crab-apples (Malus species) or aminoid, a fermenting fruit smell (Calycanthus). Most beetles have an orthognathic position of the mouthparts (perpendicular to the body axis). This is well suited for gaining access to pollen, but limits the beetle to licking nectar from very open flat blossoms. The prognathic position of mouthparts (parallel to the body axis) gives a better position for probing into crevices and between floral parts for nectar.

Beetle blossoms are found in the morphologically derived species of the family Annonaceae, a group that has been extensively researched by Gottsberger (1989a; $1989 \mathrm{~b})$. One example of beetle pollination in this group is that of the dynastid scarab beetles which pollinate a number of species of the genus Annona. To attract beetles, the flower heats up, causing intense volatilisation of the floral odour components. The floral chamber provides the beetles with nutritious food tissues and pollen, as well as a breeding place sheltered against predation and environmental changes. In a few groups of angiosperms beetles are the most prominent or the exclusive pollinators. These are Magnoliaceae, Eupomatiaceae, Calycanthaceae and Cyclanthaceae (Gottsberger 1990). In the Cape flora Leucadendron discolor is regarded as a flower converging to the Magnolia-type classical beetle blossom. The Bruniaceae, Proteaceae and Asteraceae of the southwest Cape also contain beetle flowers (Coetzee \& Giliomee 1985; Whitehead et al. 1987).

Pollination syndromes have also been described for vertebrates that visit flowers for food and effect pollination in the process. Both Aves (birds) and Mammalia (such as bats, rodents and marsupials) include such animals. 


\section{Ornithophily: birds and bird-pollinated flowers}

Birds are important pollinators amongst the vertebrates, and visit flowers for nectar and pollen. A wide range of plant families is bird-pollinated and as a result there is variation in the flower-form of bird blossoms. Bird-pollinated flowers can be grouped into five classes: gullet flowers (e.g. Eremophila spp), tubular flowers (eg. Fuchsia spp.), brush flowers (e.g. Eucalyptus spp.), capitula (flowers clustered in disc-like heads, e.g. Mutisia spp.) and spurred flowers (e.g. Impatiens capensis) (Proctor et al. 1996). Some characteristics of ornithophilous flowers are daytime flowering since their visitors are diurnal, vivid colours like scarlet red, little or no scent and copious dilute nectar. The external wall of the flower is firm, stamen-filaments are stiff and/or united and the ovary is adapted for protection from the bird's hard bill. The flowers are borne in such a way that there is a good perch for birds to land on to reach into the blossom, unless the pollinators hover during feeding, as hummingbirds do. Erythrina (Fabaceae) species pollinated by passerine (perching) birds have hexose-dominant nectar, while species pollinated by hummingbirds have sucrose-rich nectar (Baker \& Baker 1982; Baker \& Baker 1983). Large quantities of nectar meet the bird's energetic requirements, with the peak of nectar production being in the early moming. Some Aloe and Protea species in the western Cape produce such large amounts of nectar that it literally drips from the blossoms (Faegri \& van der Pijl 1966). In Australia, nectar of Banksia species drips onto flowers lower in the inflorescence (Armstrong \& Paton 1990).

\section{Chiropterophily: bats and bat-pollinated flowers}

Bat-pollination occurs mainly in the tropics. Bats obtain nectar, pollen and food such as fleshy sugary bracts from flowers. The Megachiroptera (Old World bats) are 
comprised of a single family, Pteropidae, containing fruit-eating and nectar-feeding bats. The Microchiroptera (New World bats) are mostly insectivorous, except for one family, Phyllostomidae, a group of flower-visitors (Faegri \& van der Pij1 1966). The flower forms of bat-pollinated flowers can be catergorised as brush, bell-shaped or gullet-like. Bat blossoms are present in families such as Capparidaceae, Cactaceae, Bignoniaceae, Bombaceae, Fabaceae, Agavaceae and Cannaceae (Faegri \& van der Pijl 1966; Proctor et al. 1996). The floral syndrome of bat-pollination is characterised by flowers that open only at night, creamy-white colours or shades of green and purple, and a nocturnal scent that is strong, fruity or musty, resembling the stale smell of fermentation (Buchmann \& Nabhan 1996). The flowers are robust and held in exposed positions making them accessible to bats. Flowers produce large quantities of dilute nectar, as well as large quantities of pollen. Flowers pollinated by microchiropteran bats produce hexose-rich nectar, while megachiropteran bats visit flowers with nectar slightly more rich in sucrose (Baker \& Baker 1982; Baker \& Baker 1983). For some bats pollen is a very important source of protein (Howell 1974; Law 1992; Herrera \& Martinez del Rio 1998), and the bat-pollinated Adansonia flower has up to 2000 anthers, producing sufficient pollen for the bats that visit it (Faegri and van der Pijl 1966).

\section{Therophily: Non-flying mammals and their flowers}

Flowers adapted for non-flying (NF) mammal pollination occur in Australia, South Africa, Madagascar, the Neotropics and Brazil (Sussman and Raven 1978; Turner 1982; Goldingay et al. 1991; Ferrari and Strier 1992; Overdorff 1992; Carthew \& Goldingay 1997). Certain rodents, arboreal marsupials and primates represent these NF-mammals and may visit plants that are in fact adapted for pollination by birds or 
bats, but are also suitable for visits by NF-mammals. There are also plants specifically adapted for NF-mammal pollination. Generally the syndrome of therophily is characterised by large, firmly constructed blossoms borne on robust short stems. Blossoms are dull in colour, produce abundant, concentrated and sucrose-rich nectar and have a yeast-like or musky odour (Turner 1982; Wiens et al. 1983; Proctor et al. 1996). In Australia, pollination by marsupials plays a major role in many Australian Proteaceae, especially Banksia (Cunningham 1991; Goldingay et al. 1991; Carthew \& Goldingay 1997). In South Africa, rodents play an important role as pollinators of Proteaceae in the Cape (Wiens \& Rourke 1978; Wiens et al. 1983; Rebelo \& Breytenbach 1987; van Tets 1997). Some examples are Mus minutoides, Elephantulus edwardsil, Rhabdomys pumilio and Aethomys namaquensis (van Tets 1997). The proposal made by Baker and Baker (1983), namely that the proportions of sugars in the nectar of a plant is reflected in the sugar preferences of the plant's pollinator is true for the Proteaceae pollinator, A. namaquensis (Johnson et al. 1999).

Within the therophilous pollination syndrome there are more sharply defined subsyndromes, which are characteristic of the particular NF-mammal that visits the plant and the eco-geographical situation. These are outlined in Proctor et al. (1996), for example, the upright-flowered lowland syndrome seen in Ceiba pentandra (Bombaceae) which are visited by Cebus and Saimiri monkey species. The mossy forest syndrome of rodent-pollinated Blakea species in the American tropics. The south temperate scrubland syndrome, where ground-flowering Protea spp. of the Cape fynbos vegetation are pollinated by rodents such as Aethomys namaquensis and the extraordinary savanna syndrome noted in South Africa, where there is evidence 
that Acacia nigrescens is adapted to pollination by giraffes (Giraffa camelopardalis) (Du Toit 1990).

As mentioned earlier, the idea of such well-defined pollination syndromes may be outdated. The emerging new paradigm in pollination biology is based on observations of pollinator foraging and flower patterns of all the plants in a particular landscape (Bronstein 1995). This new paradigm gives a better approximation of the diversity of plant/pollinator interactions and in applying it, biologists are able to identify plant/pollinator landscapes. Although some authors consider generalisation of pollination systems to be most important (Waser et al 1996), specialisation cannot be ignored, as plants occupy every point of the continuum from extreme generalisation to extreme specialisation in their pollination systems (Johnson \& Steiner 2000).

\section{Beetle pollination - ancestral or not?}

The Coleoptera originated some 250 million years ago during the Permian era. The earliest known herbivorous beetles fed on fungi, and today"s primitive beetles still do, but true plant-feeding in beetles arose 50 million years after their origin, when beetles became associated with cycads and conifers (Farrell 1998). These early herbivores fed on the interior juicy bark and stems of the plants, while their larvae ate the nutrientrich pollen-bearing structures inside the cones (Morell 1998). The association with cycads and conifers continued for another 100 million years, developing tissue eating behaviour in herbivorous beetles, which assisted them in taking advantage of the rise of the angiosperms at the start of the Cretaceous period. An ongoing relationship between these flowering plants and the insects associated with them has undoubtedly 
affected the radiation and success of both the angiosperms and the insects. Among the insects, the Coleoptera have been spectacularly successful. By feeding on the flowering plants, which have evolved to become the most diverse group of plants, beetles have become the most diverse group of insects, dominating the world with 330 000 known species (Yoon 1998). More than half of the known beetle species are herbivorous, exploiting nearly all parts of plants, from roots and wood to flowers and fruit.

Pollen feeding in beetles may have developed before angiosperm foliage feeding (Farrell 1998). This suggestion is based on studies of the most successful insectangiosperm associations, those of the beetle sister superfamilies Chrysomeloidea and Curculionoidea. The Jurassic Karatau beds in Kazakhstan are rich in chrysomelid and curculionoid fossils. The beds contain no angiosperm fossils (Crowson 1981), but Pteridophyta, Ginkgoales, Gnetales, Coniferales, Cycadales and Bennettitales are very well represented. Today chrysomelid and curculionoid larvae feed on the male pollenbearing strobili of conifers and cycads. This led Farrell (1998) to the conclusion that feeding on the nutrient rich reproductive structures preceded feeding on the juicy plant tissues of angiosperms.

A taste for plant tissue since before the rise of the angiosperms not only resulted in beetles becoming the most diverse group of insects, but also major pollinators in the world of flowering plants. Buchman and Nabhan (1996) claim that today beetles are responsible for the pollination of $88.3 \%$ of all flowering plants.

For a long time it was accepted that beetles were the most primitive of insect pollinators. The idea that beetles were the principal pollinators of the early 
angiosperms and thus the most primitive of insect pollinators (Grant 1950; van der Pijl 1960; Baker \& Hurd 1968) was based on two observations. Firstly, beetles pollinate many of the extant primitive angiosperms (Gottsberger 1974; Thein 1974), and secondly, beetle fossils are abundant in the Cretaceous strata representative of the time of the rise of the angiosperms (Riek 1973).

However, later studies led to disputes concerning beetles as the principal early insect pollinators. According to Thien (1980), extant primitive angiosperms can be divided into three distinct modes of pollination based on dipteran, thysanopteran and coleopteran pollination. All three groups are represented in the fossil record prior to the Cretaceous period (Riek 1973; Smart \& Hughs 1973), that is, before the rise of the angiosperms. Also, according to Crepet (1979), relationships between Coleoptera, Diptera, Hymenoptera and Lepidoptera and their respective flower types existed in the Eocene period, before the advent of the angiosperms. Evidence shows that insect pollination mechanisms were present in two anthophyte groups, the Bennettitales and Gnetales (Crepet 1991), which appeared before the angiosperms and overlap with them chronologically. Most insect families that have present-day associations with flowering plants were in place by the Jurassic (Carpenter 1992) and a great variety of anthophilous (plant-feeding) insects co-occurred with the earliest Cretaceous floral types, as the angiosperms emerged.

Therefore, although cantharophily (pollination by beetles) is the most widespread form of pollination in the extant primitive angiosperms, one cannot conclude that the coleopteran mode is representative of the first angiosperms (Thein 1980). 
The flowers of these primitive angiosperms were medium-sized sweet-smelling flowers in inflorescences or flower aggregates. Some angiosperms became adapted for more effective beetle pollination, while others became better adapted for the other insects with which they were associated (Gottsberger 1974). The beetles were however the best equipped to take advantage of this new niche since they already had an association with plants such as cycads and conifers long before the angiosperms arose (Farrell 1998), and therefore today pollinate over $80 \%$ of all flowering plants (Buchmann \& Nabhan 1996).

Adaptations that occurred to attract beetles included more nutritious tissues for them to feed on and fruit-, carrion- and dung-odours to attract a variety of beetles. Greater numbers and larger beetles could cause some destruction to the flowers, so stamens and carpels increased in number and became more densely aggregated and ovaries were sunken into the receptacle. Individual flowers became enlarged and flower aggregates or inflorescences became reduced (Gottsberger 1974; 1977).

The order Coleoptera consists of four suborders, the Archostemata, the Myxophaga, the Adephaga and the Polyphaga. The last of these is the largest group consisting of flower devourers and pollinators (Evans \& Bellamy 1996; Proctor et al. 1996). Some flower visiting families among the suborder Polyphaga are Elateridae (click beetles), Scarabaeidae (dung beetles and chafers), Cleridae (checkered beetles), Nitidulidae (sap beetles), Chrysomelidae (leaf beetles), Staphylinidae (rove beetles), Cantharidae (soldier beetles), Meloidae (blister beetles) and Cerambycidae (long horned beetles), Mordellidae (tumbling flower beetles) and Oedemeridae (false blister beetles) (Kevan and Baker 1983; Evans and Bellamy 1996; Proctor et al. 1996). 


\section{Pollen-feeding}

As well as the obvious rewards of nectar and pollen, floral rewards include perfumes and oils. Solitary bees of the genus, Rediviva (Melittidae), collect oil from oilsecreting species of Scrophulariaceae and Orchidaceae in temperate parts of southern Africa (Steiner 1998a). Other floral rewards are starchy food bodies, epidermal tissue, places of protection or prey capture and breeding sites - a place to find a mate or lay eggs (Kevan \& Baker 1983). The most common floral reward is nectar, a sugar solution with minor constituents which include amino acids, proteins, lipids, antioxidants, alkaloids, vitamins, organic acids and minerals (Baker \& Baker 1982; Kevan \& Baker 1983).

Pollen is the second most common floral reward after nectar (Kevan \& Baker 1983), and is considered to be a highly nutritive food source rich in protein. For many pollenfeeders pollen provides nutrients often lacking in other food sources. In the case of many vertebrate pollen-feeders, pollen provides nutrients at a time when other food sources are in short supply (Martinez del Rio 1994; van Tets 1997). Pollen is thought to have been the original food sought after by primitive anthophiles. It was probably the first food reward consumed by spore-dispersing arthropods, which may have been Arachnida and Collembola (Kevan et al. 1975). Smith and Mommsen (1984) studied pollen feeding in the juvenile orb-weaving spider, Araneus diadematus. These spiders regularly dismantle and eat their webs, consuming the wind-transported pollen caught in the orb web. The organic matter caught in the web may be the main food of orbweaving spiderlings and consuming pollen doubles their life expectancy. However, a diet of pollen alone is not adequate for prolonged survival as wind-transported pollen 
lacks the amino acid tyrosine, an essential amino acid for the formation of new cuticle in insects. Thus, the pollen-fed spiderlings could not moult and subsequently died (Smith \& Mommsen 1984).

Insects need protein-building amino acids. Pollens that are actively gathered by insects are nutritionally richer than wind-transported pollens, probably containing enough tyrosine for moulting to occur (Milgram 1985). Knox (1979) was among the first to note that the cytoplasm of pollen grains belonging to animal-pollinated flowers was higher in digestible amino acids and lipids than in flowers that are air-or windpollinated. Table 1 compares the chemical compositions of Virgilia divaricata pollen, a food source for the carpenter bee, Xylocopa capitata (Louw \& Nicolson 1983), and Zea mays wind-transported pollen (Stanley \& Linskens 1974).

Table 1. Chemical composition of Virgilia divaricata pollen and Zea mays pollen (\% dry mass).

\begin{tabular}{|l|c|c|}
\hline & Virgilia divaricata & Zea mays \\
\hline Ash (\%) & 5.4 & 2.6 \\
\hline Lipids (\%) & 6.9 & 2.2 \\
\hline Carbohydrates (\%) & 55.6 & 34.9 \\
\hline Proteins (\%) & 25.0 & 20.9 \\
\hline Fibre (\%) & 7.1 & 5.3 \\
\hline
\end{tabular}

Minerals are measured as the total ash of pollen dry weight, which generally lies between 2.5 and $6.5 \%$ (Stanley \& Linskens 1974). The principal elements in the mineral component of pollen are potassium, phosphorous, sulphur, calcium, sodium and magnesium. Trace elements include iron, iodine, aluminium, copper, manganese, 
nickel, titanium, zinc and boron. The total lipids in pollen are a source of stored energy and pollen high in fat is considered to be selectively sought by bees as a nutritive source (Stanley \& Linskens 1974). Total lipids include fatty acids, alcohols, saturated and unsaturated chain hydrocarbons, terpenes and sterols. There is immense variation in the nutritional quality of pollen from different plant species, especially with respect to proteins, which range from $8-44 \%$ dry mass (Paton 1981). All the essential amino acids are present in pollen, in varying amounts, as free amino acids, or bound in peptides and proteins. Proline is one of the most abundant free amino acids found in pollen. The majority of amino acids in pollen are bound. Pollen proteins contain large amounts of the acidic amino acid, glutamate and the basic amino acid, arginine. In most pollens carbohydrates constitute the major proportion of pollen dry weight. Carbohydrates are present in the form of starch, sporopollenin in the exine (outer wall), and callose, cellulose and pectin in the intine (inner wall) (Stanley \& Linskens 1974).

The outer wall or exine of a pollen grain is hard and highly resistant, to protect the contents during what can be a rather hazardous process of pollination. It is sometimes described as the "indigestible" or "chemically resistant" outer wall as it does not react with most chemicals. In the laboratory, complete dissolution of the exine will generally result from heating pollen at $97^{\circ} \mathrm{C}$ in monoethanolamine for 3 hours (Stanley \& Linskens 1974). In order to analyse the pollen exine chemically, successive removal of the pollen wall constituents not resistant to a particular treatment is required. The extractive sequence described in Stanley and Linskens (1974) shows just how extremely resistant exine is to strong chemicals. An alcohol wash removes surface coatings. This is followed by washes in solutions of potassium 
hydroxide to break down proteins, fats and waxes, and this is then followed by etheralcohol extractions to remove fats and oils. Then carbohydrates, except cellulose, are removed with solutions of concentrated sodium hydroxide and water, and finally cellulose is removed with $72 \%$ sulphuric acid. The residue remaining after this exhaustive process is the chemically resistant exine.

Pollen feeders must overcome the problem of the highly resistant exine in order to benefit nutritionally from the pollen. Although certain Collembola secrete an enzyme called exinase, which digests the wall of the pollen grain just as the grain reaches the hindgut, most pollen feeders do not secrete enzymes capable of degrading the pollen grain walls and excrete the undigested exine after digesting the pollen protoplasm (Scott \& Stojanovich 1963; Stanley \& Linskens 1974). Variation in size, behaviour, physiology, and ingestion and mastication abilities of these pollen feeders has given rise to a variety of methods used to deal with the resistant pollen wall.

\section{Piercing and sucking}

Kirk (1984) reported pollen feeding to be widespread among flower thrips, some being specialised pollen-feeders. Some flower-dwelling thrips can ingest pollen (Lewis 1973) however, due to their small size, many species are incapable of ingesting whole pollen grains. These species of thrips gain access to the protein-rich contents of the grains by using their forelegs to hold a grain, pushing it under the mouth-cone and piercing the grains with their mandibles. The fluid contents are then sucked out and the shrunken and collapsed grains are discarded. Empty pollen grains are left on the flower, their purpose for pollination destroyed (Kirk 1987). However, the bristles on the bodies of some thrips trap grains and do effect successful 
pollination. Thrips are regular pollinators of huge forest trees of the family Dipterocarpaceae in South-East Asia (Proctor et al. 1996).

A similar pollen-feeding mechanism of piercing and sucking out the contents was observed in biting-flies, Atrichopogon pollinivorus (Ceratopogonidae) (Downes 1955). Both sexes feed on nectar, but the females use the contents of pollen grains as well, providing nourishment for the development of the oocytes. The females probe with their rostrum at the pollen until they find a full grain. Held by the tip of the labrum in front and the apex of the labium behind, the grain is cut open with the strong apical teeth of the mandibles. Once opened the contents are sucked out. Within six seconds all the contents have been removed and the grain collapses completely.

\section{Leaching and imbibing}

Heliconius butterflies remove amino acids and proteins from pollen grains by a form of external digestion (Gilbert 1972). They process pollen by collecting pollen loads that adhere to the ventral side of the proboscis near the head. A clear liquid is exuded from the proboscis tip and mixed with the pollen load. The wet pollen load is then agitated through coiling and uncoiling of the proboscis and kneaded for hours in this way. According to Stanley and Linskens (1974), certain pollen grains release their contents via pores in the pollen wall when in a sucrose solution. This suggests that the clear liquid that is used to moisten the pollen load is probably nectar. Analysis of wet pollen loads of Heliconius butterflies by electrophoresis revealed the presence of only pollen enzymes and no butterfly gut enzymes (Gilbert 1972). Grogan and Hunt (1979) investigated the potential role that pollen enzymes may play in the degradation of protein and other substances in pollen digestion in pollen-feeders, and concluded that 
if sufficient quantities of the pollen enzymes were available suitable physiological activity could be achieved to digest the pollen grain nutrients. The release of the pollen grain contents by moistening the grains with nectar allows the butterflies simply to imbibe the nutrients. Parides and Battus butterflies of the rainforests of Costa Rica exhibit a pollen processing behaviour similar to that of Heliconius (De Vries 1979), as does the eucalypt nectar fly, Drosophila flavohirta (Nicolson 1994). Drosophila flavohirta gathers pollen from the anthers using its extended proboscis, and as a result a ball of pollen sits on the anterior surface of the proboscis. During the processing of the pollen, the fly remains motionless except for a continual rapid vibration of the proboscis and the pollen load. Freshly collected grains at the front of the proboscis are wet and swollen, while grains at the sides of the load are greatly shrunken due to a reduction in protoplasm.

\section{Osmotic shock}

Kroon et al. (1974) demonstrated in vitro that pollen grains may burst easily when transferred from a medium of high osmotic concentration to one of low osmotic concentration and proposed that this may happen in the digestive tracts of some pollen feeders. The osmotic shock to which grains are subjected, as they move from the honey-sac (crop) to the ventriculus (midgut) in the bees' digestive tract, is the result of filtration by the proventriculus. The proventriculus is a sphincter-like valve composed of four lips that open and close by action of circular and longitudinal muscles. Combs of filiform hairs on the margins of the lips "catch" and filter particles from the fluid moving through. By repeated action of the lips and hairs, particles are filtered and collected in pouches between folds in the anterior midgut, forming boli that are eventually passed down the midgut (Peng \& Marston 1986). In the bee the 
proventriculus filters ingested nectar, allowing mainly particulate matter and not the carbohydrate solution to pass from the crop to the midgut. As a result a gradient is created between the crop and the midgut. Osmotic concentrations measured in fluids from the alimentary canal of the carpenter bee, Xylocopa capitata revealed a steep gradient between crop and midgut osmolarity. Osmolarity in the crop was $5381 \pm 240$ $\mathrm{mOsm} / 1$, much higher than that of the midgut, which was $956 \pm 68 \mathrm{mOsm} / \mathrm{l}$ (Nicolson 1990). Peng et al. (1985) recorded some rupturing of the wall of dandelion pollen grains, but this only occurred during the later stages of digestion, as the wall became weakened. The rupturing by osmotic shock proposed by Kroon et al. (1974) would possibly only occur with very thin-walled pollen grains and would be characteristic of plant species.

\section{Pseudo-germination and exudation from ingested grains}

Another method of dealing with the resistant outer wall of pollen grains for pollen feeders that ingest whole grains is known as pseudo-germination. Warm sugar solutions are known to induce germination of pollen grains (Stanley \& Linskens 1974). Thus, nectar passing through the digestive tract or, as in some cases, nectar being temporarily stored in the crop before continuing down the gut, may stimulate germination of ingested pollen grains. Digestive enzymes in the gut can then act upon the exposed protoplasmic contents as the pollen tube "grows" out of the grain. Nectar in the stomachs of some nectarivorous bats (e.g. Leptonycteris sanborni) provides conditions for pseudo-germination to take place (Howell 1974). Such conditions may also be present in the alimentary canals of some marsupial and bird species (Turner 1984; Grant 1996). 
Nectar and pollen feeding and the mechanisms of pollen digestion have been studied in the marsupials Cercartetus namus and Tarsipes rostratus (Turner 1984; Richardson et al. 1986;). The honey possum T. rostratus, and the eastern pygmy-possum $C$. nanus both ingest large quantities of Banksia pollen and Turner (1984) examined faeces of both species, to find that the majority of the pollen grains were empty. Pollen grains present in fluid removed from the gut of $T$. rostratus possessed swollen protrusions that resembled pollen tubes. Germination of pollen grains involves the migration of the protoplast into the pollen tube, which is formed by stretching of the intine. Tumer (1984) suggested that breakage of this tube, possibly by mechanical activity in the gut, would give digestive enzymes direct access to the protoplast. In support of the idea that nectar in the gut induces germination of the grains, the honey possum produced empty pollen grains in it's faeces a lot quicker when fed on solutions containing sucrose than when feed on solutions with no sucrose present. However, Turner's (1984) findings are based on the results of experiments carried out on an individual honey possum. In a more rigorous study, Richardson et al. (1986) made no observations of germination of pollen in $T$. rostratus, and proposed that direct enzymatic action through pores in the pollen wall (a method to be discussed later) was a more likely method used by honey possums. Cercartetus nanus may employ the method of microbial digestion of pollen, but this will also be discussed in more detail later.

Grant (1996), found Darwin's finches, Geospiza scandens and Geospiza fortis, to consume nectar and pollen from Opuntia echios. Examination of the birds" faecal pellets revealed that more than $90 \%$ of ingested grains were digested. On average 
$78.3 \%$ of Opuntia pollen grains were found to germinate in vitro in a nectar and water solution and $11.5 \%$ were found to have germinated in crop samples in vivo.

In contrast, the lesser double-collared sunbird, Nectarinia chalybea, showed a digestion efficiency of less than $20 \%$ upon examination of Eucalyptus pollen grains in their cloacal fluid (van Tets \& Nicolson in press). The cloacal fluid pollen grains also showed no signs of germination. Of Eucalyptus pollen grains examined in pollensucrose mixtures, $10.9 \%$ were empty and $3.6 \%$ were germinating, so it is likely that the pollen grains do germinate in nectar, but they did not appear to germinate when inside the bird's gut. Nectar consumed by sunbirds may contain pollen grains that have fallen into it and germinated. As a result, access to the contents of these grains is easier for the sunbirds to achieve, as the grains are already germinating. Unlike the finches (Grant 1996), sunbirds do not have crops. There is no place in the gut where nectar and pollen (that has not germinated before ingestion) could be stored simultaneously, allowing the nectar to induce germination of the ingested grains. Nectar-feeding birds also have fast gut passage rates. This may account for the reduced efficiency of digestion of pollen grains observed in the sunbird $N$. chalybea.

Grant (1996) also measured the percentage of grains that germinated in a solution of style fragments and water. On average $68.3 \%$ of grains had germinated. The birds may eat some of the stigma and style when feeding, thus ingesting substances that can induce germination. However, Grant (1996) concluded that substances from these floral parts are unlikely to be essential for digestion of pollen by the finches. Many flowers visited and completely depleted of pollen never had their styles bitten off, and the frequency of Opuntia flowers with their styles snipped did not increase during the breeding season when there were more birds feeding on the flowers. 
The syrphid fly, Volucella mexicana, which mimics the buzz pollinating behaviour of the black carpenter bee, Xylocopa tabaniformis, and also buzz pollinates Solanum douglasii has been observed buzzing the Solanum flowers and then visiting Brassica species and probing for nectar (Buchmann 1983). Gut analyses of the syrphid fly revealed that whole Solanum pollen grains were being ingested. Whether the nectar consumed from Brassica induced germination of the grains inside the fly's gut and improved the efficiency of pollen digestion was not investigated. Pollen feeding has been recorded in a wide variety of syrphid flies and behaviour relating to pollen ingestion is variable among the species. The majority of syrphids, especially the more hairy ones (e.g. Eristalis tenax), collect pollen for ingestion from those adhered to specialised body hairs, while the more sparsely-haired species (e.g. Melanostoma fasciatum) feed on pollen directly from the anthers (Holloway 1976; Gilbert 1981). The method of pollen digestion has been investigated in the syrphid fly Cheilosia albitarsis (Haslett 1983). Pollen grains in the gut appeared to exude contents through one of the pores in the pollen wall. Haslett (1983) noted that exudation may start as a pollen tube, but is soon followed by a more general rupture of the grain and suggests that nectar within the gut may provide the necessary stimulus to initiate the pollen tube growth. This suggests that pseudo-germination may be a method employed by syrphid flies as well, but not to the extent recorded in marsupials (turner 1984) and birds (Grant 1996). The short pollen tubes may more likely be initiated to bring about exudation of protoplasmic contents, a method observed in bees (Peng et al. 1985; Dobson \& Peng 1997).

Bees are without a doubt the most extensively studied insects as far as pollen digestion is concerned. Authors of early papers suggested that bees used their 
mandibles to crush the outer wall of the pollen grains to gain access to the protein rich contents inside (Snodgrass 1925; Parker 1926 cited in Stanley \& Linskens 1974). Later more detailed studies by Whitcomb and Wilson (1929) revealed that less than $1 \%$ of the grains in the intestine of bees showed signs of mechanical cracking. More recent studies have shown that pollen processing in bees begins with the ingestion of the intact pollen grain followed by exudation of the protoplasmic contents via the germination pores once the grain is inside the intestine (Peng et al. 1985; Dobson \& Peng 1997). Swellings at the germination pores and very short pollen tubes were recorded in pollen consumed by Apis mellifera (Peng et al. 1985), but no extensive pollen tubes were formed, as in pseudo-germination. The digestive enzymes of the bee can then act upon the exposed contents. In the worker bee, $A$. mellifera, Peng et al. (1985) recorded the reduction of protoplasmic volume as it extruded out through germination pores, and the progressive removal of the lipid-rich pollenkit, a semisolid soluble layer of lipids, proteins and sugars which coats and embeds the exine. In the pollen specialist, Chelostema florisomne, the larvae also exhibit this method of pollen processing (Dobson and Peng 1997). The conditions that result in the exudation, and not germination of protoplasmic contents needs further study.

Howell (1974) proposed two possible methods that bats may use to increase digestive efficiency of pollen involving exudation. Allergists extract allergenic proteins from pollen by soaking the pollen in a weak urea solution. In such a solution the proteinaceous elements exude out of the pollen and the pollen is rendered nonallergenic. In the laboratory Leptonycteris sanborni has been observed to ingest urine, possibly to facilitate urea degradation of ingested pollen. Also, the $\mathrm{HCl}$ concentration 
in the stomachs of L. sanborni is $0.1 \mathrm{~N}$, and is within the range of concentrations of $\mathrm{HCl}$ solutions that allergists soak pollen in to extract proteins.

\section{Microbial digestion}

Microbial digestion of pollen in the caecum has been suggested for some bats (Rasweiler 1977) and Australian marsupials, such as Cercartetus nanus (Tumer 1984). However, evidence for this phenomenon is lacking. If pollen digestion does take place in the caecum, or a similar area of the alimentary canal, it is very little compared to the amount of digestion that occurs in the intestine of bats (Law 1992; Martinez del Rio 1994) as well as marsupials (Richardson et al 1986). Microbial digestion seems an unlikely means of digestion in pollen feeders with a fast gut passage time. If pollen travels too quickly through the gut there is little time for microbial fermentation to occur. Tumer (1984) suggested that in the eastern pygmypossum C. namus, and other Australian marsupials, the caecum may provide the enough time for microbial fermentation to liberate cell contents, by functioning as a fermentation chamber. Tumer (1984) provided evidence to support this suggestion by recording the fact that captive $C$. nanus were unable to digest Banksia pollen as efficiently as free-living individuals and proposed that it was because they had lost the microflora necessary to digest pollen through years of being in captivity (Turner 1984). However, there were only two captive C. nanus individuals to provide this information.

\section{Enzyme penetration}

Small mammals feeding on the pollen of Protea species in the Cape fynbos are capable of extracting the contents of ingested pollen grains (van Tets 1997). Similar 
observations have been made for Syconycteris australis and Rattus fuscipes feeding on Banksia pollen in Australia (Law 1992; van Tets \& Whelan 1997). In the above studies animals were observed feeding on the pollen, and then a count of the number of empty pollen grains in their faeces was taken. A reduction of protoplasmic contents of ingested pollen grains was recorded in Aethomys namaquensis, the Namaqua rock mouse, after consuming Protea humiflora pollen (van Tets 1997). The method by which the contents were extracted from grains was not investigated, but suggestions were given. Grains could be releasing their contents by pseudo-germination, but no pollen tubes were found. Another possibility was that grains were bursting due to osmotic gradients, but no burst grains were found. The most likely method suggested was enzymatic digestion of the protoplast through pores in the pollen wall (van Tets 1997). Evidence to support this method was the presence of partially digested pollen grains together with intact exines and the absence of burst or germinating grains. Simpson and Neff (1983) suggested such enzyme penetration by birds, where the digestive enzymes mechanically penetrate the pollen wall through pores and process the contents inside the grain. Digested material then extrudes out through the pores and is absorbed by the gut. As mentioned earlier, T. rostratus may fall into this catergory as well, since there was no evidence of pollen tubes or bursting of pollen grains in faecal and alimentary canal samples (Richardson et al. 1986).

\section{Pollen-feeding in beetles - what methods do beetles use to break through the exine?}

Beetles tend to be long-lived insects that need to take protein food for growth of the exoskeleton (protein is the major constituent of insect cuticle), and usually have strong biting mandibles to facilitate such food intake. Flower-visiting beetles have 
been classically associated with actively consuming protein-rich pollen. Little is known about the ways in which beetles deal with pollen in their diet. Three known ways have been documented (Bernhardt 1996):

a) Crowson (1981) suggested that pollen-eating beetles might use their mandibles to crack the walls of pollen grains to get to the contents. This is the method used by most beetles dependent on pollen as a food source (Barth 1985; Samuelson 1994).

b) The family Oedomeridae (false blister beetles) is an exception in Coleoptera. Instead of having the posterior end of the oesophagus dilated to form a crop, the adult beetles in Oedomeridae have a large sac-like diverticulum (Crowson 1981). A member of this family, Asclera coerulea has been observed with this diverticulum packed with pollen grains. In an unpublished thesis by A.Hay (Glasgow University), cited by Crowson (1981) clear signs of germination of the grains were observed. In some Oedomeridae the diverticulum stores floral nectar which induces germination of the pollen grains (Amett 1968; Samuelson 1994). Other reasons for this pseudo-germination in beetles were considered by Crowson (1981): either beetles are able to produce substances in their gut similar to the germination-inducing secretions of the stigma, or the beetles actively ingest the secretions from the stigma when they visit the flowers. In a study on the pollination of Cyclanthus by beetles of the genus Cyclocephala (Scarabaeidae) Beach (1982) said that it was not clear whether the beetles fed on the stigma or the stigmatic secretions of the flowers. A possible function of the sticky stigmatic fluid may be to form an adhesive coat on the beetles to which pollen grains will stick. This adhesive function has been observed in flowers of 
Talauma ovata (Gottsberger 1977) and Degeneria flowers (Thien 1980). A floral secretion other than nectar, that has been reported to raise the edibility of pollen for pollen feeding insects, is a secretion from anther glands. In Thryptomene calycina (Myrtaceae) this secretion is hydrophobic and mixes with the pollen, raising the levels of edible lipids in particular (Bernhardt 1996).

c) Rickson et al. (1990) proposed another method that beetles may use to deal with pollen in the gut. They observed that the scarab beetle Cyclocephala amazona, when feeding on the peach palm, Bactris gasipaes, always consumes the trichomes, found on the inflorescence's epidermal surface, before ingesting the pollen of the plant. Trichomes have highly lignified cell walls but no nutritive value, suggesting that they may be used as gastroliths, grinding the pollen grains in the beetle's digestive tract.

Since so very little is known about pollen feeding in beetles, the present study is an investigation into some aspects of the nutritional physiology of three pollen-eating scarab beetle species in South Africa, with the aim of determining how the pollen in their diet is processed under natural conditions. How do they overcome the obstacle of the highly resistant outer wall?

\section{Beetle pollination in the Cape flora}

In the southwestern Cape, beetles frequently visit Proteacea, Bruniaceae and Asteraceae, and for many of the plant species the beetles play an important role as pollinators (Coetzee \& Giliomee 1985; Whitehead et al. 1987). Many members of the 
genera Protea, Berzelia, Brunia and asteraceous flowers such as Arctotis, Euryops, Gazania, Didelta and Oldenburgia may be considered "beetle flowers" (Whitehead et al. 1987).

Potentially important beetles in the pollination of the Cape flora include Halticidae, Nitidulidae and Staphylinidae (reported to occur on Protea), Phalacridae (on Asteraceae), Melyridae and Chrysomelidae (on Asteraceae and Bruniaceae) (Gess 1968; Whitehead et al. 1987). However, both the major groups of beetle pollinators in the south-westem Cape belong to the Scarabaeidae: the Cetoninae and the Hopliini (Rutelinae) (Whitehead et al. 1987). Scarabaeoidea is one of the most diverse superfamilies in the Coleoptera. Cetoniinae has 400 genera and 3000 species worldwide, and the Rutelinae is comprised of 200 genera and 4100 species (Scholtz \& Chown 1995). Members of the Scarabaeoidea are inclined to be associated with fungi and higher plants. South Africa has a rich and unique scarabaeoid fauna, which is systematically and biologically poorly known. The beetle species focussed on in the present study belong to the two major groups of beetle pollinators in the southwestern Cape.

The green protea beetle Trichostetha fascicularis Linn. (Scarabaeidae: Cetoniinae: Cetonini) is endemic to South Africa and a known pollinator of some Proteaceae in the southwestern Cape (Gess 1968). The larvae live on organic matter in the soil, often beneath termite mounds, for eighteen months. When the adult beetles emerge they feed on Protea nectar and pollen (Skaife 1955). Protea flowerheads are often full of insects (Coetzee \& Giliomee 1985), the most conspicuous being T. fascicularis. The adult beetles have a striking appearance with dark green elytra, a black prothorax 
with white stripes running longitudinally and orange-brown hairs on the sides and ventral surface of the body. It is easy to see that pollen can get caught in the hairs. Another variety of this species, T. fascicularis var. natalis, has reddish-brown elytra with white spots. This variety can occur in conjunction with $T$. fascicularis, but is less abundant. $T$. fascicularis is most abundant during September, October and November. The green protea beetle has been observed visiting and feeding on many Protea species (e.g. Protea eximia, $P$. grandiceps, $P$. cynaroides, $P$. aristata, $P$. repens, $P$. coronata and $P$. magnifica), depending on what is in flower at a particular time of the year. The distribution range of the protea beetle is determined by the occurrence of Protea plant species (Gess 1968). In more isolated cases, the protea beetle has also been observed on Leucospermum cordifolium (Proteaceae) and Berzelia lanuginosa (Bruniaceae) (Brunhuber 1964).

In South Africa, especially in the southwestern Cape and Namaqualand, flowervisiting monkey beetles (Scarabaeidae: Rutelinae: Hoplini) show their greatest species diversity compared to anywhere else in the world. There are approximately 786 species of monkey beetles worldwide, and $62 \%$ of these are endemic to South Africa (Steiner 1998b). They derive their name from the many species that have dark, hairy bodies and elongate or thickened hind legs. Very little is known about the biology of Hoplini and their associations with their host plants (Dombrow 1997). Picker and Midgley (1994) described the association between the hopliine Hoplocnemis crassipes and Eriocephalus ericoides (Asteraceae). Individuals were observed swarming around the host plant, where they found mates and burrowed into the soil in copula or burrowed into the soil and found mates once underground. Louw (1987), who described the mating behaviour of Platychelus brevis reported the only 
other case of this swarming and burrowing behaviour of a South African species of monkey beetle.

Steiner (1998b) describes the association between hopliines and the peacock moraeas (Iridaceae) in South Africa. This is the first well-documented report of pollination by hopliines. Three species of Moraea were found to be exclusively visited and pollinated by monkey beetles. The beetles visited the flowers for nectar and pollen and for mating purposes. Goldblatt et al. (1998) reported that modification of the irid flower for pollination primarily by monkey beetles has occurred in several genera, and that the Iridaceae have undergone their greatest adaptive radiation and speciation in southwestern South Africa, where the Hoplini also show their greatest diversity.

The Hopliini are also important pollinators of Asteraceae and Mesembryanthemaceae (Picker \& Midgley 1996), two groups well known for their mass flowering displays in spring in the southwestern Cape Province and Namaqualand. Picker and Midgley (1996) studied monkey beetle behaviour with regard to flower colour preferences and foraging. As a group hopliine beetles are diverse in their colour preferences. Many flower-visiting species, especially Lepthrix species, visit red, orange and yellow flowers, while species of Peritrichia and Anisonyx visit blue and white flowers. Hoplines are known pollen-feeders (Picker \& Midgley 1996; Goldblatt 1998). They feed on pollen directly from the anthers and some push their heads into the flower centre, possibly feeding on nectar as well. The sight of a monkey beetle with its head embedded in the floral disc of a daisy and its prominent hind legs extended into the air is common during the flowering season in Namaqualand. Picker and Midgley (1996) were able to recognise three systems of monkey beetle pollination: 
a) The blue/white flower non-embedding non-asteraceous guild comprises Peritrichia and Anisonyx species. These beetles show no marked sexual dimorphism, are darkly coloured and densely pilose. They visit blue or white flowers, do not burrow into flowerheads (the flower structure is not suitable for burrowing) and feed on both pollen and nectar.

b) The embedding guild is comprised of beetles that are sexually dimorphic the males are larger and more brightly coloured than the females) and relatively hairless. They are most commonly, but not exclusively, attracted to brightly coloured asteraceous flowers, as well as some Mesembryanthemaceae. They feed on pollen and nectar and are characteristically found embedded in the floral disc of their host flower.

c) The asteraceous pollen-feeding guild is typically comprised of Lepithrix species. These beetles are densely hirsute and feed actively on the discs of Asteraceae and Mesembryanthemaceae, only ingesting pollen and not nectar. In some ways they form an intermediate guild between the other two guilds. Like the blue/white nonembedding non-asteraceous guild they are non-embedders, yet they are attracted to the same flowers as the embedding guild: brightly coloured Asteraceae and Mesembryanthemaceae. The two non-embedding guilds are likely to be the most important pollinators, as they do not damage the flowers when feeding and are extremely hirsute.

The three pollen-eating scarab beetles, Trichostetha fascicularis, Peritrichia cinerea and Pachycnema flovolineata selected for the present study are important pollinators 
of Cape flora plant species. The beetles could easily be observed in their natural environments and collected from flowers that they naturally visit, feed on and pollinate.

In context of the range of methods used by pollen-feeders, the present study examines the selected scarab beetles behaviour, morphology and physiology, with the aim of determining what methods these beetles use to deal with the highly resistant outer wall (exine) of pollen grains. The study also looks at the digestion of different nutrient types from pollen and considers the efficiency with which the beetles are able to digest pollen. 


\section{Materials and Methods}

\section{Specimen collection and preparation}

All Trichostetha fascicularis specimens were observed and collected at Kirstenbosch Botanic Gardens during the months of September and October. During this time two of the flower species that $T$, facicularis is known to visit, namely, Protea eximia (Fig. 1) and Berzelia lanuginosa were in flower. $P$. eximia flowerheads were sometimes covered with green protea beetles (Fig. 2). All monkey beetle specimens were observed and collected from the area of Darling (33.22S 18.23E) in the southwestern Cape during the same period. Two species of monkey beetle, Peritrichia cinerea and Pachycnema flavolineata focused on in this study were abundant at this site, where they fed on Ornithogalum thyrsoides (Liliaceae), a small creamy-white flower (Fig. 3). Peritrichia cinerea is a characteristic member of the blue/white non-embedding non-asteraceous pollinator guild: a dark, densely hirsute, sexually monomorphic monkey beetle. Pachycnema flavolineata is a member of the embedding pollinator guild: large, sexually dimorphic and relatively hairless monkey beetles with males larger, more brightly coloured than females and possessing hypertrophied hindlegs. Members of the embedding guild are more commonly found on brightly coloured asteraceous flowers. This site presented the rare occurrence of members of this guild visiting white flowers not suitable for burrowing.

Pollen fresh from the flowers' anthers, as well as pollen from the gut of the beetles, was stained for the presence of nutrients such as carbohydrate, proteins and lipids. Pollen from the anthers was used as the control pollen for comparison with the pollen processed in the beetle's gut. Reference pollen was also collected from respective 
flowers to enable identification of pollen grains in the gut and faeces. Faecal samples were collected from beetles in the field and smeared onto microscope slides for examination under a light microscope. Also, reference pollen was collected for germination tests. In these tests pollen from the respective plants was placed in $20 \%$ and $30 \%$ sucrose solutions (concentrations similar to that of the nectar of the plants from which they originate) and checked for germination tubes every few hours over a 24 hour period.

Beetles were killed in the field by decapitation. The elytra and membranous wings were then removed and the bodies immersed in a fixative solution to stop all processes and preserve tissues in as life-like a state as possible. Rossman's fixative, neutral formal saline and formal calcium (see Appendix 1) were the fixative solutions used for specimen preparation for carbohydrate, protein and lipid staining respectively (Sheehan \& Hrapchak 1980; Bancroft \& Stevens 1990). Fifteen beetles were placed in each fixative solution. In the laboratory specimens were stored in the fixative solutions for no longer than 4 days before dissection. The digestive systems were dissected out of each beetle: nine intact digestive systems were set aside for scanning electron microscopy and the rest were divided into sections in preparation for wax embedding, sectioning and subsequent staining. The digestive systems of $T$. fascicularis (approximately $6.5 \mathrm{~cm}$ in length) were divided into six sections - anterior midgut, median midgut, median-posterior midgut, posterior midgut, anterior hindgut and posterior hindgut. The monkey beetles were smaller than the protea beetles and their digestive systems (approximately $1.9 \mathrm{~cm}$ in length) were divided into three sections - anterior midgut, posterior midgut and hindgut. 


\section{Morphological examinations}

Some of the heads removed in the field were used to obtain the individual mouthparts of the beetles for examination under a light microscope. The rest of the heads and the intact digestive systems were prepared for scanning electron microscopy (SEM), which was carried out at the Electron Microscope Unit (EMU) at the University of Cape Town. Some of the intact digestive systems were sliced open so that the interior of the gut could be seen. In preparation for SEM samples were dehydrated in an alcohol series $(30,50,60,70,80,95$ and $100 \%)$. Samples were then critical point dried using carbon dioxide in a Balzers Critical Point Drier and mounted on aluminium SEM stubs using a mixture of glue and carbon/graphite solution. When the glue had dried, stubs were sputter coated with gold palladium, and examined with a Leica S440 scanning electron microscope.

\section{Embedding and Sectioning}

Gut sections were prepared for histological analysis by manual processing, following a procedure similar to that described in Dobson and Peng (1997):

\section{Carbohydrates}

After fixation in Rossman's fixative, sections were rinsed several times in $95 \%$ ethanol, then dehydrated in a series of $70,80,95$, and $2 \times 100 \%$ ethanol. Dehydrated sections were immediately placed in paraffin wax (melting point $56^{\circ} \mathrm{C}$ ) in an oven for 24 hours, allowing the wax to penetrate the specimen. After 24 hours the sections were orientated in the wax for longitudinal or transverse sectioning, and the wax 
block was allowed to harden in a refrigerator set at $0^{\circ} \mathrm{C}$. The prepared blocks were sent to the Postmortem Histology Laboratory, Anatomical Pathology Department at the University of Cape Town Medical School for sectioning. Sections were cut at 4 $\mu \mathrm{m}$ and adhered to microscope slides for staining. Prior to staining, serial sections had to be dewaxed in 100\% xylene followed by $1: 1100 \%$ xylene: $100 \%$ ethanol, and rehydrated in a reverse series of ethanol solutions, as follows: $100,100,95,95,80,70$ and $60 \%$.

\section{Proteins}

After fixation in neutral formal saline, sections were rinsed in distilled water, followed by $50 \%$ and $70 \%$ ethanol, then embedded in paraffin wax and sectioned as described above for carbohydrates. Microscope slides with the $4 \mu \mathrm{m}$ sections were then dewaxed in $100 \%$ xylene followed by $1: 1100 \%$ xylene: $100 \%$ ethanol, and rehydrated in a reverse series of ethanol solutions $(100,100,95,95,80,70$ and $60 \%)$.

\section{Lipids}

Fixed in formal calcium, sections were prepared for cryosectioning through the following procedure: washed twice in 10\% phosphate buffer solution (PBS) in water, then washed in $2.5 \%$ glutaraldehyde in PBS and refrigerated overnight. Sections were then washed in $10 \%$ PBS in water again, and infiltrated with gelatin at $37 \%$. The gelatin was graded in increments of two up to $10 \%$ gelatin in PBS. Sections were infiltrated with sucrose graded up to $2.3 \mathrm{M}$ as follows: $1 \mathrm{M}, 1.5 \mathrm{M}, 2.0 \mathrm{M}$ and $2.3 \mathrm{M}$. These sucrose infiltrated sections were then frozen in liquid nitrogen and sectioned on an ultramicrotome at the EMU, University of Cape Town. In addition to the 
cryosections, slides were also made from fresh smears of gut contents for lipid staining.

\section{Staining}

To gain a general idea of the shape and size of the different pollen grains encountered in the study, reference pollen from the plant species on which beetles occurred most commonly was stained with cotton blue-lactophenol for viewing under a light microscope.

For histological analysis of control pollen and the pollen grains present in the digestive systems of the beetles, the following staining procedures were followed (Bancroft \& Cook 1984; Bancroft \& Stevens 1990):

\section{Amyloids and cellulose}

Amyloid is a general term for a variety of different protein-carbohydrate fibrils (pers. comm. N. Illing). Congo Red dye binds with amyloids and cellulose. Resulting in a dull red stain. Harris' haematoxylin was used to counterstain nuclei blue.

\section{General carbohydrates (including starch)}

The Periodic Acid Schiff (PAS) technique was used. Substances containing glycol groups (carbohydrate groups) are oxidized by periodic acid to form dialdehydes, which combine with Schiff's reagent forming PAS-positive material that stains magenta. Harris' haematoxylin was used to counterstain nuclei blue. 


\section{Proteins}

The Ninhydrin-Schiff method was used to stain for proteins. Ninhydrin at neutral pH reacts with amino groups to form aldehydes, which recolour Schiff's reagent. Amino acids acquire a pinkish-purple stain. Nuclei were stained blue with Harris" haematoxylin.

\section{Lipids}

Oil red $\mathrm{O}$ is an oil-soluble dye that stains lipids by being more soluble in lipids than in the solvent, isopropyl alcohol. As a result of the oil red technique, unsaturated hydrophobic lipids stain red and phospholipids stain pink. Mayer's haematoxylin was used to counterstain nuclei blue.

\section{Pollen digestion}

To assess the extent of digestion that took place along the length of the gut, pollen grains in each gut region were subjectively rated on the basis of a stain uptake intensity index (Dobson and Peng 1997). The index scale has unitary values 1-3, with 1 being the lowest uptake intensity and equivalent to the background colour, and 3 being the highest and equivalent to the stain uptake intensity of control pollen. Ratings were made randomly on 10 pollen grains in each gut region of five beetles, making a total of 50 ratings for each region. The resulting mean values for stain uptake intensity were compared:

1) along the 6 gut regions of $T$. fascicularis digestive system and the 3 gut regions of the monkey beetles' digestive system, using a non-parametric Kruskal-Wallis one-way analysis of variance (ANOVA) of ranks (Zar 1984), and 
2) between two gut regions in any one beetle in all possible combinations, using a Multiple Comparison Test, the Tukey-type Test (Zar 1984). 


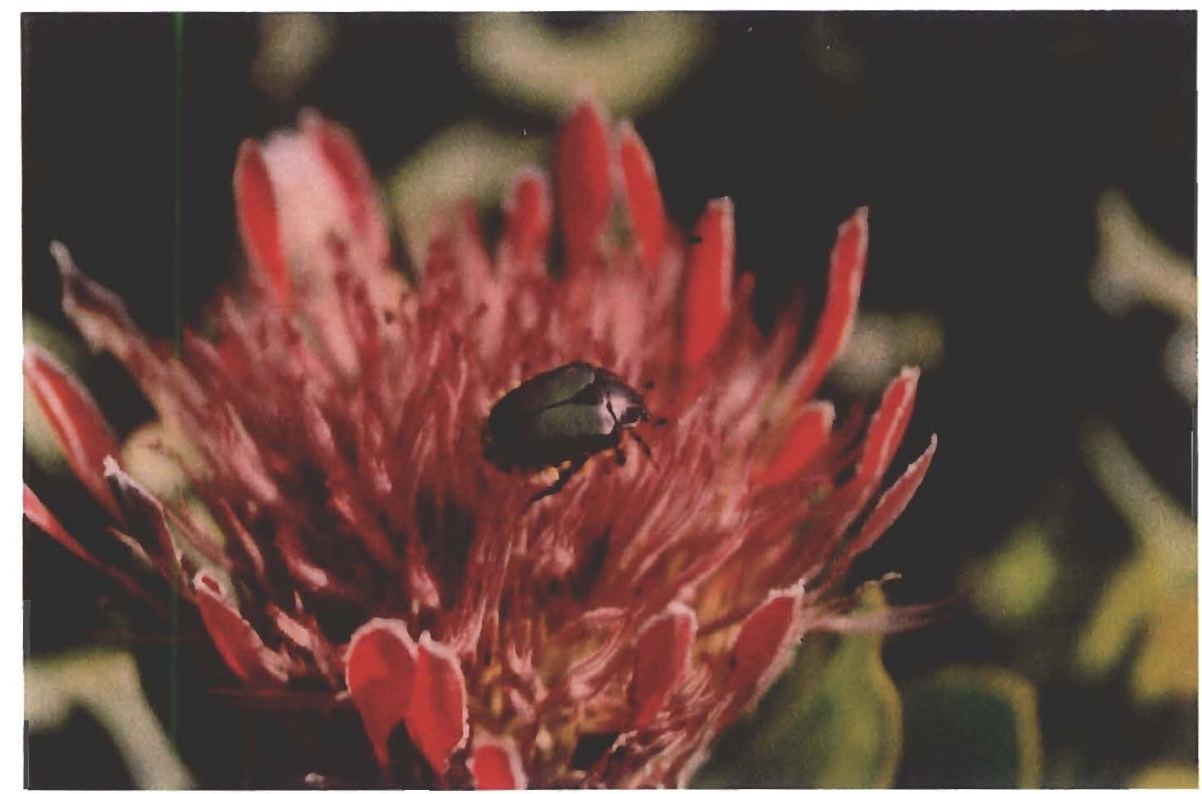

Fig. 1. Trichostetha fascicularis landing on a Protea eximia flowerhead. (Photograph by B. Spence)

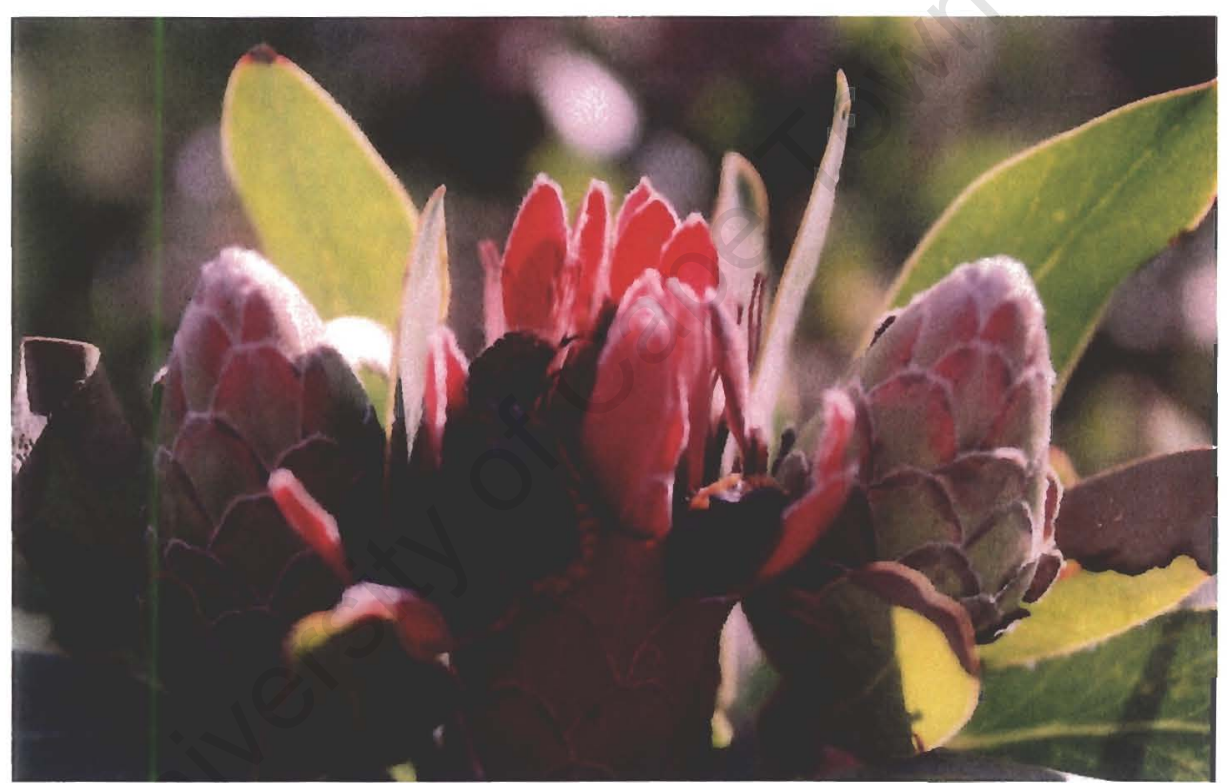

Fig. 2. P. eximia flowerhead not yet fully opened, but beetles force their way between petals and try to reach pollen enclosed within the perianth lobes of the anthers. (Photograph by B. Spence)

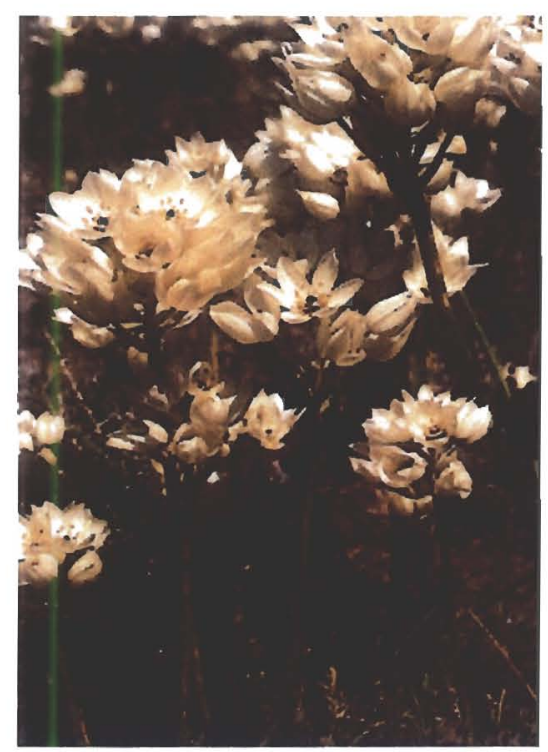

Fig. 3. Ornithagolum thyrsoides flowers. Monkey beetles, $P$. cinerea and $P$. flavolineata were found feeding on the pollen of these creamy-white flowers. (Photograph from Manning \& Goldblatt 1996) 


\section{Results}

\section{Head and mouthparts}

In Insecta mouthparts are external to the head and not enclosed within the head cavity. This is known as an ectognathous condition (Chapman 1998). Most beetles also have mouthparts in the orthognathous position (perpendicular to the body axis). Others bear their mouthparts in a prognathous position (parallel to the body axis). The three beetle species in the present study belong to the latter group. The mouthparts of $T$. fascicularis (Figs. 4\& 5), P. cinerea (Fig. 6) and P. flovolineata (Fig. 7) are parallel to the body axis and directed forward. The prognathous position is most pronounced in $P$. cinerea. This position allows the beetles to probe into flowers and reach between floral parts for pollen and nectar. Such a prognathous condition puts mouthparts and sensory structures in an exposed position. As a means of protection sensory structures, such as antennae and labial and maxillary palpi, can be drawn up very close to the head. The extent to which beetles can do this is seen in Figs. 5,6 and 8. The protea beetle (Fig. 5) can withdraw maxillary and labial palps directly under the clypeus and both the protea beetle and the monkey beetles (Figs. 5,6\&8) can retract the antennae so close to the head that they are not visible dorsally.

Protea beetles have tufts of hair along the sides of their bodies and on their ventral surface (Figs. $4 \& 5$ ). Most monkey beetles are generally hairy all over (Figs. $6 \& 7$ ). P. cinerea is a particularly hairy species (Fig. 6). Pollen grains are easily trapped in the hairs on the body surface of these flower visitors (Figs. 6,7\& 9). 
The antennae (Fig. 10) are made up of three parts: the scape, the pedicel and the flagellum. The scape is inserted in the antennifer, a ball-and-socket type extension that enables the antenna to rotate in all directions. The flagellum consists of segments or annuli that vary in form and number among species. In the protea beetle and monkey beetles the flagellum is lamellate, i.e. the terminal annuli are flattened or platelike. The surface of each plate-like annulus is covered in sensory pits and mechanosensory hairs (Fig. 11). The platelike lamellae of protea beetles and monkey beetles were observed in one of two positions: retracted into a club or expanded into a fan (Figs. $12 \& 13$ ).

The mouthparts of the adult protea beetles and monkey beetles examined bear numerous setae and in places, such as the tips of the maxillae, the setae form a dense brush (Fig.14). The mandibles and maxillae are smooth edged plates, lacking cutting edges. Observation of T. fascicularis feeding on droplets of a sucrose-water solution confirmed that these brushes are used in mopping up liquid food. By watching the beetles through the underside of a petri dish the action of the maxillae could be seen. The maxillae appeared to move in a semi-circular motion. The brushes are extended out of the mouth and to the sides, collect the fluid and then come together and are drawn back into the mouth. Here the liquid may be squeezed out by pressure between the labrum and labium, or by clearing of the fluid-laden brushes against other brushes inside the mouth, such as those on the labrum. This semi-circular movement of the brushes was also observed in beetles feeding at the anthers of flowers, where they appeared to be sweeping up and ingesting pollen. Fig. 4 shows the brushes in a partly extended position, and Fig. 5 shows the brushes drawn back into the mouth. The 
maxillary and labial palps are sensory appendages attached to the maxilla and labium respectively, and are covered in sensory pits and papillae (Fig. 15).

\section{Alimentary canal}

The alimentary canal of insects is divided into three main regions: the foregut or stomodeum, the midgut or mesenteron and the hindgut or proctodeum (Chapman 1998) (Fig. 16). The epithelium of the gut consists of a single layer of cells, ectodermal in origin in the fore gut and hindgut, and endodermal in origin in the midgut. In the protea beetle and monkey beetle species studied, the foregut is relatively short and was removed when the beetles were decapitated in the field, thus there are no micrographs or digestion assessments for the foregut.

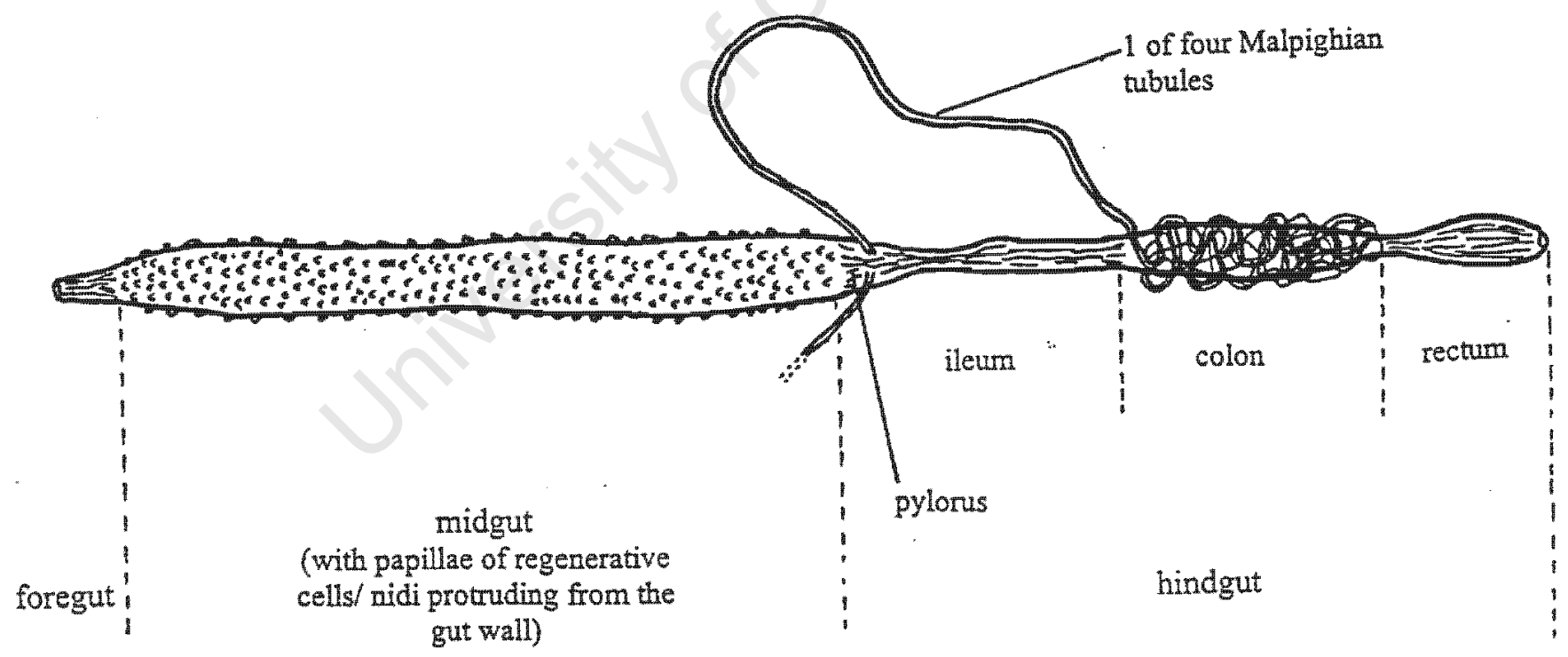

Fig. 16. Generalised diagram of the alimentary canal of $T$. fascicularis.

Note: The four Malpighian tubules are closely associated with the colon and distal ends of the tubules are free.) 
Numerous small papillae are conspicuous on the external surface of the protea beetle's midgut (Fig. 17). They arise from the gut wall and extend along the length of the midgut, ending abruptly at the midgut-hindgut junction (Fig. 18). These are groups of regenerative cells known as nidi, that continually replace the endodermal cells of the midgut (Fig. 19) (Chapman 1998). There were no papillae or nidi in any form apparent in the SEMs of $P$. flavolineata midgut (Figs. 20 \& 21),

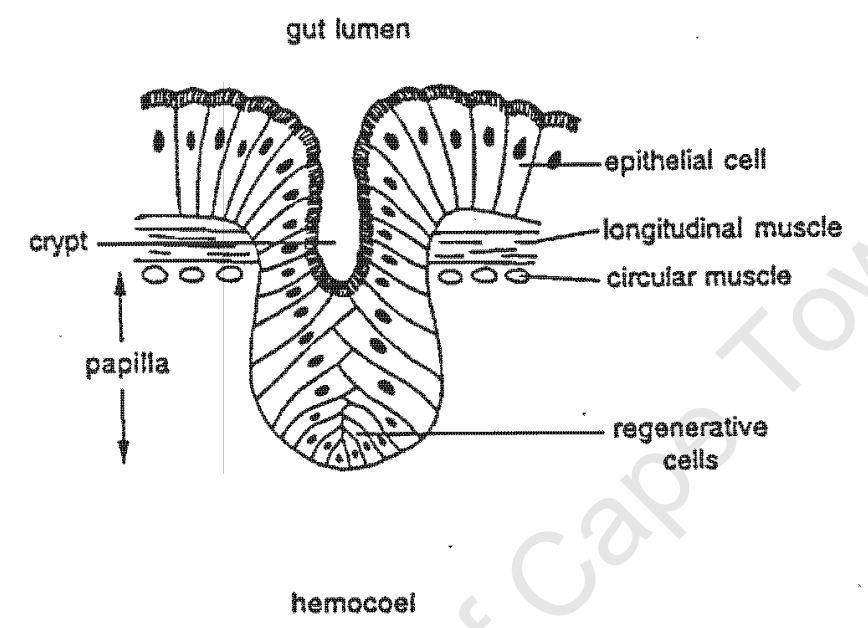

Fig. 19. Diagram of a midgut crypt in a beetle extending through the muscle layer to form a papilla (Chapman 1998).

Ectodermal cells of the epithelium in the foregut and hindgut secrete an internal cuticular lining known as the intima. In the midgut, a lining secreted by the endodermal cells, the peritrophic membrane, envelops the contents of the midgut (Tellam 1996). A function of the peritrophic membrane is to protect the cells of the gut wall from damage caused by the food passing down the gut. Figs. 22 and 25 show the peritrophic membrane which has broken in places during processing, revealing the gut contents. 
Certain places along the midgut of the protea beetle were packed with gregarines, protozoan parasites that inhabit the digestive tracts of insects (Tanoda \& Kaya 1992). For example, in Fig. 22, numerous gregarines are enclosed in the peritrophic membrane of the midgut. In other places along the midgut where gregarines were present, the protozoans were excluded from the gut contents by the peritrophic membrane (Fig. 24). Gregarines were conspicuous in the digestive tract of the protea beetle (Figs. 22, $23 \& 24$ ), but were not apparent in the monkey beetles examined.

There are two types of muscles associated with the gut in insects: 1) extrinsic muscles which arise from the body wall and are inserted into the gut, and 2) intrinsic visceral muscles which are associated only with the gut. Extrinsic visceral muscles resemble typical skeletal muscles and are associated with the foregut and hindgut, functioning as dilators. The intrinsic visceral muscles consist of circular muscles encircling the gut and longitudinal muscles extending along its length (Chapman 1998).

Along the foregut, the circular muscles are external to the longitudinal muscles (Chapman 1998). The intrinsic muscles of the midgut consist of prominent longitudinal muscles, which are external to the less prominent circular muscles (Fig. 26). Hindgut musculature is complex: along the ileum, longitudinal muscles continue from the midgut external to the circular muscles (Fig. 27a); along the colon, longitudinal muscles are still external, but there are fewer of them present (Fig. 27b). Finally, along the rectum the circular muscles are well-developed and there are very few longitudinal muscles (Fig. 27c). 


\section{Pollen digestion}

Reference pollen from the plants on which the beetles were found was stained with cotton blue-lactophenol (Figs. 28a, b \& c). Protea beetles were collected from Protea eximia flowers only since it was the only Protea species on which the beetle was found at Kirstenbosch Botanic Gardens at the time. However, Berzelia lanuginosa was in flower in the vicinity of the proteas from which beetles were collected, and since protea beetles have been observed visiting Berzelia (Brunhuber 1964), pollen was collected from this plant species as well. All monkey beetles were collected from the chinkerichee species, Ornithogalum thyrsoides. However, both spherical $O$. thyrsoides pollen and unidentified oval pollen grains were seen trapped in the hair on the body surface of monkey beetles, but mostly $O$. thyrsoides grains were found inside the gut.

Pollen collected from each plant species on which beetles were found was processed using the same staining procedures as for beetle gut sections, in order to provide controls (e.g. Figs. $29 \& 30$ ). The intensity of stain uptake by control pollen was taken as 3 , the highest on the index scale. Pollen grains in the gut region were rated in relation to the stain uptake intensity of the control pollen.

In the protea beetle most pollen grains remained full and intact in the anterior midgut. In the median posterior and posterior midgut there were visible signs of loss of protoplasmic contents of the pollen grains. For example, in Fig. 31 most grains appear to still be full when stained for proteins, but a few have visibly lost protoplasmic contents while remaining otherwise intact. The loss of protoplasmic contents is even 
more prominent in Fig. 32. The pale colour of the gut contents indicates that there are many empty pollen grains present. The crypts of regenerative cells or nidi, mentioned earlier (Fig. 17), can be seen in the sectioned material in Figs. 31 and 32 . Fig. 33 shows that the majority of the pollen grains are empty in the anterior hindgut of the protea beetle. The triangular shape of the empty $P$. eximia pollen grains can be seen.

In both monkey beetle species studied, by the time pollen grains reached the posterior midgut and hindgut they were just empty shells (Figs. $34 \& 35$ ). Fig. 35 shows clearly that the walls of the pollen grains had become weakened during passage through the gut and once the protoplasmic contents had been removed the walls were so weak that they collapsed and eventually broke.

Faecal samples collected from beetles in the field and examined under light microscopy in the lab showed that the majority of excreted pollen grains were empty. Pollen grains placed in $20 \%$ and $30 \%$ sucrose solutions showed no signs of germination.

Graphical analysis of the stain uptake intensity indices obtained from viewing stained gut sections under a light microscope is represented in Figs. 36, 37 and 38 . The graphs give a good overall view of the rate of digestion of each major nutrient as it passes along the gut. Each nutrient gradually disappears from the gut as the pollen grains move from the anterior midgut to the hindgut. Rates at which nutrients are digested and absorbed differ for each nutrient and for each species. 
Statistical analysis of stain uptake intensity indices gives a more accurate determination of the rates of digestion for each major nutrient.

The protea beetle, T. fascicularis: (Fig. 36)

The Kruskal-Wallis test (nonparametric analysis of variance) revealed that there was a significant difference between indices in different gut regions for each major nutrient $(\mathrm{p}<0.001)$

Tukey-type tests (nonparametric multiple comparisons) showed that for amyloids and cellulose all regions of the midgut except the posterior midgut were significantly different from the hindgut $(p<0.05)$. Digestion of amyloids and cellulose only began in the median posterior midgut, whereas for all the other nutrients stained, digestion had started by the time pollen grains reached the median posterior midgut (Fig. 36). For general carbohydrates, digestion is initiated in the median midgut, and the anterior midgut differed significantly in stain uptake intensity from median posterior midgut to the posterior hindgut $(p<0.05)$. Protein digestion also began in the median midgut (Fig. 36), and here the anterior midgut was significantly different in stain uptake intensity, from the rest of the gut $(p<0.05)$. Although both carbohydrate and protein digestion began in the median midgut, the initial digestion of proteins appeared to be at a faster rate than that of carbohydrates (Fig. 36). The rate of protein digestion then slowed down, matching that of carbohydrates. Lipids are the only nutrient for which digestion was initiated in the anterior midgut (Fig. 36). There was a dramatic decrease in stain uptake intensity from the anterior midgut to the median posterior midgut $(p<0.05)$ and thereafter, the decrease was very gradual until empty pollen grains reached the hindgut. There was variation in the rate of digestive progress (i.e. the 
change in steepness of the columns in the graph) for all the nutrients. It appears that lipids are digested by the protea beetle at a faster rate than any of the other major nutrients in pollen.

\section{Monkey beetles, $P$. cinerea and $P$. flavolineata: (Figs. $37 \& 38$ )}

The Kruskal-Wallis test revealed a significant difference between indices in different gut regions for each major nutrient $(p<0.001)$.

Graphical and statistical results were similar for both monkey beetle species studied. In both species digestion of all nutrients began in the anterior midgut (Figs. $37 \& 38$ ), and Tukey-type tests show that the anterior midgut differed significantly from the hindgut for all nutrients $(\mathrm{p}<0.05)$. In $P$. cinerea, the anterior midgut differed significantly from the posterior midgut $(\mathrm{p}<0.05)$ for carbohydrates, proteins and lipids, while the posterior midgut differed significantly from the hindgut $(p<0.05)$ for carbohydrates only. In P. flavolineata, the anterior midgut differed significantly from the posterior midgut $(\mathrm{p}<0.05)$ for proteins only, and the posterior midgut differed significantly from the hindgut $(p<0.05)$ for all the nutrients except lipids. In the monkey beetles, digestion of amyloids, cellulose and lipids occurs before that of carbohydrates and proteins (Figs. $37 \& 38$ ). As in the protea beetle, monkey beetles appear to be digesting lipids faster than any of the other major nutrients in pollen. 


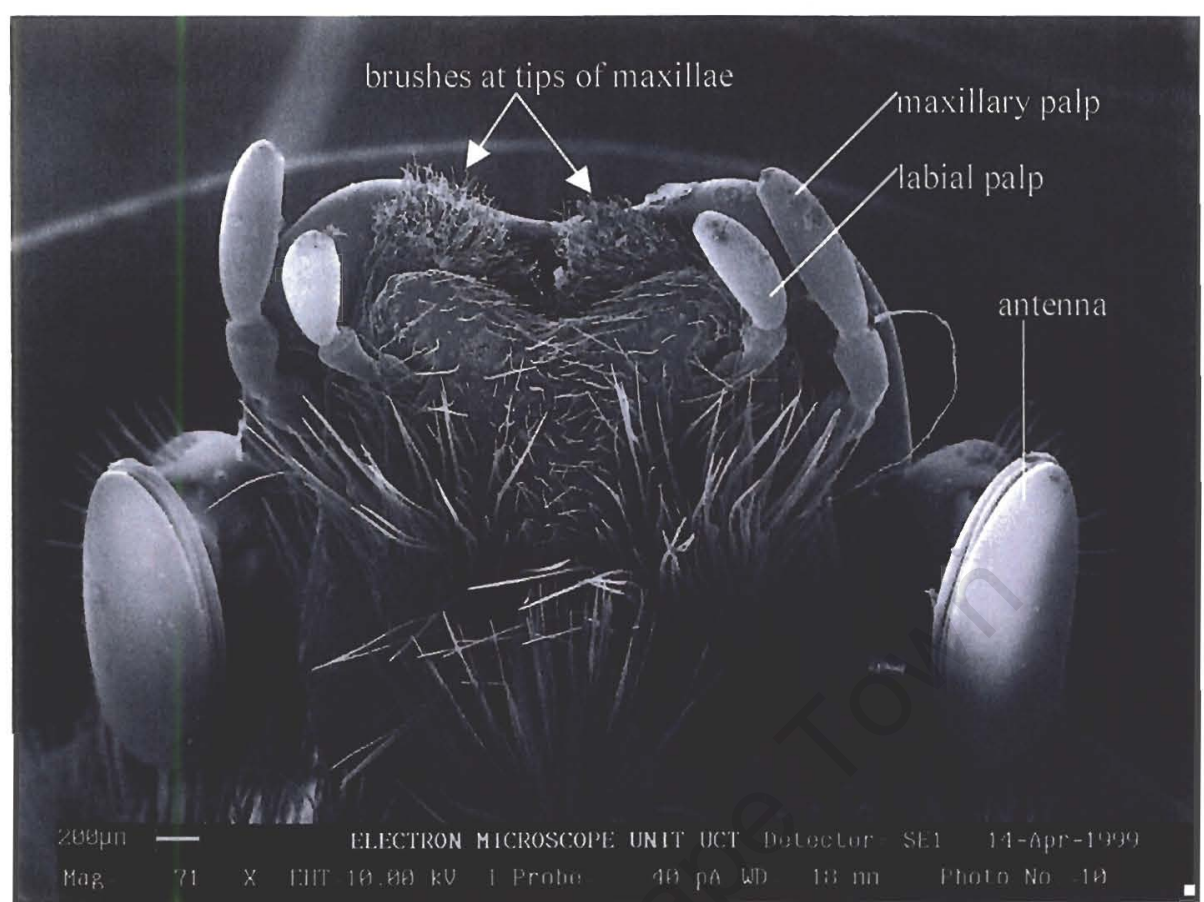

Fig. 4. Ventral view of the head of Trichostetha fascicularis. The mouth appears to be open as the brushes at the tips of the maxillae are extended outwards.

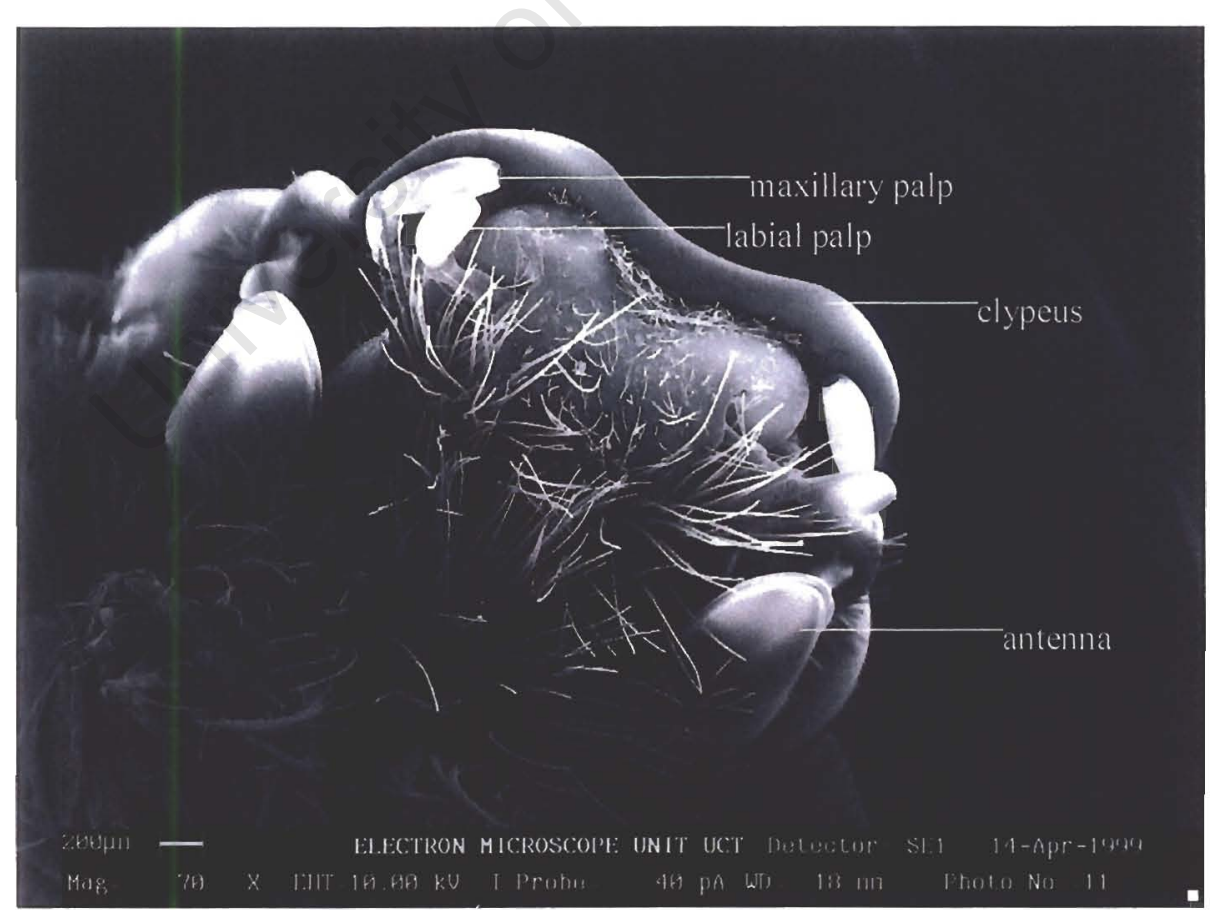

Fig. 5. Ventral view of the head of $T$. fascicularis. The brushes at the tips of the maxillae have been drawn into the mouth. 


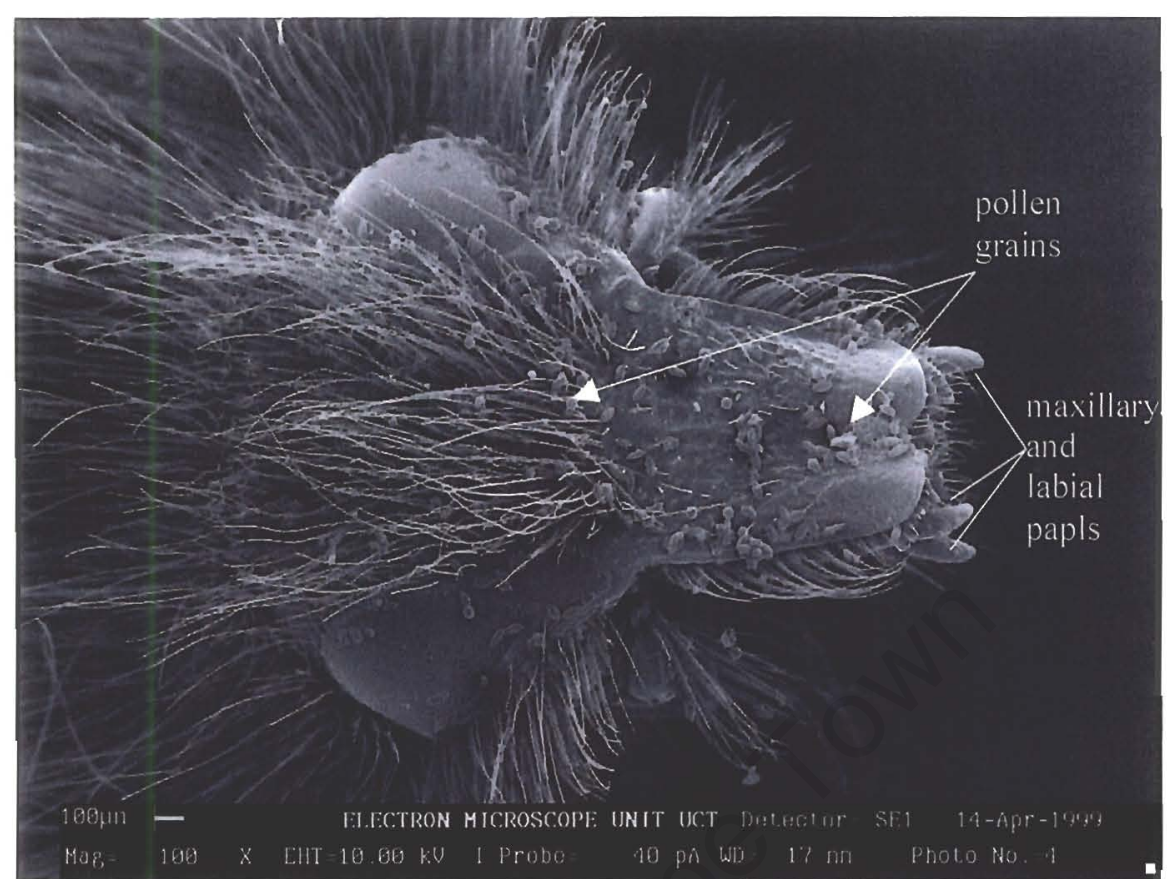

Fig. 6. Dorsal view of head of Peritrichia cinerea. Numerous spherical and oval pollen grains are visible on top of the head and trapped in the hair. Note how mouthparts are projected forwards, typical of the prognathous condition in some beetles.

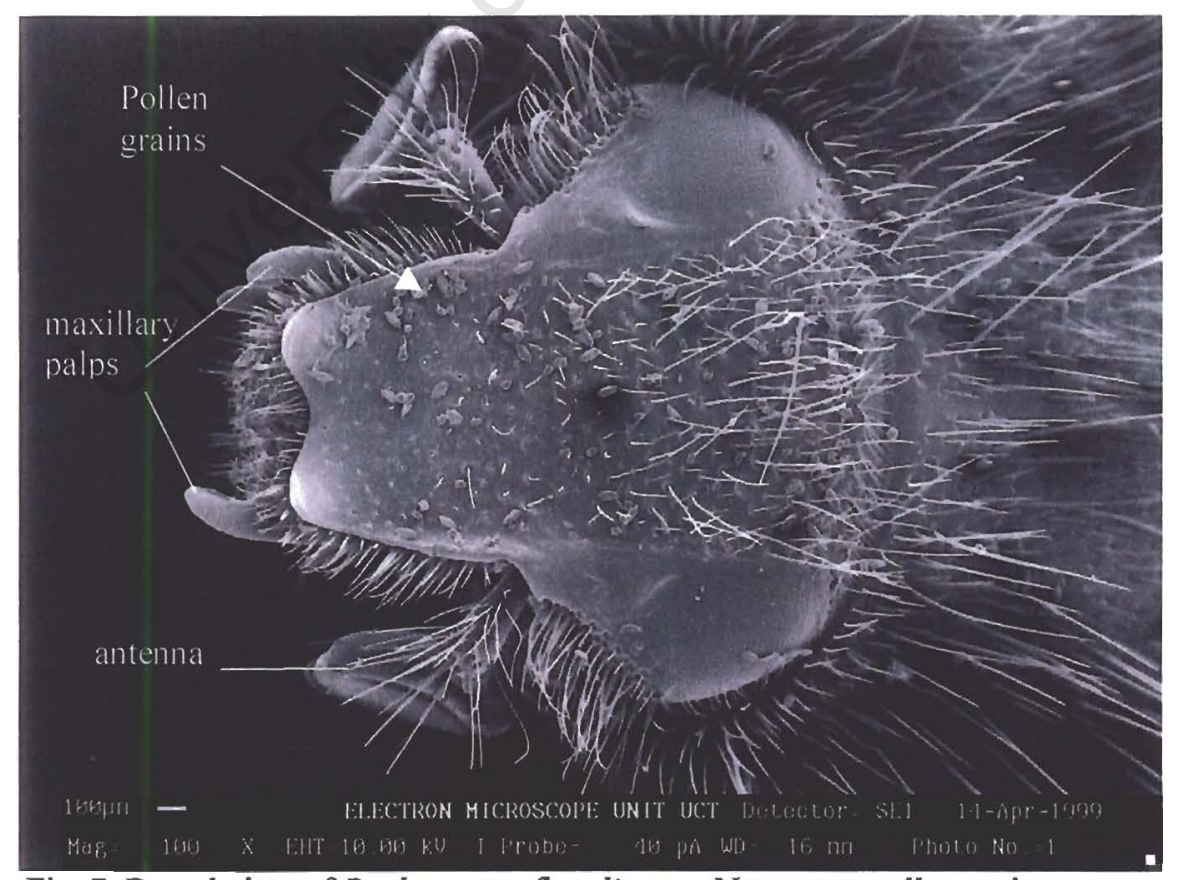

Fig. 7. Dorsal view of Pachycnema flavolineata. Numerous pollen grains are visible on the top of the head. The prognathic position of mouthparts is not as pronounced in $P$. flavolineata as in $P$. cinerea. 


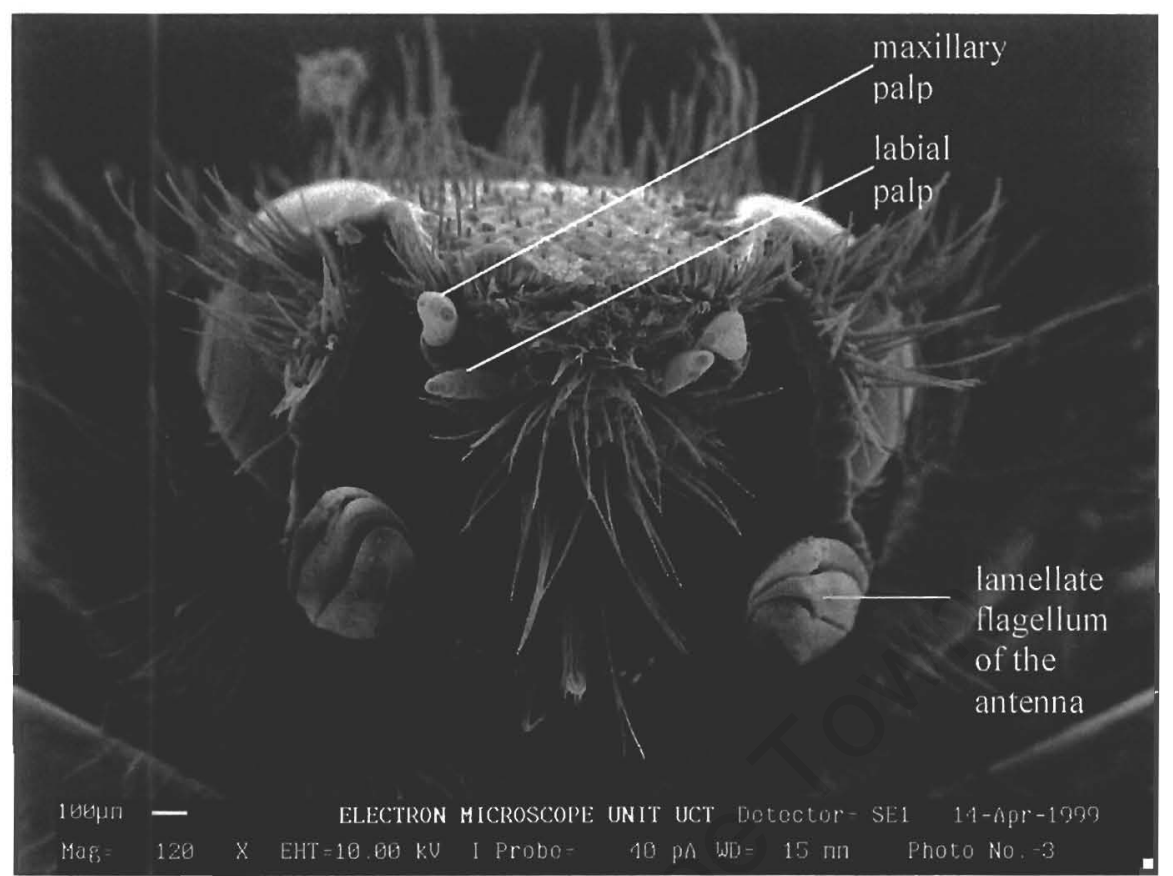

Fig. 8. Frontal view of the head of $P$. flovolineata. Antennae are drawn up close to the head for protection.

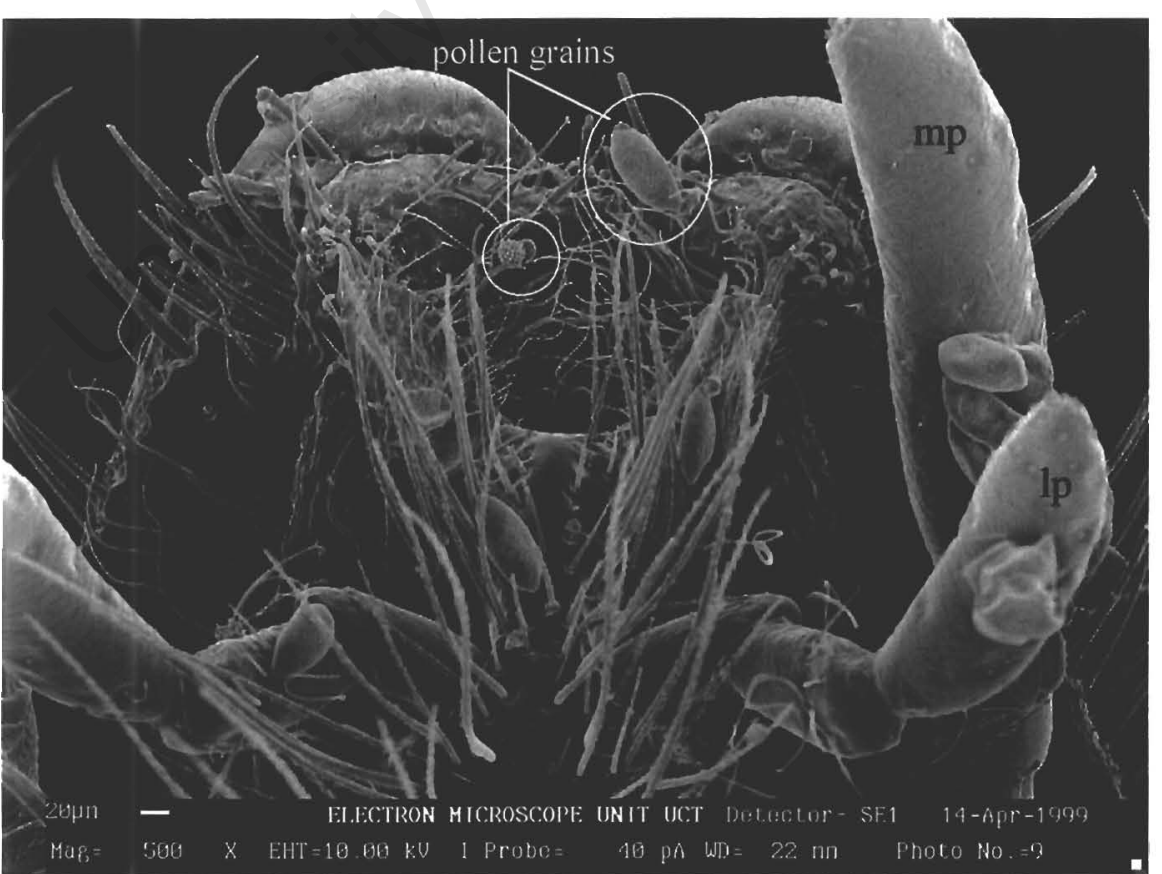

Fig. 9. Ventral view of the mouth of $P$. cinerea. A spherical pollen grain, as well as a number of oval pollen grains are visible, trapped in the hair. $\mathrm{lp}$ - labial palp; $\mathrm{mp}$ - maxillary palp 


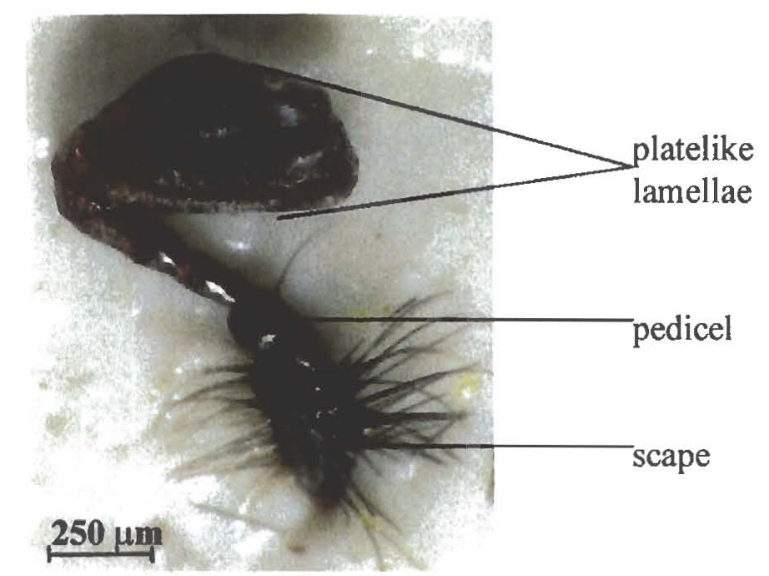

Fig. 10. Antenna of $P$. flavolineata.

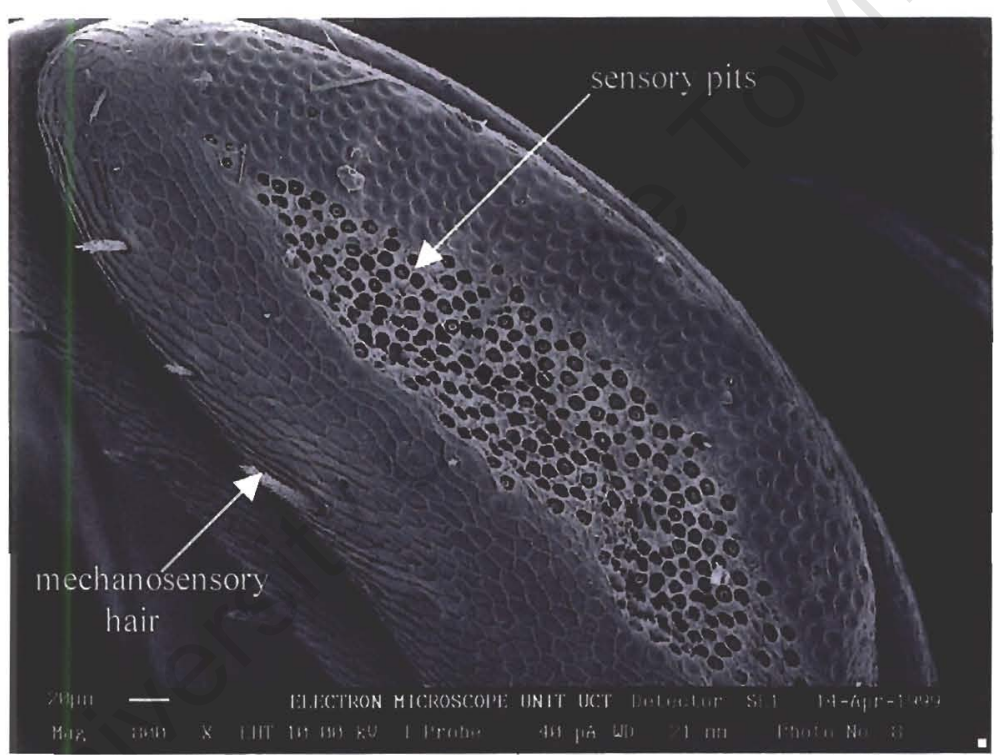

Fig. 11. Surface of one terminal annuli of the antenna of $P$. flavolineata.

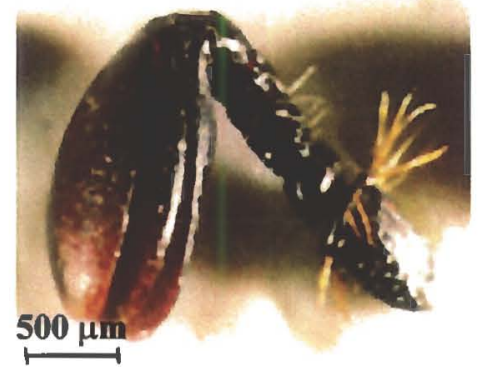

Fig. 12. Antenna of $T$. fascicularis with terminal annuli in club shape.

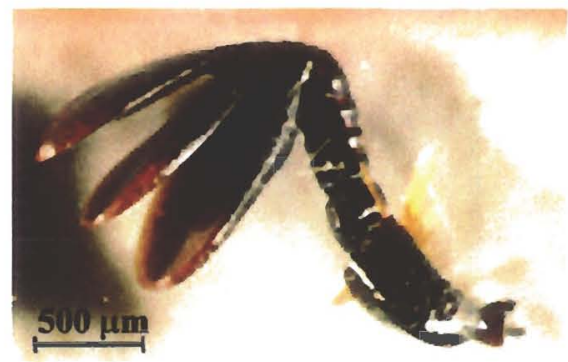

Fig. 13. Antenna of $T$. fascicularis. Terminal annuli expanding into fan shape. 


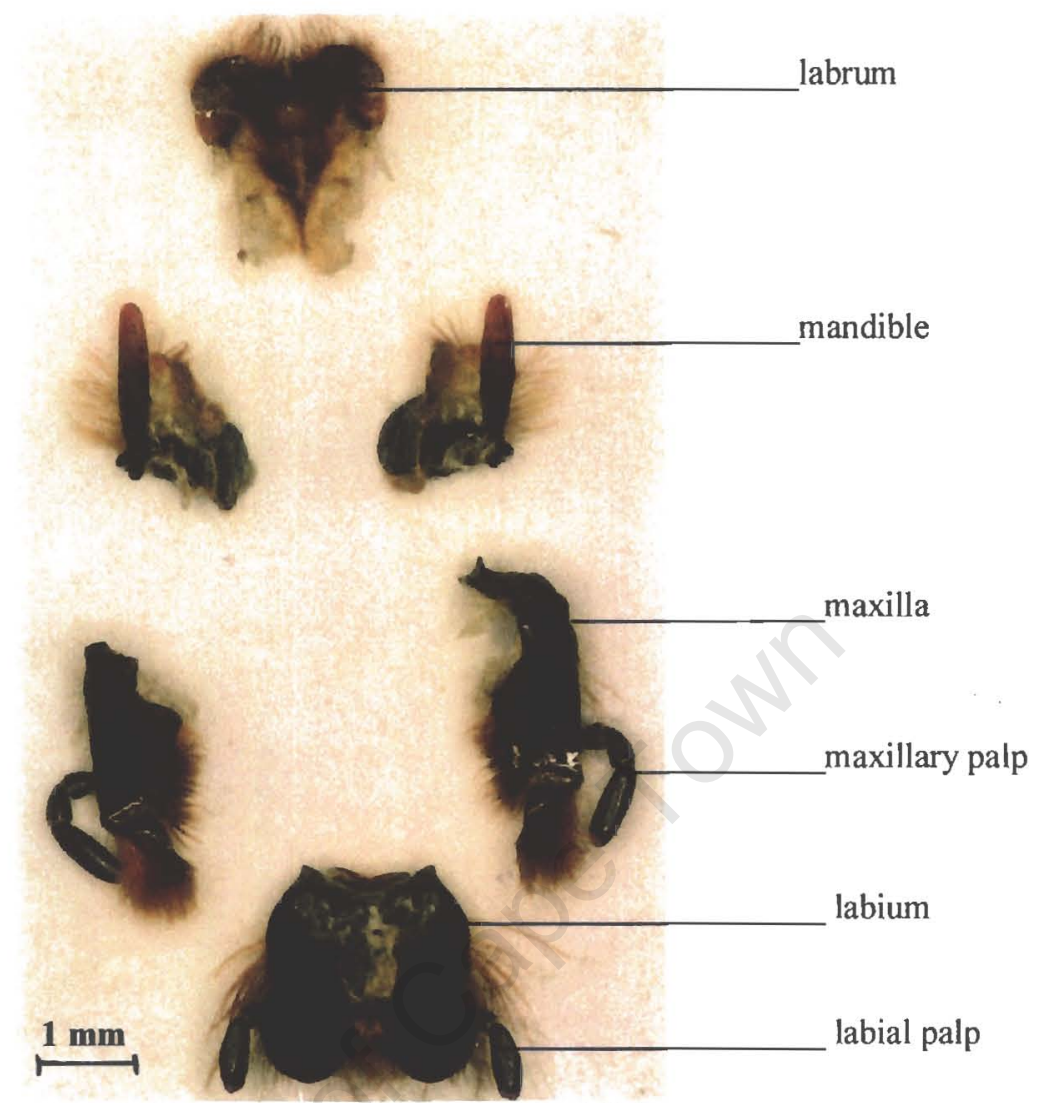

Fig. 14. Mouthparts of $T$. fascicularis. All the mouthparts bear orange-brown bristles. The most dense aggregation of setae form little brushes at the tips of the maxillae.

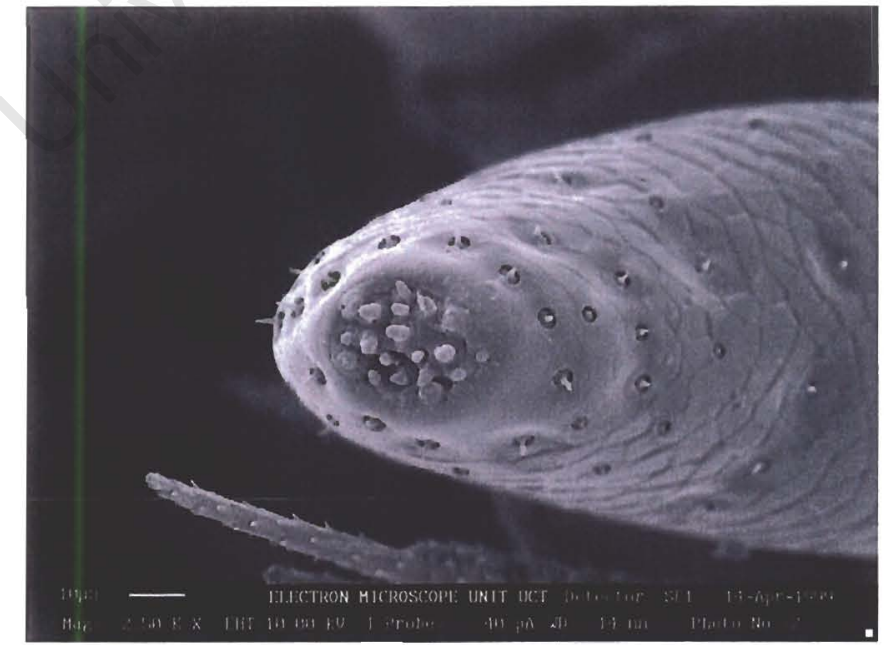

Fig. 15. Tip of labial palp of $P$. flavolineata. Note the sensory pits on the surface and the sensory papillae at the tip. 


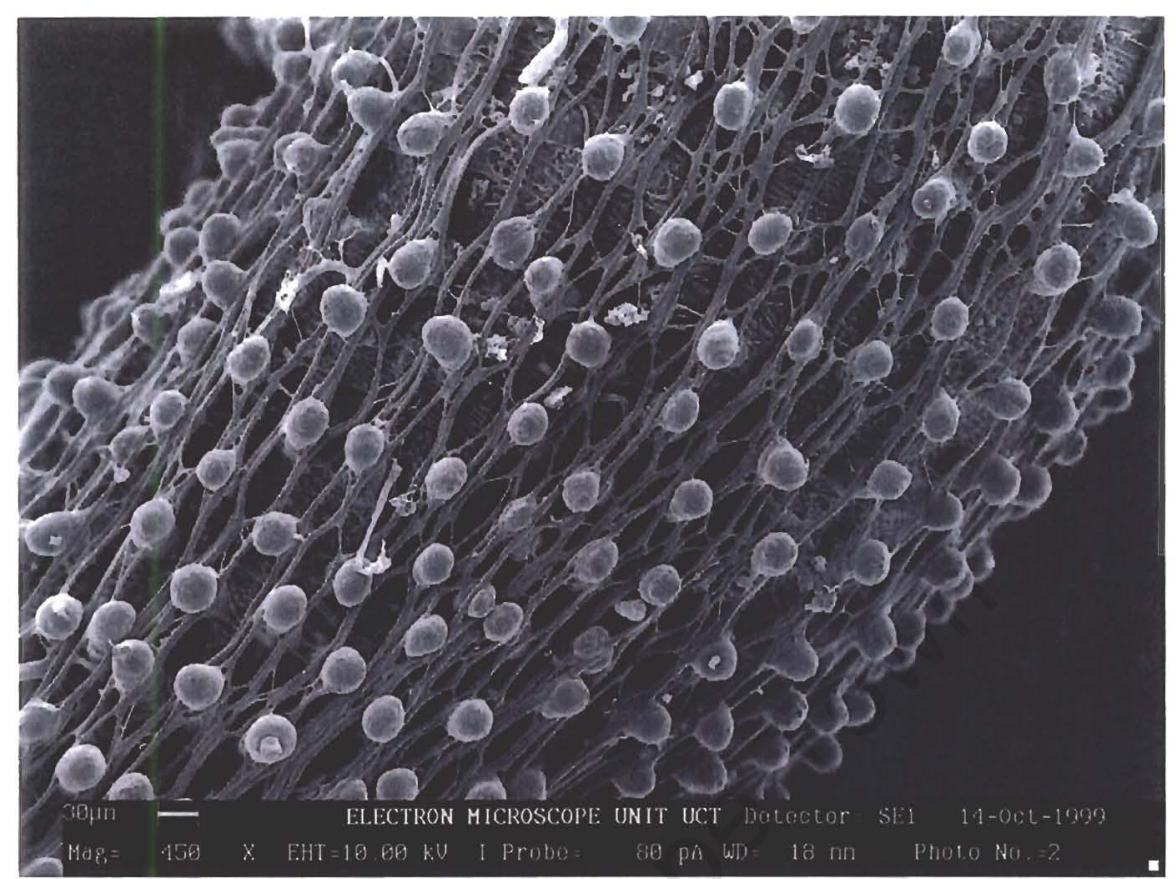

Fig. 17. Exterior of T. fascicularis midgut. Numerous small papillae (crypts containing groups of regenerative cells or nidi) arise from the gut wall and protrude through the strands of muscles running longitudinally along the length of the gut.

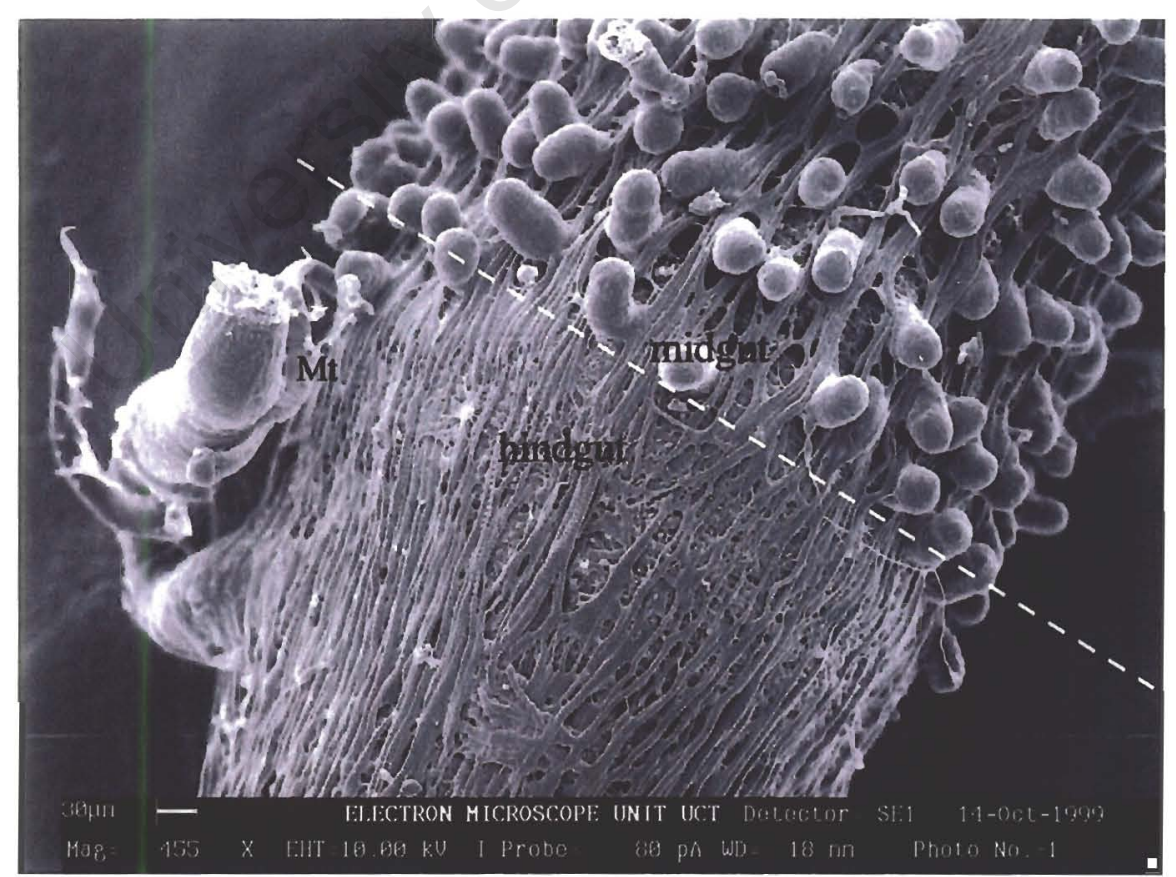

Fig. 18. Junction between midgut and hindgut of $T$. fascicularis. Nidi end abruptly where the hindgut begins. The beginning of the hindgut is also the origin of the Malphigian tubules (Mt). One tubule is shown, severed during dissection. 


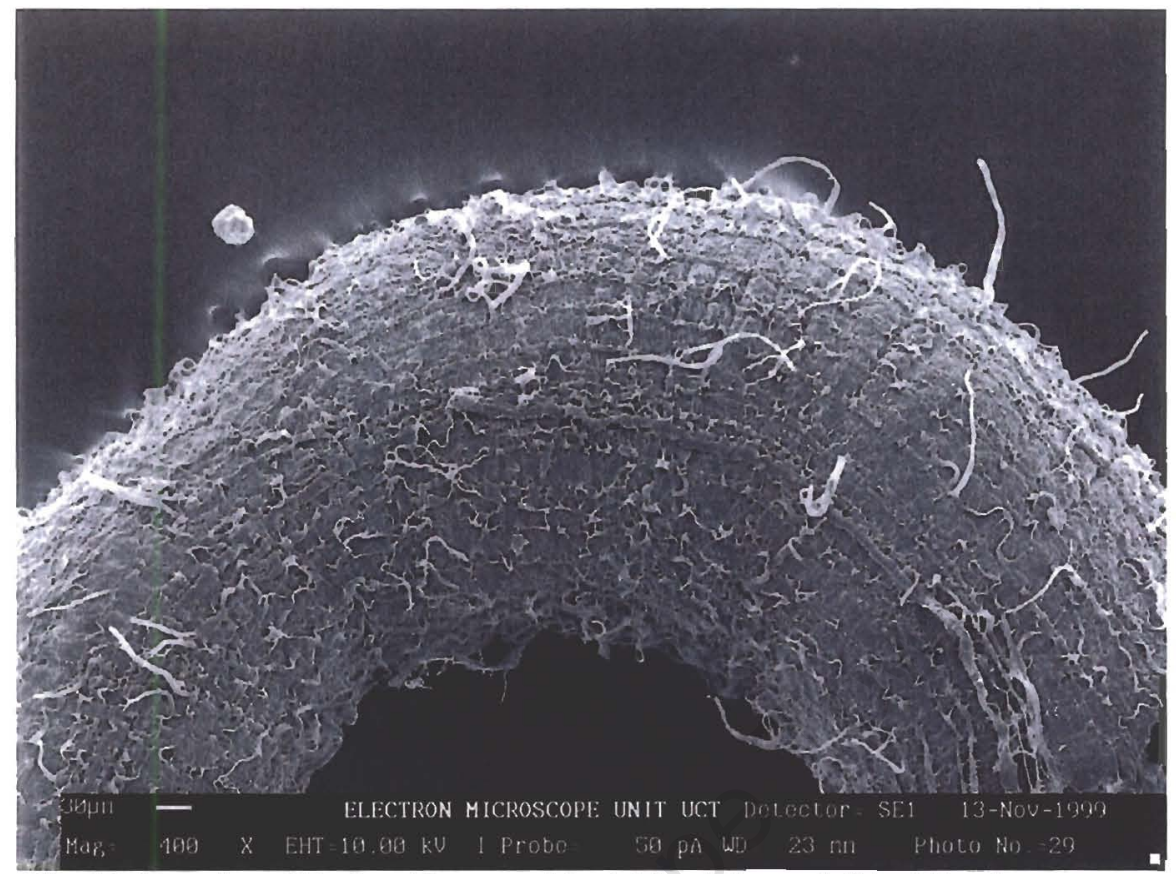

Fig. 20. Exterior of $P$. flavolineata midgut. No nidi are visible. Muscles running longitudinally along the length of the midgut, as well as circular muscles and some branches of tracheoles can be seen.

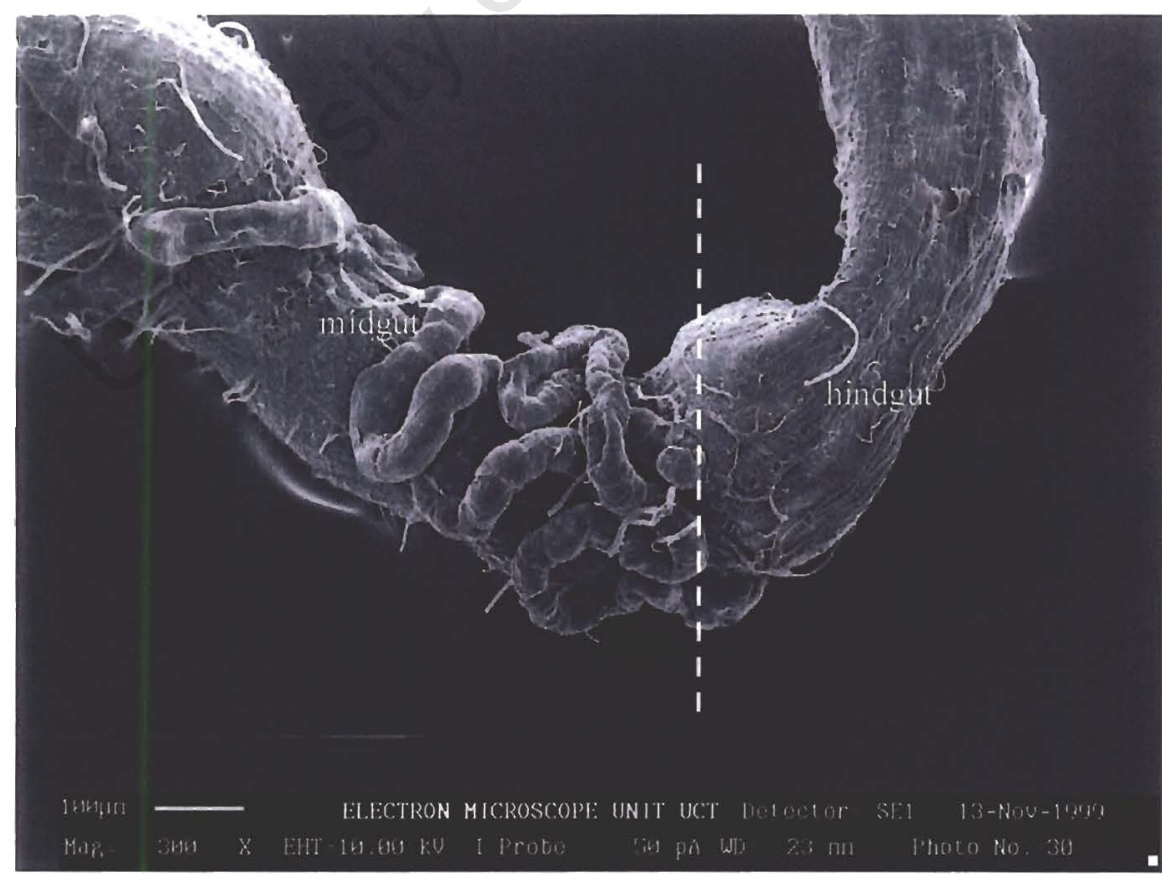

Fig. 21. Junction between the midgut and hindgut of $P$. flovolineata. No nidi are visible on the midgut. Malphigian tubules originating at the midgut-hindgut junction are coiled around the gut. 


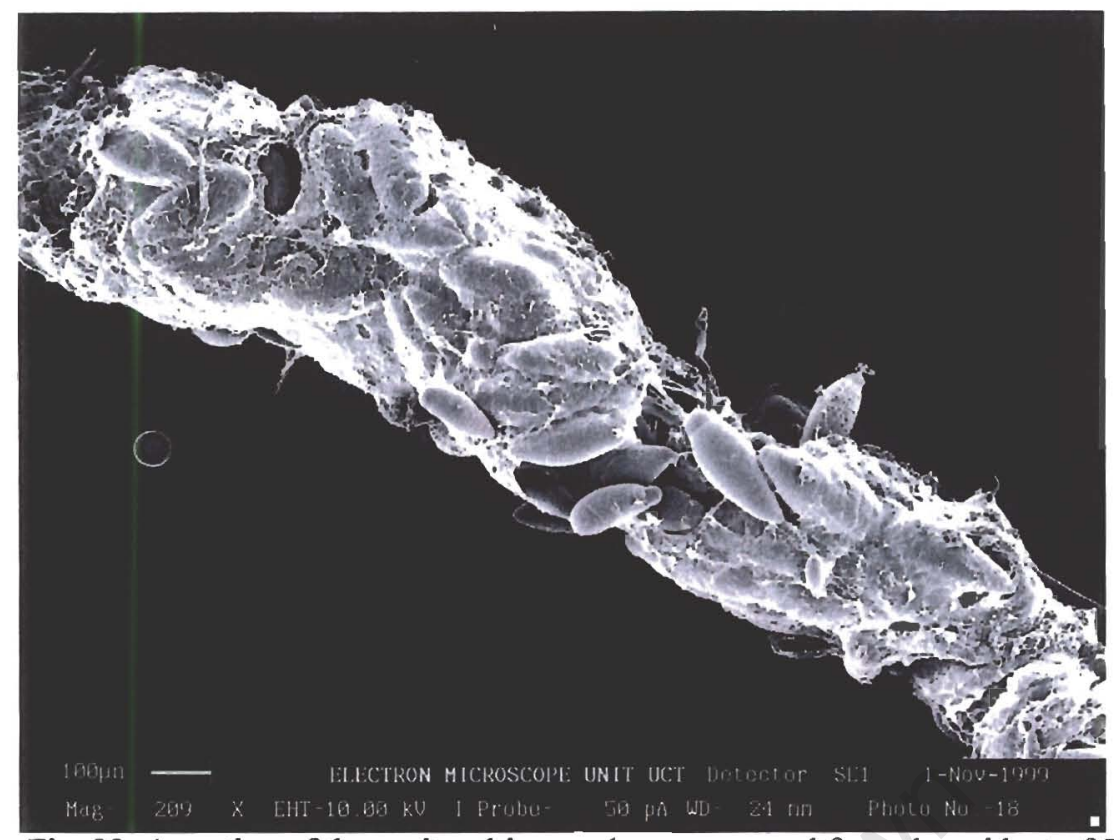

Fig. 22. A section of the peritrophic membrane removed from the midgut of $T$. fascicularis, packed with gregarines, protozoan parasites that inhabit the digestive tracts of insects. In this case the gregarines are enclosed within the peritrophic membrane and are not being excluded from the gut contents by it.

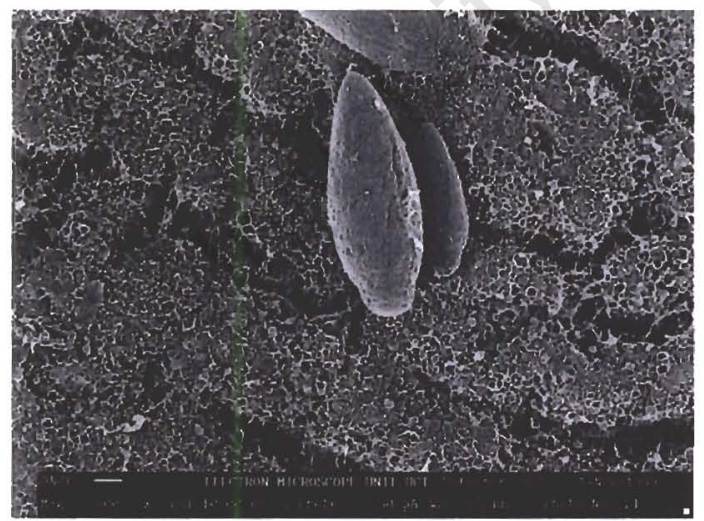

Fig. 23. Gregarines on the internal surface (microvilli) of the gut wall of the midgut in $\mathrm{T}$. fascicularis.

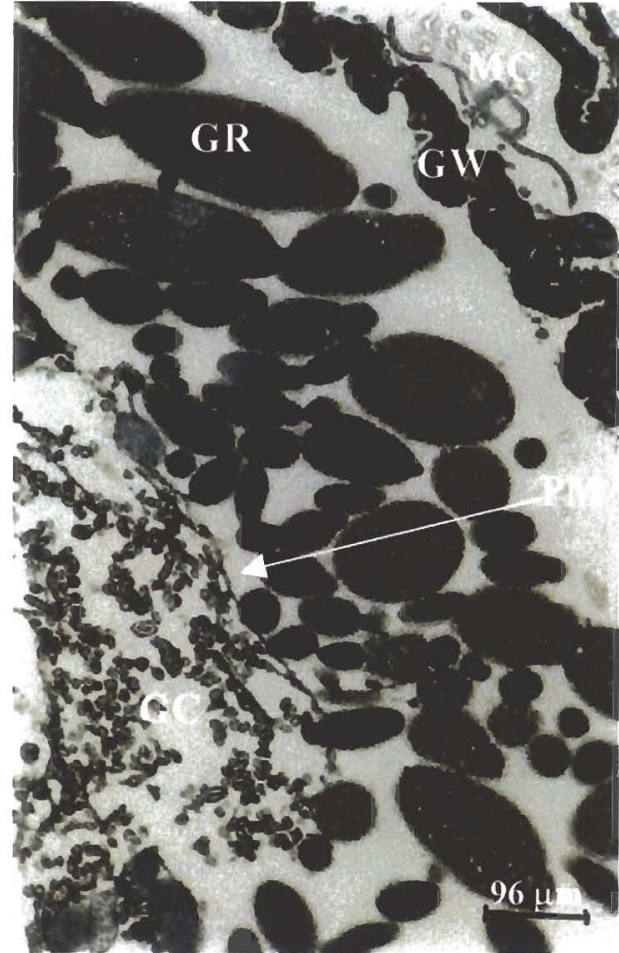

Fig. 24. A serial section of the midgut of $T$. fascicularis. Note how gregarines $(\mathrm{G})$ are excluded from the gut contents (GC) by the peritrophic membrane (PM). GW - gut wall, $\mathrm{MC}$ - midgut cells. 


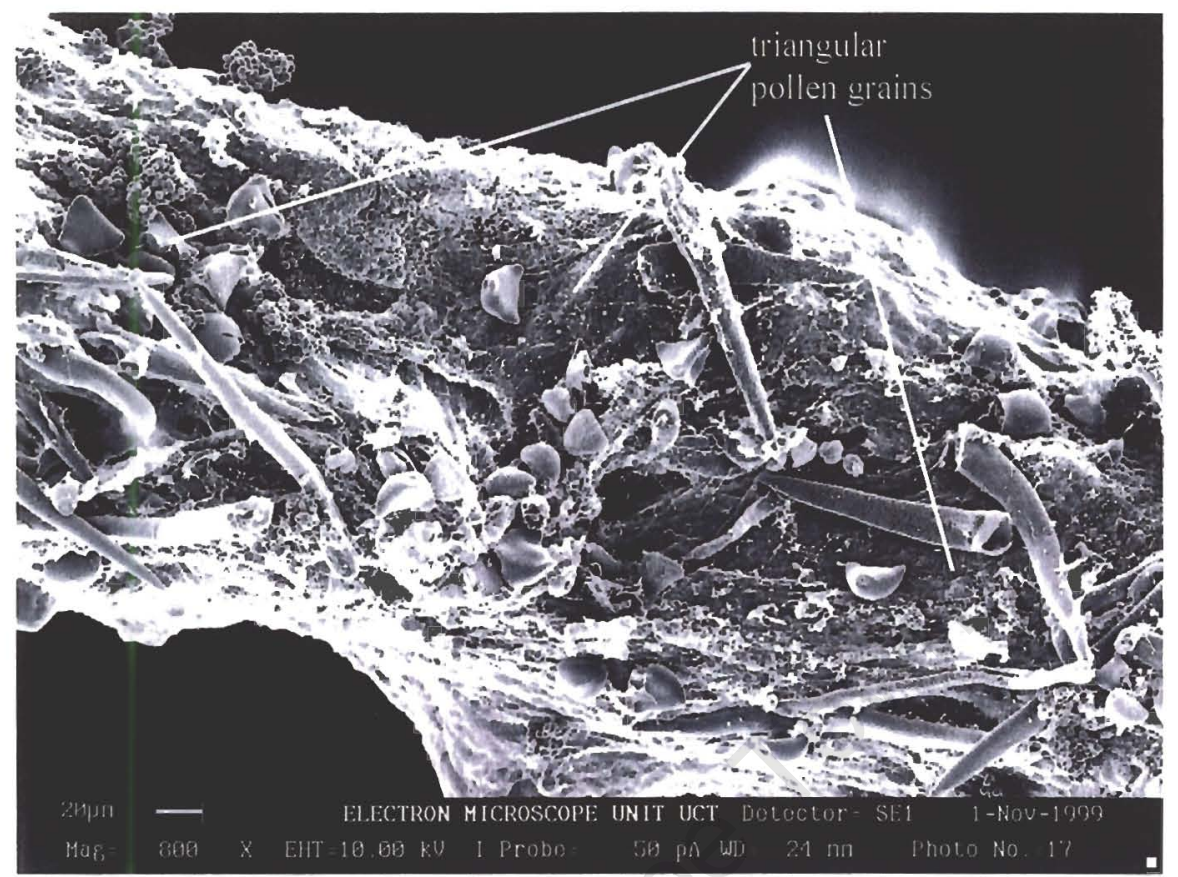

Fig. 25. Peritrophic membrane from the midgut of $T$. fascicularis. The membrane is very thin and as a result broke during processing, revealing the gut contents. No gregarines are visible. The triangular pollen grains in the gut contents are most likely grains from Protea eximia, since the beetles were found on this plant species and $P$. eximia reference pollen grains were triangular in shape. The elongated structures are probably bits of perianth segments ingested by the beetle.

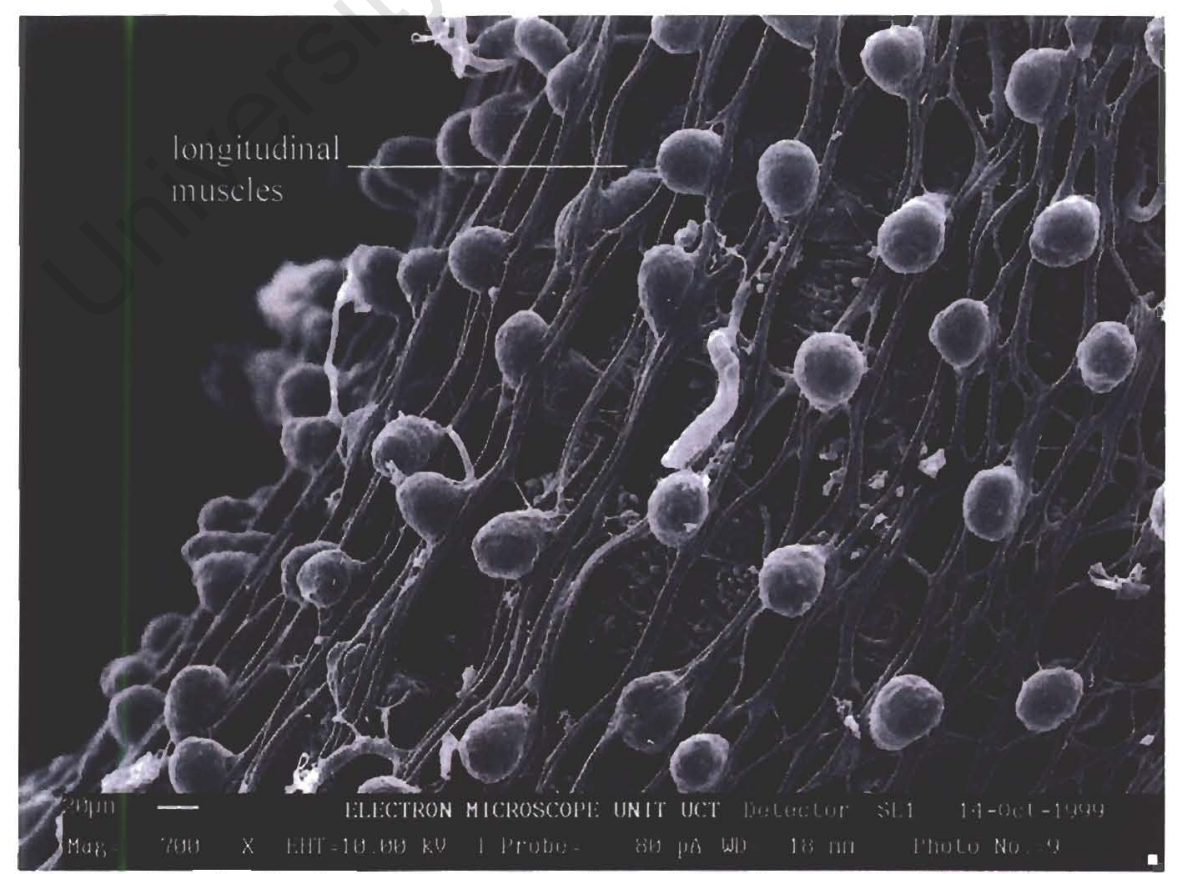

Fig. 26. Longitudinal muscles running along the midgut, with nidi protruding through the muscle strands. Circular muscles are visible underneath. 


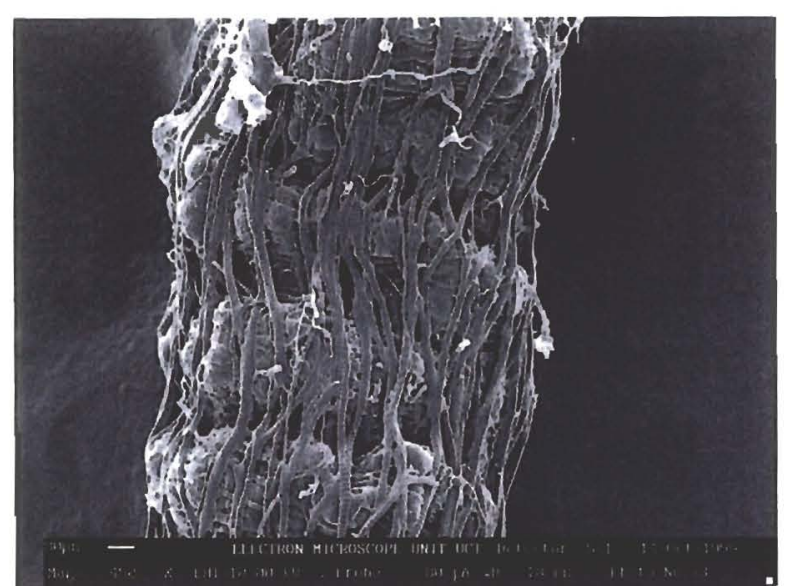

Fig. 27a. Longitudinal and circular muscles of the ileum in T. fascicularis.

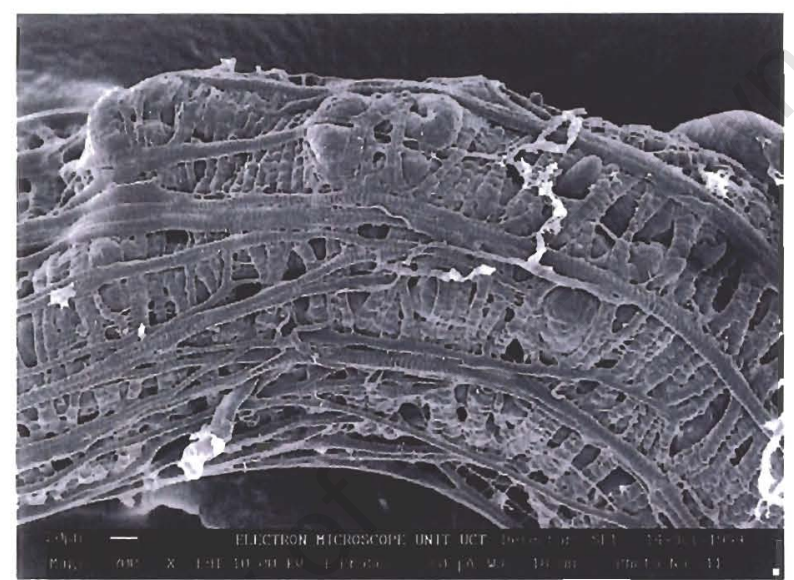

Fig. 27b. Longitudinal and circular muscles of the colon in T. fascicularis. Circular muscles are more prominent here than in the ileum.

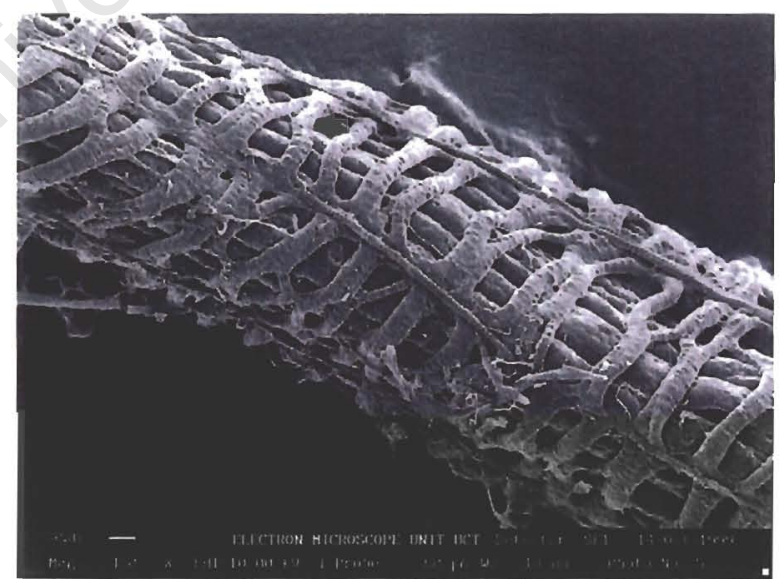

Fig. 27c. Prominent circular muscles of the rectum in T. fascicularis. There are very few longitudinal muscles along this section of the hindgut. 


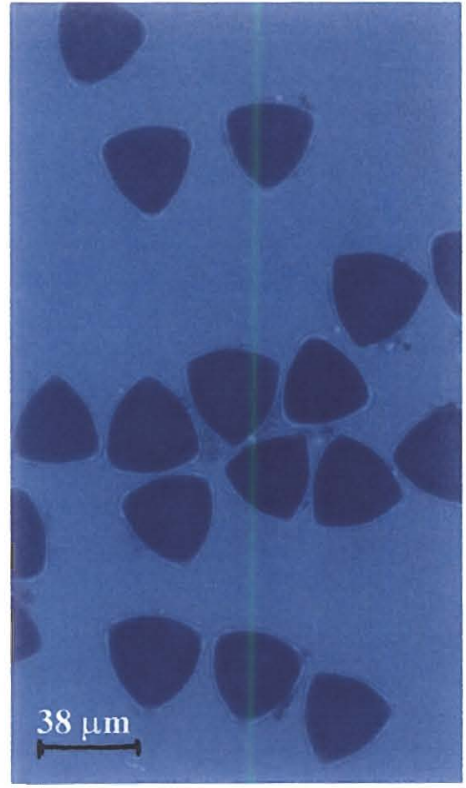

Fig. 28a.

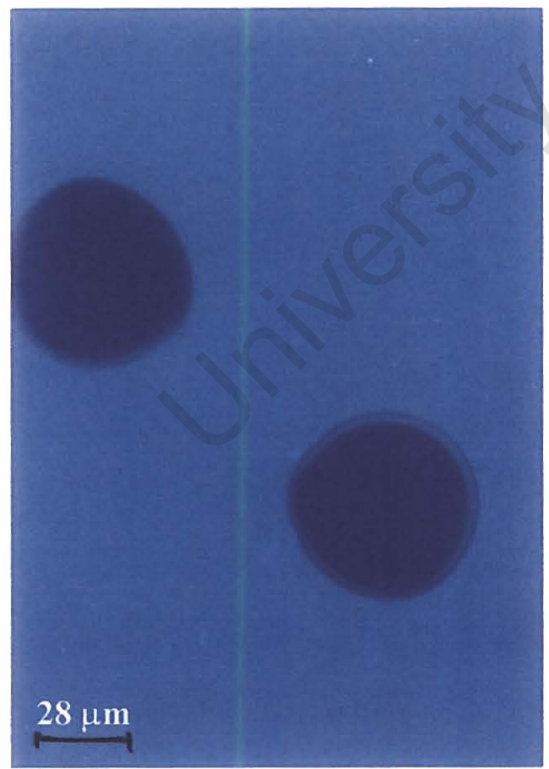

Fig. 28c.

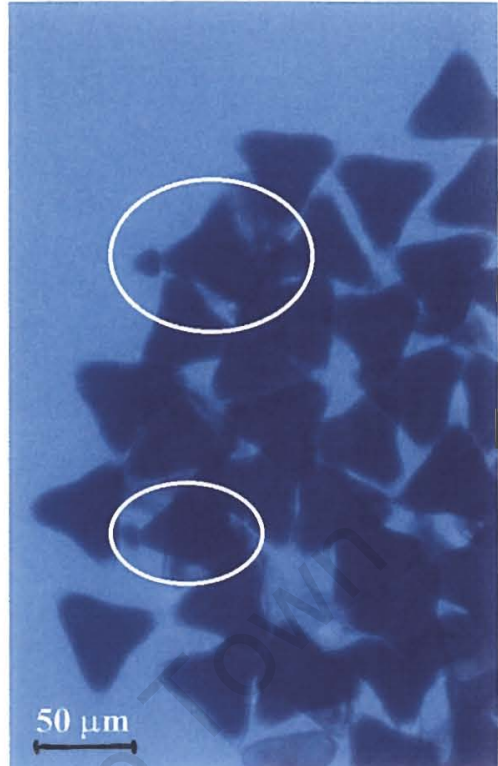

Fig. $28 \mathrm{~b}$.

Fig. $28 \mathrm{a}$, b and c. Reference pollen stained with cotton blue-lactophenol. a) $P$. eximia pollen has a rounded triangular shape. b) Triangular $B$. lanuginosa pollen. The two encircled grains are exhibiting extrusion of protoplasmic contents via germination pores. c) The spherical pollen grains of $O$. thyrsoides. 


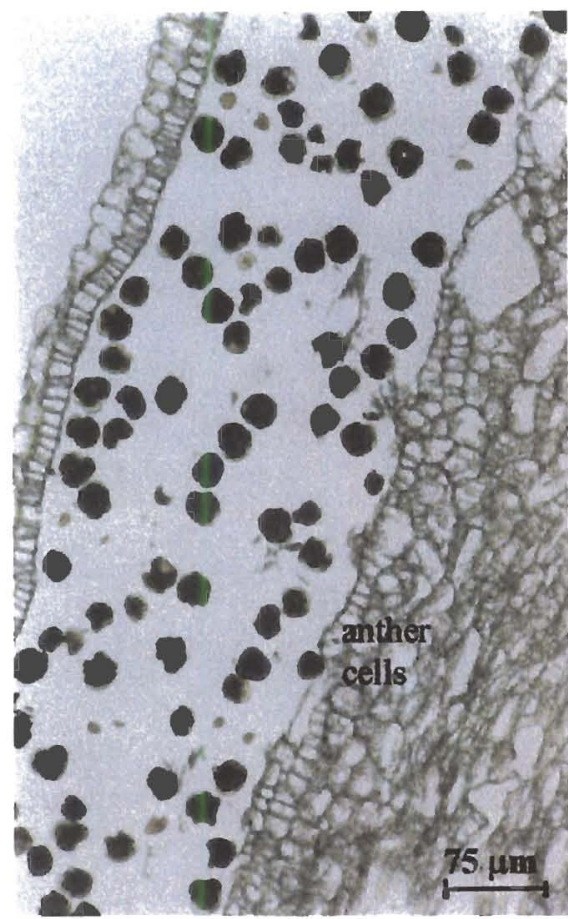

Fig. 29. O. thyrsoides control pollen stained for general carbohydrates by the Periodic Acid Schiff method.

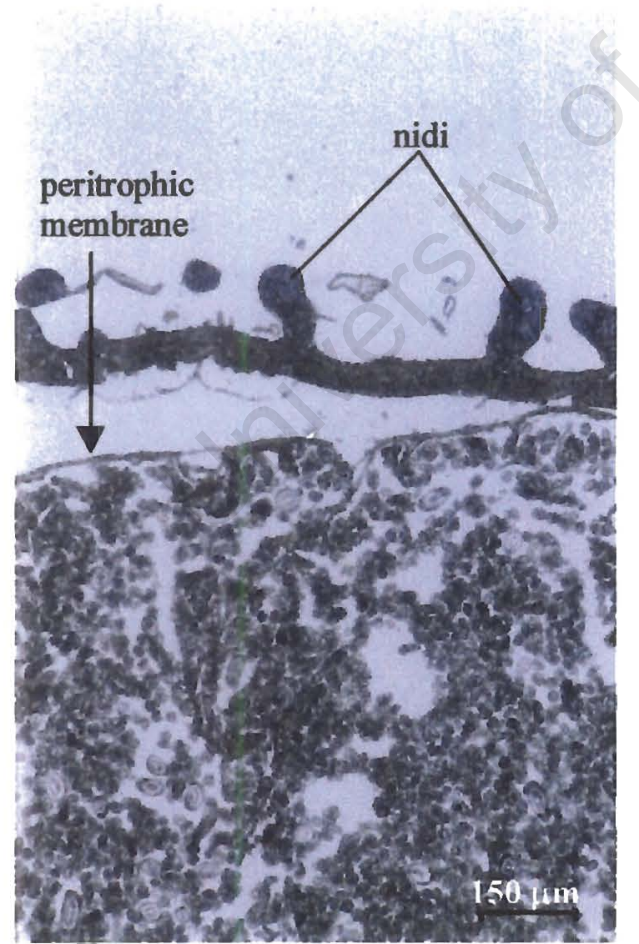

Fig. 31. Longitudinal section of the median posterior midgut of a protea beetle, stained for proteins by the Ninhydrin-Schiff method.

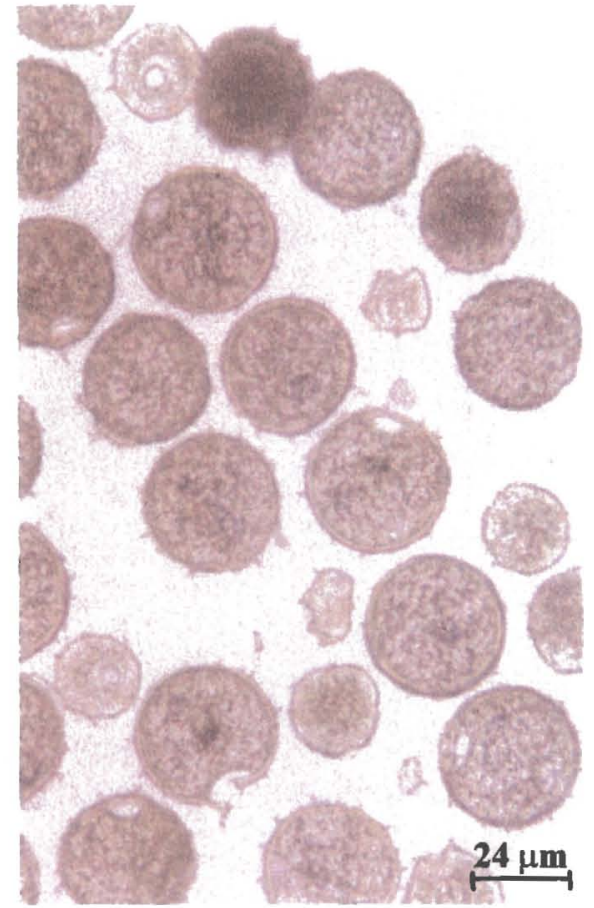

Fig. 30. O. thyrsoides control pollen stained for lipids with Oil Red $O$. Note that the pollenkit, which is rich in lipids, stained slightly darker than the rest of the grain. The phospholipids produce a pink stain.

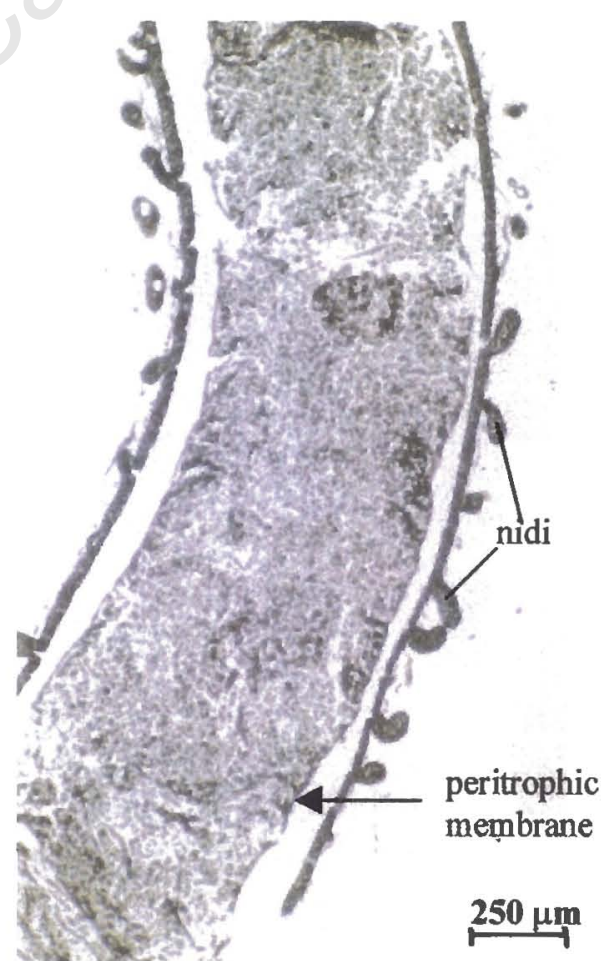

Fig. 32. Longitudinal section of the posterior midgut of the protea beetle, stained for cellulose and amyloids with Congo Red. 


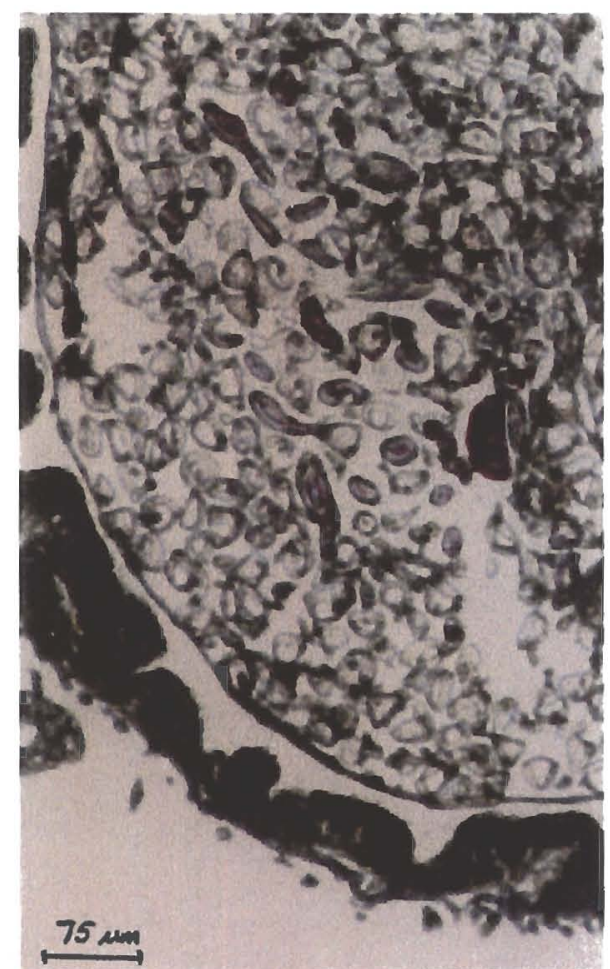

Fig. 33. Cross section of the anterior hindgut of a protea beetle stained for proteins by the Ninhydrin-Schiff method. Note the triangular shape of empty pollen grain shells.

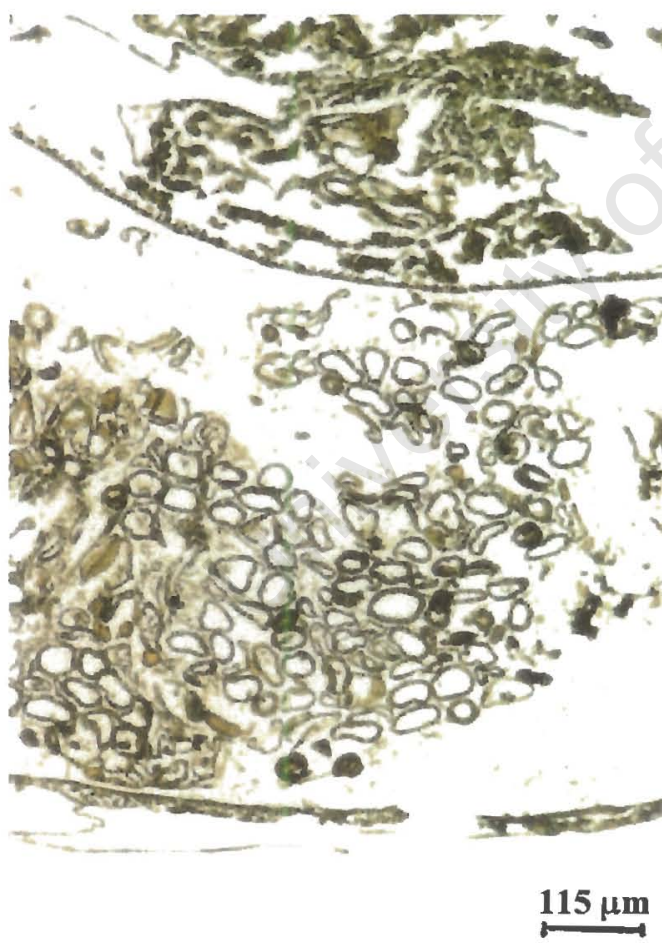

Fig. 34. Longitudinal section of the hindgut of a monkey beetle, stained for cellulose and amyloids with Congo Red.

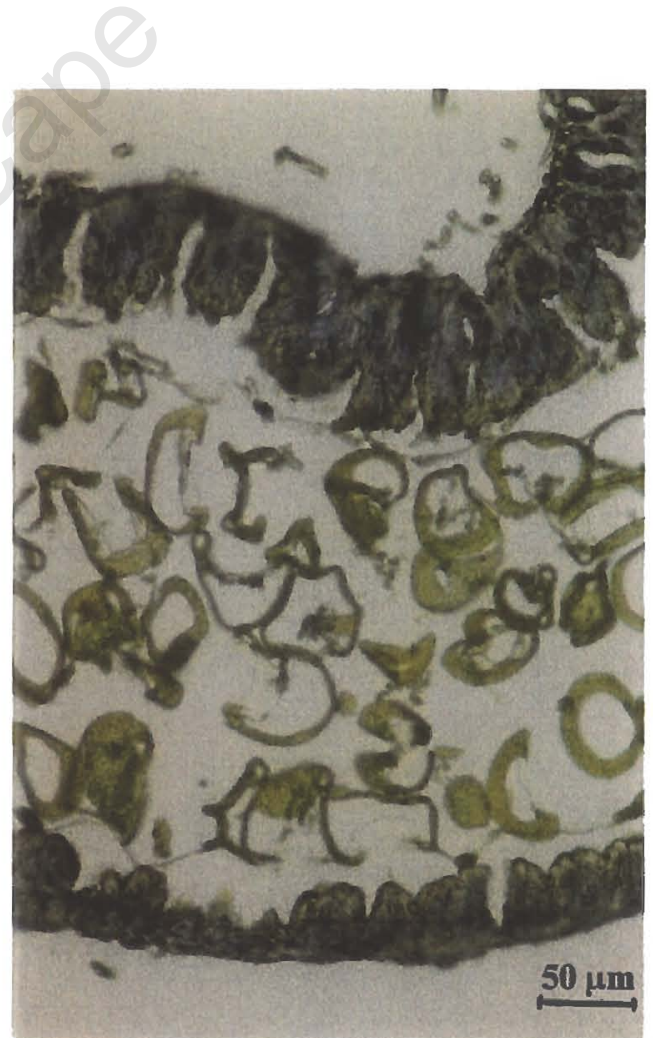

Fig. 35. Longitudinal section of the posterior midgut of a monkey beetle, stained for general carbohydrates by the Periodic Acid Schiff method. 


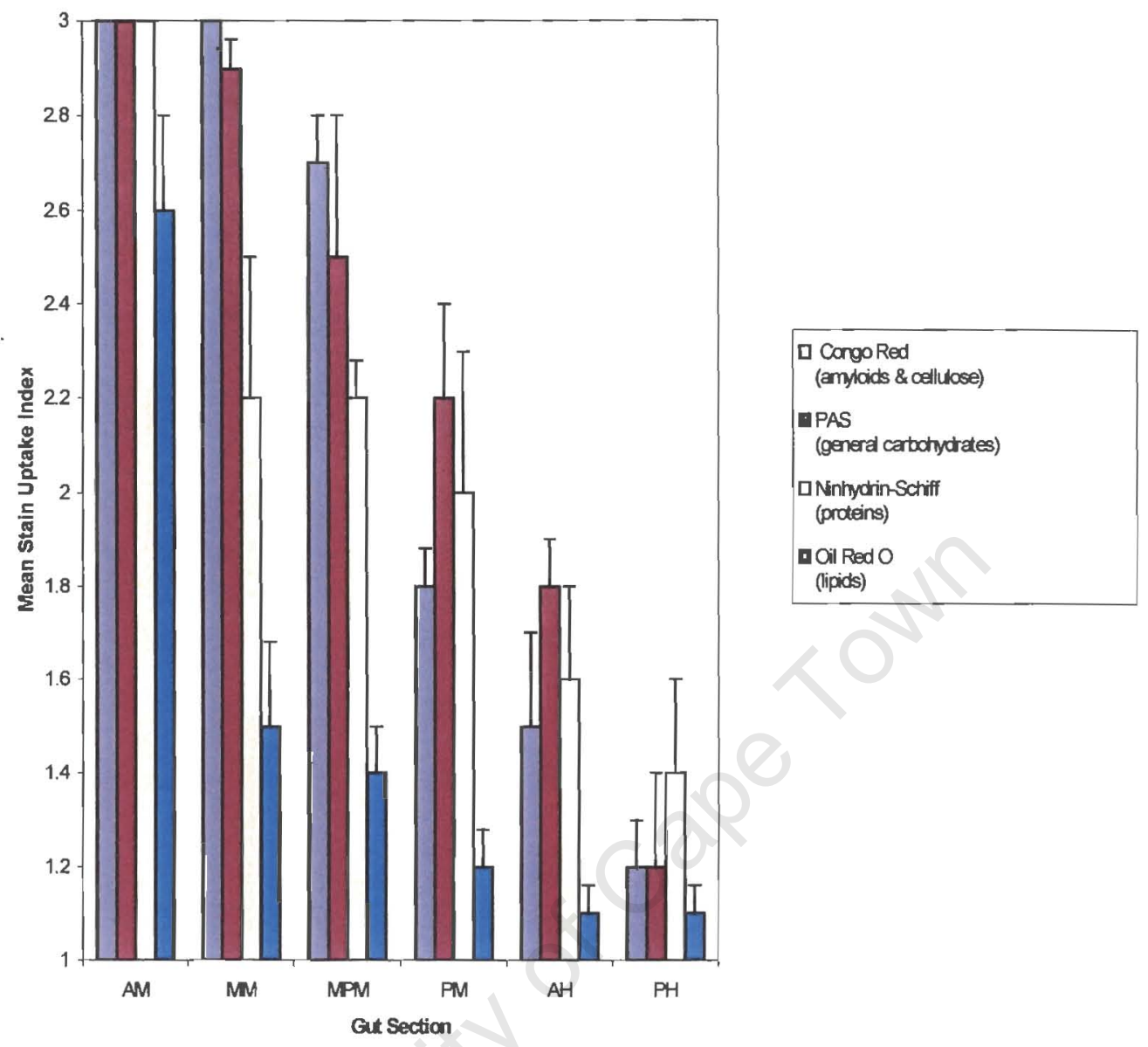

Fig. 36. Mean stain uptake index $( \pm \mathrm{SE})$ for each nutrient in gut regions of $T$. fascicularis $(\mathrm{n}=50)$.

(AM- anterior midgut; MM- median midgut; MPM- median posterior midgut; PM- posterior midgut; $\mathrm{AH}$ - anterior hindgut; $\mathrm{PH}$ - posterior hindgut). 


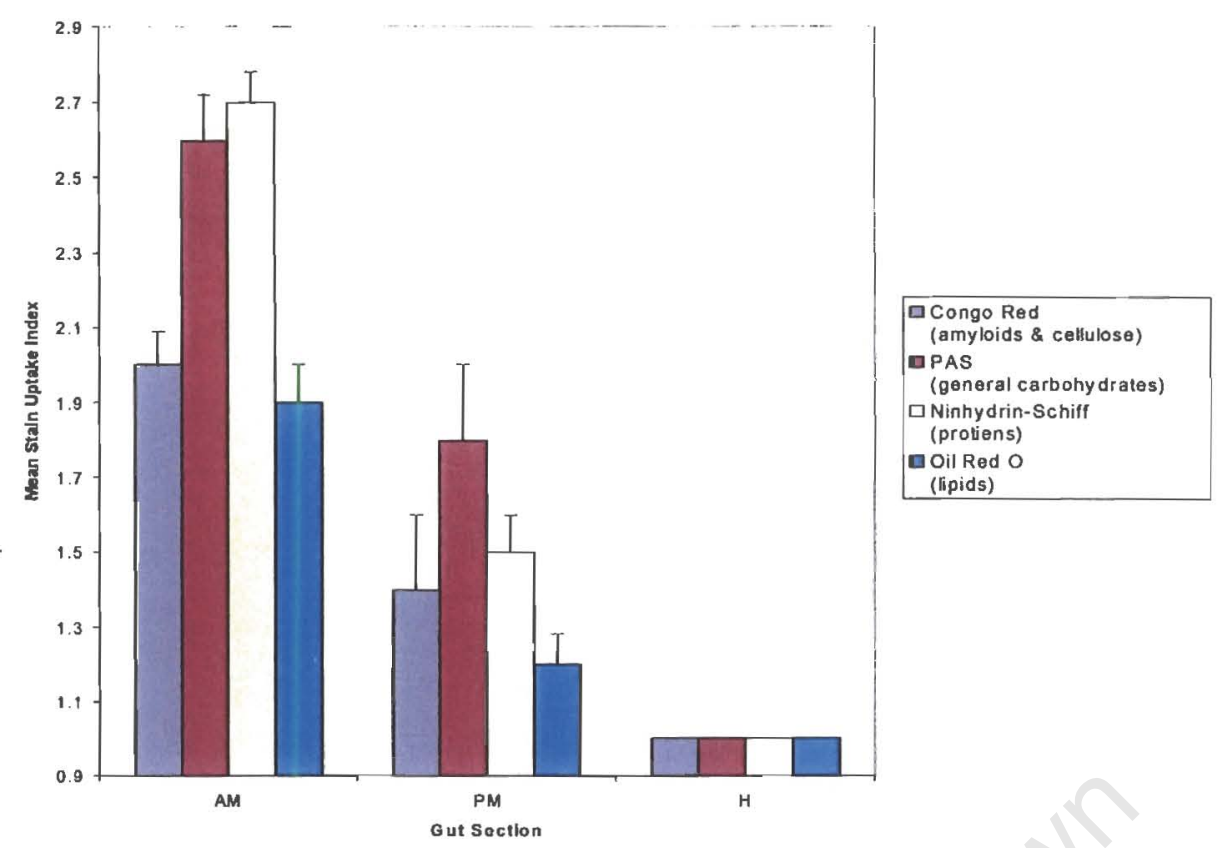

Fig. 37. Mean stain uptake index $( \pm \mathrm{SE})$ for each nutrient in gut regions of $P$. cinerea $(\mathrm{n}=50)$.

(AM- anterior midgut; PM- posterior midgut; $\mathrm{H}$ - hindgut).

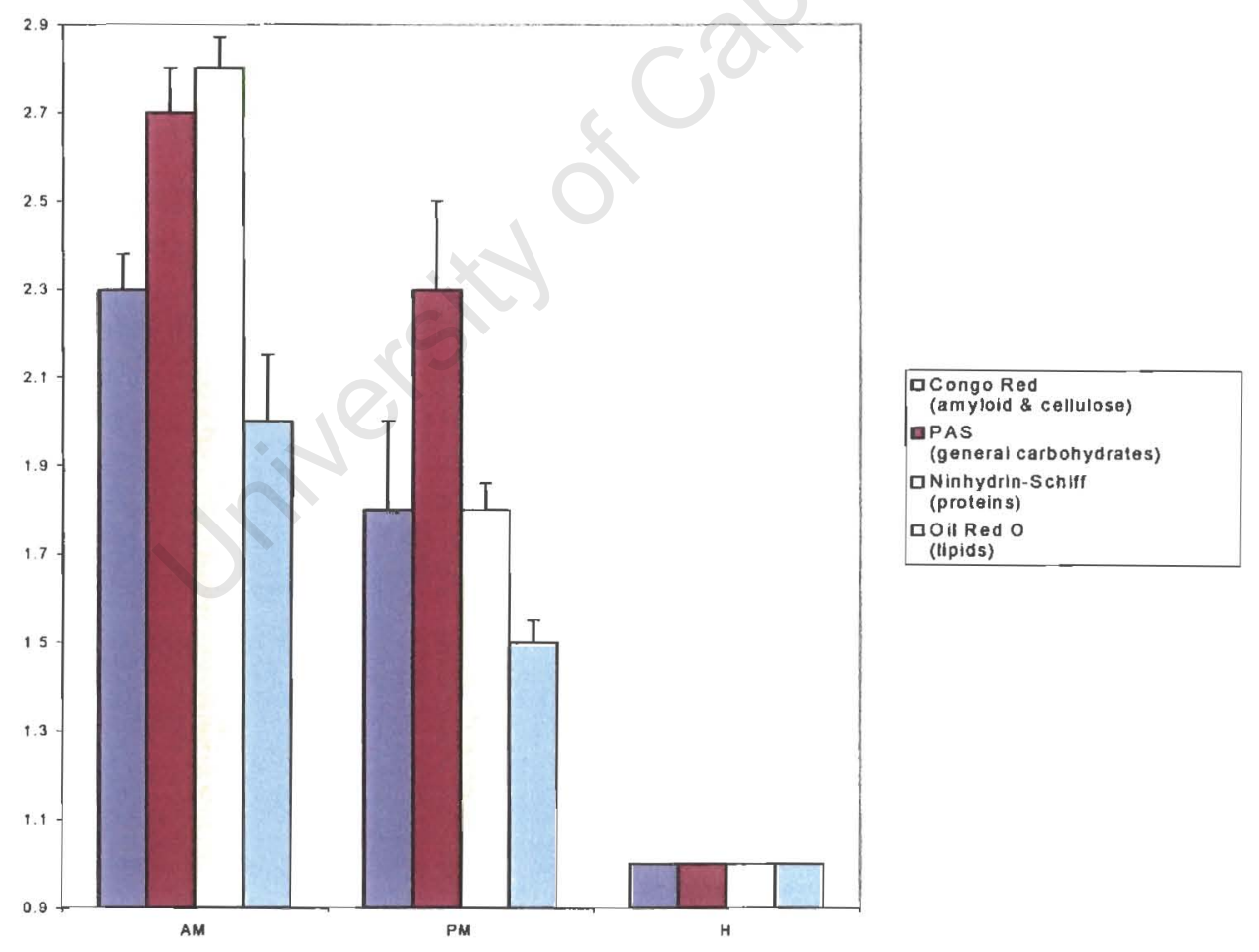

Fig. 38. Mean stain uptake index $( \pm \mathrm{SE})$ for each nutrient in gut regions of $P$. flavolineata $(\mathrm{n}=50)$. (AM- anterior midgut; PM- posterior midgut; H- hindgut). 


\section{Discussion}

It is now possible to consider the morphological and physiological abilities of these scarab beetles to extract and make use of the floral rewards they seek out. Sense organs used in detecting the rewards and feeding appendages that facilitate ingestion are modified to suit the beetles' feeding habits. The following section compares the head, mouthparts and alimentary canal of these scarab beetles with the anatomical features of a generalised insect. Adaptations relating to pollen and nectar feeding are considered and lastly, the results of the pollen digestion experiments in comparison with other studies are discussed. The aim is to determine which of the possible methods of digestion described in the introduction are used by $T$. fascicularis, $P$. cinerea and $P$. flavolineata to digest the pollen which is a major component of their diet.

\section{Head and mouthparts}

The prognathous position of the mouthparts of $T$. fascicularis and the monkey beetles P. cinerea and $P$. flavolineata is probably advantageous to their way of feeding. Although pollen is easily accessible, protea beetles push through densely packed florets in Protea flowerheads in search of nectar. Monkey beetles bury their heads within the reproductive structures of the flowers they visit, such as the central floret disc of asteraceous flowers. Such elongated and forwardly projecting mouthparts facilitate probing between floral parts for nectar and pollen. 


\section{Protection of sensory structures}

Characteristic of the beetle head, a median ventral plate known as the gula protects the mouthparts from underneath (Chapman 1998). Delicate sensory appendages such as antennae and labial and maxillary palps, the latter also facilitating the intake of food, need to be protected as the beetles probe within flowerheads. The antennae are the primary olfactory sense organs of all insects. They are equipped with sensors that detect food, locate egg-laying sites, detect vibrations and assess environmental factors such as temperature and humidity. As a form of protection, protea beetles and monkey beetles are able to retract their antennae very close to the head and withdraw palps directly underneath the clypeus, the dorsal plate at the anterior end of the head. Having antennal insertions close to the eyes is also a protective adaptation and is often associated with beetles that feed on nectar (Evans \& Bellamy 1996). Beetles that live in symbiotic relationships with ants and termites are known as myrmecophiles and termitophiles respectively, and some of them have grooves into which the antennae and other appendages can be partially or completely retracted. This is a form of physical mimicry and reduces the chances that the beetle will be attacked by its hosts (Evans \& Bellamy 1996).

The size, shape and modifications of antennae vary from species to species. The terminal plate-like annuli of the antennae in the protea beetle and monkey beetles studied here were observed in a club and a fan shape. The ability to retract these annuli of the flagellum into a compact club or expand them into a fan is a feature that distinguishes Scarabaeidae from all other beetles (Evans \& Bellamy 1996). The compact club shape may be another form of protection as the inner surfaces of the 
plate-like annuli bear numerous olfactory sensillae (Barth 1985). Expanding the annuli into a fan exposes all these sensillae and sensory ability is improved.

\section{Feeding mechanism}

Insect mouthparts are related to their diet. There are two principal types: biting and chewing mouthparts or mouthparts modified to suck up fluids (Chapman 1998). Carnivorous insects have mandibles modified into shearing cusps or chisel edged "incisors", while insects that chew tough vegetation, e.g. grass-feeding species, have flattened molar regions for grinding. Insects that suck up fluids have mouthparts modified in various ways to form a tube or food canal through which liquid can be drawn up into the mouth. Biting and chewing mouthparts form the basic beetle mouthparts.

In larval Coleoptera the mouthparts are usually well developed for crushing, grinding and tearing, rarely sucking. Beetle larvae may scavenge on carrion, feed within a dung ball, attack roots, mine the tissue between the upper and lower layers of a leaf, chew through dead wood, feed within ant and termite mounds or feed on decaying plant material. Among the Scarabaeoidea larval feeding can be just as varied (Evans \& Bellamy 1996). Major food sources of scarab larvae are: rooting wood (Passalidae, Lucanidae); carrion (Scarabaeinae, Aphodinae) or other animal remains (Trogidae); hypogeous (Bolboceratidae, Geotrupinae) or arboreal fungi (Ceratocanthidae); associations with social insects like ants and termites (Ceratocanthidae, Aphodinae, Valginae); living plant roots (Pleocomidae, Melolonthinae, Dynastinae, Rutelinae); humus (several groups including Cetoniinae); and herbivore dung (Scarabaeinae, Aphodiinae, some Geotrupidae) (Scholtz \& Chown 1995). 
The larvae of the cetoniine T. fascicularis are found in organic matter in soil, sometimes beneath termite mounds (Skaife 1955). Whether they live in association with the termites is not known, but they do feed on decaying plant matter (humus) (Gess 1968). Larvae of Rutelinae feed on living plant roots. There is evidence that some species of monkey beetles have associations with host plants when mating (Louw 1987; Picker \& Midgley 1994). Individuals and pairs were observed burrowing into the ground at the base of the host plant, possibly laying eggs there so that the larvae are close to their food source.

In many cases adults feed in situations and on food similar to those of the larvae (Terra 1990; Scholtz \& Chown 1995). However, in some groups of Scarabaeoidea the adults feed differently to the larvae. Some adults do not feed (examples are included among the Pleocomidae, Diphyllostomatidae, Melolonthinae, Dynastidae, Rutelinae); some adults turn to feeding on foliage, fruit and flowers (Melolonthinae, Rutelinae, Cetoniinae); or become carnivorous (Hybosoridae, Cetoniinae) (Scholtz \& Chown 1995). Adult T. fascicularis and hopliines belong to those groups (Cetoniinae and Rutelinae respectively), which feed on foliage, fruit and flowers.

The adult protea beetle and monkey beetles do not have any apparent biting or chewing mouthparts, which form the basic beetle mouthparts. Instead, there are brushes of setae on all the mouthparts, and especially dense brushes at the tips of the maxillae. These brushes appear to be very well suited for mopping up nectar and sweeping up pollen. Observations of $T$. fascicularis feeding on a droplet of a sucrosewater solution confirmed the suggestion that the brushes may be used to mop up nectar in the flower. The sucrose-water solution was mopped up by repeated 
semicircular motion of the brushes. The process can be described in the following way: the brushes are extended outwards and into the nectar, allowed to trap some of the nectar, and are then drawn back into the mouth where the nectar is removed and taken into the foregut. The nectar held within the dense brushes on the ends of the maxillae may be removed by setae on the labrum as the semicircular action brings the maxillae inside the mouth and takes them out again or it may squeezed out by pressure between the labrum and labium. Similar elongated hairy lobes on the maxillae and /or labia have been associated with nectar collection in Dascillus species (Bernhardt 1996). These brushes have also been described as pollen brooms and the beetles bearing them, pollen-sweeping machines (Barth 1985). Some examples are Strangalia maculata (a member of the Cerambycidae, a group that includes the most regular flower-visitors among beetles) and Cetonia aurata (Scarabaeidae) (Barth 1985). Protea beetles and monkey beetles were observed feeding on pollen directly from anthers. Moving in the same semicircular motion as described above, the "brooms" gather pollen grains together trapping them in the setae and taking them into the mouth, where pollen is wiped off against the setae on the labium and swallowed. The brushes facilitate both nectar and pollen ingestion by mopping up nectar and sweeping up pollen.

It is possible that the protea beetle also uses the dense brushes of setae to rasp away plant tissue in order to reach the pollen on anthers still enclosed within the perianth lobes in Protea flowerheads. When T. fascicularis were fed on a piece of blotting paper soaked in honey (Brunhuber 1964), the paper was torn to shreds and left as small frayed bits when the beetles had finished feeding, suggesting that the setae and mouthparts are capable of rasping through plant tissue. Since the mandibles and 
maxillae are just smooth edged plates, except for the dense brushes of hair, and lack cutting edges, it is unlikely that the pollen is chewed when ingested, but instead is swallowed intact.

\section{Alimentary canal}

The alimentary canals of $T$. fascicularis, $P$. cinerea and $P$. flavolineata differ from the generalised insect alimentary canal in that there is no crop and no midgut caeca. The three beetle species studied here belong to the suborder Polyphaga. Crops are present in adephagous beetles, but are absent or only slightly developed in beetle larvae and polyphagous adults (Crowson 1981). In adult Coleoptera, the anterior midgut caeca have been lost and replaced in function by the anterior midgut (Terra 1990).

\section{Regenerative cel/s}

The midgut is the major area of digestion. The endodermal cells of the epithelium are actively involved in the production and secretion of enzymes and the absorption of nutrients. The principal cells of the midgut have a limited life and in most insects they are replaced from regenerative cells after degradation or injury (Snodgrass 1935; Smith 1968; Billingsley \& Lehane 1996). In most cases these cells are located at the base of the midgut epithelium either singly, paired, or in groups known as nidi (Billingsley \& Lehane 1996). In some insects such as cockroaches, the fully formed midgut is renewed continuously from regenerative cells, and in Tenebrio molitor the whole midgut epithelium is replaced on a four-day cycle (Billingsley \& Lehane 1996). Cell replacement may be rare or absent in some insects even if regenerative cells are common. 
Nidi take on an interesting form in some Coleoptera. The group of cells are contained in evaginations of the midgut epithelium, forming crypts visible as small papillae on the outside of the midgut (Snodgrass 1935; Chapman 1998). These were most conspicuous on the external surface of the protea beetles' midgut, but none were apparent in SEMs of either monkey beetle species studied. This suggests that the regenerative cells in the monkey beetles' midgut are located within the epithelium surrounded by digestive cells and are not in crypts protruding from the midgut wall. The reason for nidi being contained in crypts in some beetles such as $T$. fascicularis and not in others, such as the monkey beetles, is not known. Neither is the rate at which epithelial cells of the midgut are replaced in T. fascicularis, $P$. cinerea and $P$. flavolineata. The need for replacement may be important in plant feeders, as plant tissue can be tough enough to cause damage to the epithelial cells. Monkey beetles do eat bits of the floral tissue when they visit flowers. In addition, the degradation of digestive cells in the midgut of pollen-feeders may be increased by the nature of pollen digestion without the help of the enzyme exinase. More enzymes need to be secreted into the midgut lumen to deal with the pollen. Secretion of enzymes is an exhaustive process that leads to cell degradation and the need for cell replacement (Smith 1968).

\section{Peritrophic membrane}

The peritrophic membrane secreted by the cells of the midgut epithelium has protective and physiological functions. It is made up of a number of separate laminae, consisting of networks of chitin microfibrils embedded in a matrix of proteins and glycoproteins (Tellam 1996). When the cells of the midgut secrete precursors of the peritrophic membrane, these initially form a fluid material. In some insects it remains 
fluid, but in most insects it condenses into a delicate membrane enveloping the food (Terra 1990) as seen in the beetles studied here. Sometimes the membrane is so delicate that it is not recognised as being present. In some insects the membrane is only secreted after a meal has been ingested and the gut is distended, e.g. bloodsucking flies (Lehane et al. 1996). The peritrophic membrane occurs in almost all insects, the most notable exception being the Hemiptera. Hemipterans have a membranous covering of the microvilli ensheathed by an outer lipoprotein membrane known as the perimicrovillar membrane (Richards \& Richards 1977 ; Terra \& Ferreira 1994). This microvillar membrane system may be analogous to a peritrophic membrane.

By forming an envelope around the food bolus, the peritrophic membrane plays a role in protection and digestive efficiency of the insect. When an insect eats solid food, the membrane prevents the food particles from coming in direct contact with the microvilli, thus reducing damage to the cells. It also creates ecto- and endoperitrophic spaces separated by a barrier that is permeable to digestive enzymes and products of digestion. This means that the digestive process can be compartmentalised and it may be possible for countercurrents to flow within the midgut, increasing absorption efficiency and preventing digestive enzyme excretion (Terra 1990; Tellam 1996; Chapman 1998). Terra and Ferreira (1981) measured the excretory rates of digestive enzymes in Rhynchosciara americana (Diptera) larvae. Low rates revealed that $80 \%$ of enzymes present in the endoperitrophic space are removed from the food bolus before it is expelled from the animal. The authors proposed that only endoectoperitrophic circulation of digestive enzymes would make this possible. The endo- 
ectoperitrophic circulation of enzymes functions differently in different insects (Terra 1990).

The impermeability of the membrane may also give some protection against harmful chemicals in the food of phytophagous insects. For example, tannic acid is present in some plants and if the membrane is permeable to the acid (as in Locusta), the insect could die as a result of lesions to the midgut epithelium caused by tannic acid. The peritrophic membrane of Schistocerca, which feeds on plant matter containing tannin, is impermeable to tannic acid (Chapman 1998).

The membrane also forms a physical barrier to microorganisms and protects insects against pathogenic organisms that get ingested with the food. Pores in the membrane are too small to allow most bacteria to reach the midgut epithelium, and they remain contained within the envelope (Peters 1992). Some bacterial flora in the midgut are able to overcome this barrier by invading the tissues when the envelope is not yet fully developed. For example, in some honeybees, younger larvae are more susceptible to American foulbrood disease caused by Bacillus larvae than the older bee larvae, in which the peritrophic membrane is already developed and the bacterium cannot penetrate (Chapman 1998).

\section{Gregarines}

Protozoans such as gregarines are commonly found in the digestive tracts of invertebrates (Tanoda \& Kaya 1992). They were conspicuous in the digestive tract of the protea beetle, but none were seen in either monkey beetle species. The class Gregarinia consists of four orders: Blastgregarinida, Archgregarinida, Eugregarinida 
and Neogregarinida. The Eugregarinida includes species of gregarines that infect insects, but are of low virulence to them. Insect-eugregarine associations have been studied for many years. Studies of associations of the same species of host and gregarine but in different dietary situations have resulted in different conclusions about the associations. Gregarina polymorpha, a eugregarine inhabiting the midgut of the larval mealworm, Tenebrio molitor, was studied by Sumner (1936), who concluded that the association was mutualistic since the presence of the eugregarine increased the growth rate and reduced the death rate of mealworm larvae fed swine thyroid gland. However, Harry (1967) studied the same association and concluded that it was parasitic, as the presence of gregarines had a detrimental effect on the development of mealworm larvae fed on a suboptimal diet of white flour and oats (the optimal diet being wholemeal flour and oats). Dunkeld and Boush (1968) studied the relationship between black carpet beetle larvae Attagenus megatoma, and the eugregarine Pyxinia frenzeli. Starved last-instar black carpet beetle larvae infected with $P$. frenzeli lost weight twice as fast as uninfected larvae. Schwalbe and Baker (1976) performed a similar study and concluded that $P$. frenzeli is a commensal or a mutualist and not a pathogen. The theory exists that the insect-eugregarine relationships are normally commensal, but can become mildly pathogenic under severe nutrition stress and starvation.

The life cycle of gregarines varies greatly and is complex. It starts with the insect ingesting a mature oocyst, from which several sporozoites emerge and develop into trophozoites, and eventually into mature gamonts inhabiting the lumen of the midgut (Tanoda \& Kaya 1992). Mature gamonts were present in the midgut of $T$. fascicularis, sometimes within the peritrophic membrane and sometimes excluded from midgut 
contents by the peritrophic membrane. The gregarines did not appear to be harmful to the beetles, except in a few isolated cases where the inside of the peritrophic membrane was packed to capacity with the protozoans. Gregarines outside the peritrophic membrane were probably able to penetrate the membrane before it was properly developed, while others may have been ingested later and remained trapped within the membrane. However, the presence of small numbers of gregarines within the peritrophic membrane did not affect pollen digestion, it only reduced space in the gut lumen for ingested food. The pollen grains were digested equally well whether gregarines were enclosed within the peritrophic membrane or not. Although gregarines are common and potentially problematic organisms in the gut of $T$. fascicularis, it appears from the results that they do not impair the beetles' ability to digest pollen.

\section{Hindgut structure}

Where the midgut ends and the hindgut begins, the pyloric valve controls food entry into the hindgut. This anterior part of the hindgut is known as the pylorus and is the part of the alimentary canal from which the Malpighian tubules originate. In the beetle species studied, although the tubules were very closely associated with the hindgut, the distal ends of the tubules were free and did not form a cryptonephridial system with the hindgut. Cryptonephridial systems occur in many larval and adult Coleoptera to improve the efficiency of water reabsorption from the gut (Chapman 1998). The pylorus is followed by the ileum, a narrow tube that runs into the rectum. The posterior part of the ileum may be recognisably different from the anterior part, forming the colon. This difference was evident in T. fascicularis, but not in either monkey beetle species. The rectum is usually an enlarged sac with a thin epithelium. 
Again, this was apparent in T. fascicularis, but not in the monkey beetles studied. The cells of the rectum have a rich tracheal supply, consistent with their high levels of metabolism associated with absorption of water, salts and nutrients (Chapman 1998).

\section{Musculature}

The extrinsic and intrinsic visceral muscles extending along the length of the gut facilitate the passage of food along the gut. When the longitudinal muscles contract cross-sectional ridges are created along the gut, and when the circular muscles contract longitudinal folds are created along the epithelium. These ridges and folds were apparent in SEMs of both the protea beetle and monkey beetles.

\section{Pollen digestion}

Due to brood care and social organization in bees and wasps, they are considered to be the most important pollen collectors that specifically seek out and collect pollen (Barth 1985; D' Arcy et al 1996). Among bees in particular, there is much interest in pollen consumption and digestion among castes in the colony (Crailsheim et al 1992; Szolderitis \& Crailsheim 1993). Prior to the present study, the only work on the digestion of specific pollen grain nutrients by a pollen-feeder was carried out on two species of bees. Peng et al. (1985) looked at pollen digestion in the adult worker bee Apis mellifera, and Dobson and Peng (1997) considered pollen digestion in larval Chelostoma florisomne. Both studies reported extrusion of protoplasmic contents through germination pores and digestive enzymes then acted upon the exudate. Pollen in the gut of $A$. mellifera exhibited growth of short pollen tubes from swollen germination pores, similar to that observed in pollen ingested by hoverflies (Haslett 
1983). These short tubes were probably caused by a difference in osmotic concentration between the crop and midgut. As in the hoverflies, there was no extensive formation of the pollen tubes. Instead, tube growth stopped and contents gradually exuded out of the pores. Towards the end of the gut of both adult $A$. mellifera and larval C. florisomne, the walls of the pollen grains became weakened, probably due to enzymatic degradation, and grains appeared compressed or flattened.

Ingested pollen grains in the anterior midgut of $T$, fasciculoris, $P$. cinerea and $P$. flavolineata appeared to have intact walls and the grains were generally full. By the time grains reached the hindgut, the majority of the grains were empty and the wall that remained had collapsed and was broken in places (particularly in $P$. cinerea and P. flavolineata). The indigestible exine was finally excreted from the digestive system together with other waste products. The exact means by which protoplasmic contents were released from the pollen grains in the beetles studied here requires consideration of a number of possible mechanisms, as outlined in the introduction.

\section{Dealing with the exine}

It has already been established that the undigested exine wall is present in the faeces, so the beetles do not secrete the enzyme exinase, which collembolans use to break down the pollen wall (Scott \& Stojanovich 1963; Stanley \& Linskens 1974). The beetles ingest the whole pollen grain and there is no evidence of the use of methods such as "piercing and sucking" or "leaching and imbibing". These methods, described in the introduction, are used by insects that do not ingest the pollen such as thrips (Kirk 1984; 1987), biting flies (Downes 1955), butterflies (Gilbert 1972; De Vries 1979) and the eucalypt nectar fly (Nicolson 1994). 
It is unlikely that osmotic shock experienced by pollen grains in the beetle's gut is strong enough to cause the grains to burst and release their contents. Kroon et al. (1974) explained how the proventriculus in honeybees filters nectar ingested by the bee, allowing only particulate matter and not the carbohydrate solution to pass from the crop to the midgut. As a result, an osmotic pressure gradient is created between the crop and the midgut, and this sudden change in environment, from a high to a low osmotic concentration, may cause the pollen grains to burst. Kroon et al. (1974) demonstrated such a situation in vitro, but Peng et al. (1985), found that in $A$. mellifera rupturing of the pollen wall only occurred in the later stages of digestion and not at the point of passage into the midgut. Osmotic shock may cause rupturing only of thin-walled pollen grains. Moreover, there is no visible separation in the beetle's digestive system, equivalent to the proventricular valve in bees, to create such an osmotic gradient. Very few of the $P$. eximia and $B$. lamginosa pollen grains in the gut of the protea beetle were observed as being broken. The majority of empty grains in the hindgut remained intact, even when the walls did collapse inwards. Rupturing of O. thyrsoides pollen walls was observed in the monkey beetle's guts, but this was only at the end of digestion when grains were already empty and the pollen wall was probably weak from the action of enzymes in the lumen.

Some pollen-feeders may gain access to the protoplasmic contents of pollen grains by stimulating pseudo-germination with nectar or a similar solution, since germination of pollen grains is known to occur in vitro in solutions of sugar and water (Stanley \& Linskens 1974). Once the protoplasmic contents are outside the grain, digestive enzymes can begin to act upon them and begin digestion. Short pollen tube growth by 
pseudo-germination is sometimes followed by exudation, as mentioned above for bees (Peng et al 1985; Dobson \& Peng 1997) and hoverflies (Haslett 1983). Pseudogermination that results in extensive growth of the pollen tube has been reported in one study on the marsupial Tarsipes rostratus (Tumer 1984) and in some birds that have crops, such as the finches Geospiza scandens and Geospiza fortis (Grant 1996). The efficiency of digestion in the latter cases was above $90 \%$.

Turner (1984) reported that pseudo-germination occurs in the low $\mathrm{pH}$ environments present in the gut of $T$. rostratus. However, Scarabaeoidea families (Scarabaeidae and Passalidae) have very alkaline midgut contents (Terra \& Ferreira 1994) and if low pH is a prerequisite for pseudo-germination, it is unlikely to occur in the midgut of scarab beetles.

The finches, $G$. scandens and $G$. fortis were observed by Grant (1996) consuming nectar and pollen from Opuntia echios, the prickly pear cactus. It is highly likely that nectar stimulates pseudo-germination in this case, as Opuntia pollen grains germinated in vitro in a nectar and water solution, and germination was observed in crop samples in vivo (Grant 1996). However, in the present study sample pollen from $P$. eximia, $B$ lanuginosa and $O$. thyrsoides did not germinate when placed in $20 \%$ and $30 \%$ sucrose solutions (similar to the nectar concentrations of the same plants). Also, no observations on the stained slide material showed germination taking place in the gut.

The beetles studied here do not have crops. There is no place where nectar and pollen could be stored simultaneously for a long enough period for germination to be 
induced. The lesser double-collared sunbird Nectarinia chalybea also lacks a crop and there is no significant evidence of pseudo-germination occurring in its gut when the diet is a sugar solution containing Eucalyptus pollen (van Tets \& Nicolson in press). In contrast to the finches $G$. scandens and $G$. fortis, where a crop is present, pseudogermination does take place, and digestion efficiency is more than $90 \%$, efficiency of pollen digestion in the sunbird is less than $20 \%$ (van Tets \& Nicolson in press). Like the sunbirds, T. fascicularis, $P$. cinerea and $P$. flavlineata do not have crops; however digestion efficiency appears to be high, since all the nutrients are removed effectively and the majority of the grains reaching the hindgut and in the faeces are empty. There was no evidence that pseudo-germination was used by the beetles to gain access to the protoplasmic contents of the pollen grains, but whatever method is used, it must be highly efficient.

Microbial digestion of pollen in the caecum of some bats (Rasweiler 1977), and marsupials, such as Cercartetus nanus (Turner 1984) may occur where the caecum acts as a fermentation chamber and stores pollen grains with the gut microflora long enough for a significant amount of digestion to take place. However, the adult protea beetle and monkey beetles do not have caeca or any other specialised storage area in the gut that may facilitate microbial digestion. Microbial digestion of pollen in the gut is also only viable if gut passage rate is slow enough to allow time for microbial fermentation to liberate cell contents. The gut passage rates of the beetles in this study were not determined, but are unlikely to be slow enough to allow for microbial fermentation to take place as grains move through the gut. 
Besides osmotic shock, pseudo-germination and microbial digestion there are a number of other ways in which enzymes in the gut can come in contact with the pollen contents. Enzymes may mechanically penetrate the exine or pass through a germination pore or a pore in the exine that has been weakened by osmotic concentration differences (Simpson and Neff 1983). Such action of the enzymes is likely to occur in the beetles studied here, since firstly, as expected, the wall itself is not digested. Secondly, no bursting of the grains due to an osmotic gradient was observed, and thirdly, no evidence of pseudo-germination or exudation was found in the gut sections or in sugar solutions in vitro. Osmotic gradients, as well as digestive enzyme action in the lumen of the gut, probably weaken the wall of the pollen grain. It is this weakening of the wall that makes it easier for digestive enzymes to enter via pores or through smaller micro-channels in the wall. However, the intine barrier also needs to be taken into consideration. The intine is the inner layer of the pollen wall and together with the exine it lines the pollen wall pores, but it is not as resistant to digestion as the exine. The portion of the intine covering the germination pores probably has the greatest influence on digestion (Whitcomb and Wilson 1929; Peng et al 1985). The products of digestion inside the grain may extrude out via the same germination pores and other smaller pores in the wall that allowed the digestive enzymes to enter. It is the ability of enzymes and the products of digestion to overcome the intine barrier that is probably crucial for the digestion of all protoplasmic contents (Dobson and Peng 1997). There was no evidence of exudation from pollen grains in the beetles' gut. It is necessary to consider whether the exudation of products of digestion may be less obvious than the exudation of protoplasmic contents before digestive enzymes have acted upon it. Exudation of protoplasmic contents was evident in bees, where digestive enzymes only acted upon 
the exudate, which then disappeared as digestion progressed. When enzymes penetrate the pollen wall and digest nutrients inside the grain, the resulting exudate is already in a digested form and stain intensity would be much lower than in an exudate that has not been digested yet. Thus, when the claim is made that there was no evidence of exudation from pollen ingested by the beetles in the present study, it is specifically the exudation of undigested protoplasmic contents that is being referred to.

The proposed method of gaining access to the protoplasmic contents of the ingested pollen grain has not been previously reported for beetles. There are only three possible methods used by beetles reported to date: (1) Crowson (1981) suggested that beetles make use of their strong mandibles to chew the pollen and physically break its wall. (2) Pseudo-germination has been observed in the family Oedomeridae, where nectar stored in a diverticulum induces germination of ingested pollen grains (Arnett 1968; Crowson 1981; Samuelson 1994). (3) Rickson et al. (1990) proposed that the scarab beetle, Cyclocephala amazona, ingests trichomes with highly lignified cell walls to act as gastroliths and grind the pollen grains in its gut. None of these three methods occurs in the beetles studied here.

\section{Digestion of different nutrient types}

In the only two previous studies on the digestion of specific nutrients from within the pollen grain, the adult bee $A$. mellifera and the larval bee $C$. floristomne showed similar results for the disappearance of nutrients along the length of the gut (Peng et al. 1985; Dobson and Peng 1995). Proteins were digested and absorbed rapidly in the anterior and median midgut. Digestion of general carbohydrates (including starch) 
was evident in the anterior midgut, but absorption of the starch was the slowest of all the pollen nutrients. Amyloid and cellulose carbohydrates were digested and absorbed more rapidly than general carbohydrates. However, digestion and absorption of lipids occurred the most rapidly and completely of all the pollen nutrients.

All three beetle species in the present study exhibit a progression of nutrient digestion similar to that seen in the above mentioned bees in some ways. As in A. mellifera and C. floristomne, lipids were digested to a much greater extent than any other nutrient in the anterior midgut, and were digested at the fastest rate throughout the gut of the protea beetle and the monkey beetles. Initial disappearance of proteins in $T$. fascicularis was rapid and then slowed. For general carbohydrates (including starch) digestion was slow and gradual throughout the gut, compared to other nutrients. Amyloid and cellulose carbohydrates only began digestion in the median posterior midgut, but from this point on digestion occurred rapidly. In the monkey beetles $P$. cinerea and $P$. flavolineata all nutrients began digestion in the anterior midgut, whereas in T. fascicularis only lipids began digestion in the anterior midgut. As in the bees, the rate of digestion in monkey beetles was also fastest for lipids and slowest for general carbohydrates. The quick and efficient digestion of lipids observed here in beetles, as well as in bees (Peng et al. 1985; Dobson \& Peng 1997) may suggest that early lipid breakdown aids pollen digestion and that lipids are important nutrients in the diets of pollen-feeders. The prevalence of lipids as the main food storage in pollen of plants pollinated by pollen-feeders (Baker \& Baker 1979) supports the latter suggestion. 


\section{Digestion efficiency}

The protoplasmic contents of the pollen grains consumed by T. fascicularis, $P$. cinerea and $P$. flavolineata were clearly utilised, since nutrients were so effectively removed from the grains as they passed down the gut. Differences in digestion efficiencies between the beetles and between the nutrients themselves depend on a number of factors.

The degree of specialisation of a pollen-feeder plays a role in the efficiency with which pollen is digested. By counting the number of empty grains in the faeces Herrera and Martinez del Rio (1998) found that certain specialized nectarivorous and pollen-feeding species of bats were more efficient at digesting pollen than the frugivorous species studied. In addition, regular pollen-feeders species digested a higher percentage of pollen grains than did seasonal pollen-feeders (even if seasonal pollen-feeders were good at digesting pollen). The green protea beetle and monkey beetles are known pollen-feeders (Skaife 1955; Picker \& Midgley 1996), observed to consume nectar too if it is available. Such feeding behaviour would support the high degree of digestive ability noted in the beetles.

The length of the gut may be another determining factor in the efficiency of pollen digestion. Grant (1996) found that the high digestive ability (>90\%) of G. fortis and G. scandens is considerably high when compared to a specialist pollen and nectar feeder, the purple-crowned lorikeet, where efficiency of pollen digestion was $<50 \%$. The lorikeet has a relatively short gut, which is possibly long enough for the complete digestion of nectar, but is not long enough for all the ingested pollen to be processed (Richardson and Wooller, 1990). However, G. scandens does not have a significantly 
longer gut than the lorikeets relative to body size (Grant 1996), so gut length may be irrelevant here. The protea beetle has a gut 3.4 times the length of that of the monkey beetles studied. However in this case it is the monkey beetles, with the shorter gut (relative to body size), which display more efficient digestion. Digestion of all the nutrients starts in the anterior midgut and ends in the hindgut, where the stain uptake index recorded for all the nutrients is 1 ; i.e. the grains are empty. The protea beetle starts digestion of only one nutrient type, the lipids, in the anterior midgut. One would think that because the gut is so long digestion can be started later, but by the time grains reach the posterior hindgut all nutrients have a stain uptake index still $>1$; i.e. there is still some undigested material inside the pollen grains. A longer gut then does not necessarily mean increased efficiency.

The pollen from different plant species has different pollen wall components and compositions, and this too may affect pollen digestion efficiency. In studies on pollen digestion in flower-visiting birds, efficiencies ranged from less than $10 \%$ to more than 90\% (Martinez del Rio 1994; Grant 1996). As in the case of the finches, sunbirds and lorikeets mentioned above, the differences in digestion efficiency might be due to differences in digestibility and nutritive value of the pollen on which each species feeds (Grant 1996). Digestion of the pollen in the monkey beetles" gut is faster than that of the pollen in the protea beetle. This suggests that $O$. thyrsoides pollen consumed by the monkey beetles is more easily digested than $P$. eximia and $B$. lanuginosa pollen consumed by the protea beetle. Pollen type, rather than beetle species, may be responsible for the differences in digestion efficiencies. It is therefore important that both the digestive ability of the pollen-feeder and the digestibility of the pollen consumed needs to be considered in determining digestion efficiency. 


\section{The flowers and the beetles: a close relationship}

Important pollinators of the flowers they visit, the scarab beetles make good use of the rich supply of pollen available to them. Both partners benefiting from flower visits maintain the relationship between flower and pollinator by the beetle. An individual floret in the inflorescence of the genus Protea is self-sterile, although florets are compatible with other florets in the same inflorescence, and, since wind cannot pollinate the flowers, another vector is needed to transfer pollen to a compatible stigma (Coetzee \& Giliomee 1985). T. fascicularis is the largest and among the most typical Protea insects (Gess 1968) and in its quest to obtain food from the Protea inflorescence it effects pollination. The protea beetle is so closely associated with the genus Protea for food and shelter that their distribution is determined by the distribution of their host plants (Gess 1968). Monkey beetles are closely associated with the flowers of Namaqualand, particularly Asteraceae and Mesembryanthaceae (Picker \& Midgley 1996). The hairy beetles effectively bring about pollination of the flowers they visit to obtain pollen and nectar.

An additional benefit for the monkey beetles is created when the flowers close at night or during rainy and cool conditions. This phenomenon of nocturnal and coldweather flower closure has been considered as a means of providing a sanctuary for beetles and other cold-blooded pollinators (Cowling \& Pierce 1999). The closed flower creates a warm and protected environment for the embedded beetles, and when the outside temperature increases and the flower opens the beetles are relatively mobile and able to fly. This gives these beetles a thermal advantage over nonembedding beetles (Kirkman 1998) and other pollinators such as bees and flies, that 
have not had the warmth of a closed-flower shelter during the cold night and still need to warm up before being able to fly. The advantage to the plant is that chances of receiving pollen from neighbouring flowers are increased, especially on cooler days when other pollinators are less active. A more plausible reason for flower closure is explained by the plant's need to protect floral reproductive parts from exposure to unfavourable conditions (von Hase 1998; Cowling \& Pierce 1999). When wet, pollen of many plant species swells and bursts (Knox 1979), so the role in reproduction is destroyed. Von Hase (1998) studied the effects of moisture on pollen viability and the reasons for flower closure in Asteraceae and Mesembryanthaceae in Namaqualand. Some Asteraceae and Mesembryathaceae species experienced significant damage to pollen grains when exposed to moisture. The most important environmental influences that bring about flower closure are temperature and moisture. By closing their petals around the anthers the flowers create a relatively warm micro-climate, protecting the pollen from rain, fog and dew and in doing so, create a sanctuary for the beetles.

\section{Conclusion}

It is important to note that the various mechanisms used by pollen-feeders to overcome the barrier presented by the resistant exine require further study. Mechanisms used by pollen-feeders that do not ingest the pollen grains (such as, piercing and sucking or leaching and imbibing) seem easier to study and describe than those used by pollen-feeders that ingest the grains (osmotic shock, pseudogermination, exudation, microbial digestion or enzyme penetration). More speculation and inconsistency is evident in studies on pollen-feeders that ingest intact pollen 
grains. In some cases results are not definitive and no one particular mechanism can be determined as being solely responsible for access to protoplasmic contents. For example, although osmotic shock has been demonstrated in vitro (Kroon et al 1974) it has never been reported as the sole mechanism used to gain access to pollen protoplasmic contents. It has been considered to initiate germination pore swellings in pollen ingested by Apis mellifera (Peng et al 1985). Short pollen tubes were formed from these pores, but there was no extensive formation of the tubes. Instead tube growth stopped and was followed by exudation of protoplasmic contents. Thus, there is evidence of osmotic shock, pseudo-germination and exudation occurring together in one study on pollen digestion. In cases where overcoming the exine barrier has been attributed to pseudo-germination, other studies have found little or no evidence of the mechanism (Turner 1984; Richardson et al. 1986). The same applies for microbial digestion of pollen by bats and marsupials (Rasweiler 1977; Turner 1984; Richardson et al. 1986; Law 1992). Enzyme penetration (Simpson and Neff 1983) seems to be an effective method and is probably attainable by most pollen-feeders. It is possible that even in cases where there is evidence of the other methods, enzyme penetration may also be occurring. With further studies on pollen-feeding and pollen digestion, enzyme penetration may emerge as the most common method used. 


\section{Appendix 1}

\section{Fixative solutions}

(Sheehan \& Hrapchak 1980; Bancroft \& Stevens 1990)

Rossman's fixative:

$90 \mathrm{ml} 100 \%$ ethanol saturated with picric acid

$10 \mathrm{ml}$ neutralised commercial formalin

Neutral formal saline:

$100 \mathrm{ml} 40 \%$ formaldehyde

$900 \mathrm{ml}$ tap water

$9 \mathrm{~g}$ sodium chloride

Formal calcium:

$100 \mathrm{ml} 40 \%$ formaldehyde

$100 \mathrm{ml} 10 \%$ calcium chloride

$900 \mathrm{ml}$ distilled water

$7 \mathrm{~g}$ cadmium chloride 


\section{References}

ARMSTRONG, D. P. \& PATON, D. C. 1990. Methods for measuring amounts of energy available from banksia inflorescences. Australian Journal of Ecology $15: 291-297$.

ARNETT, R. H. 1968. Pollen feeding by Oedomeridae (Coleoptera). Bulletin of the Entomological Society of America 14: 184, 204 (abstract).

BAKER, H. G. \& BAKER, I. 1979. Starch in angiosperm grains and its evolutionary significance. American Journal of Botany 66: 591-600.

BAKER, H. G. \& BAKER, I. 1982. Chemical constituents of nectar in relation to pollination mechanisms and phylogeny. In: Biochemical aspects of evolutionary biology. (ed M. H. Nitecki), pp. 131-171. University of Chicago Press, Chicago.

BAKER, H. G. \& BAKER, I. 1983. Floral nectar sugar constituents in relation to pollinator type. In: Handbook of experimental pollination bioloy. (eds C. E. Jones \& R. L. Little), pp. 117-141. Van Nostrand Reinhold, New York.

BAKER, H. G. \& HURD, P. D. 1968. Intrafloral ecology. Annual Review of Entomology 13: 385-414.

BANCROFT, J. D. \& COOK, H. C. 1984. Manual of histological techniques. Churchill Livingstone, Edinburgh.

BANCROFT, J. D. \& STEVENS, A. 1990. Theory and practise of histological techniques. Churchill Livingstone, Edinburgh.

BARTH, F. G. 1985. Insects and flowers: the biology of partnerships. Princeton University Press, Princeton.

BEACH, J. H. 1982. Beetle pollination of Cyclanthus bipartitus (Cyclanthaceae). American Journal of Botany 69: 1074-1081.

BERNHARDT, P. 1996. Anther adaptations in animal pollination. In: The anther: form, function and phylogeny. (eds W. G. D'Arcy \& R. C. Keating), pp. 192220. Cambridge University Press, Cambridge.

BILLINSLEY, P. F. \& LEHANE, M. J. 1996.Structure and ultrastructure of the insect midgut. In: Biology of the insect midgut. (eds M. J. Lehane \& P. F. Billingsley), pp. 3-30. Chapman \& Hall, London.

BRACKENBURY, J. 1995. Insects and flowers: a biological partnership. Blanford, London. 
BRONSTEIN, J. L. 1995. The plant/pollinator landscape. In: Mosaic landscapes and ecological processes. (eds L. Hansson, L. Fahrig \& G. Merriam), pp. 257-288. Chapman and Hall, London.

BRUNHUBER, B. S. 1964. An investigation into the mechanisms of orientation connected with feeding in the protea beetle, Trichostetha fascicularis (Linn). Honours Project. Zoology Department, University of Cape Town.

BUCHMANN, S. L. 1983. Buzz pollination in angiosperms. In: Handbook of experimental pollination biology. (eds C. E. Jones \& R. L. Little), pp.73113. Van Nostrand Reinhold, New York.

BUCHMANN, S. L. \& NABHAN, G. P. 1996. The Forgotten Pollinators. Island Press/Shearwater Books, Washington D.C.

CARPENTER, F. M. 1992. Treatise on Invertebrate Paleontology. Part R of Arthropoda, vol. 4 of Superclass Hexapoda. Geological Society of America. CARTHEW, S. M. \& GOLDINGAY, R. L. 1997. Non-flying mammals as pollinators. Trends in Ecology and Evolution 12: 104-108.

CHAPMAN, R. F. 1998. The insects: structure and function. Cambridge University Press, Cambridge.

COETZEE, J. H. \& GILIOMEE, J.H. 1985. Insects in assosiation with the inflorescence of Protea repens (L.) (Proteaceae) and their role in pollination. Journal of the Entomological Society of Southern Africa. 48: 303-314.

COWLING, R. \& PIERCE, S. 1999. Namaqualand: a succulent desert. Fernwood Press, South Africa.

CRAILSHEIM, K., SCHNEIDER, L. H. W., HRASSNIGG, N., BUHLMANN, G., BROSCH, U., GMEINBAUER, R. \& SCHOFFMANN, B. 1992. Pollen consumption and utilization in worker honeybees (Apis mellifera carnica): dependence on individual age and function. Journal of Insect Physiology 38 : 409-419.

CREPET, W. L. 1979. Insect pollination: a paleontological perspective. Bioscience 29: 102-108.

CREPET, W. L., FRIIS, E. M. \& NIXON, K.C. 1991. Fossil evidence for the evolution of biotic pollination. In: The evolutionary interaction of animals and plants. (eds W. G. Chaloner, J. L. Harper \& J. H. Lawton), pp. 187-195. The Royal Society, London. 
CROWSON, R. A. 1981. The Biology of Coleoptera. Academic Press, London.

CUNNINGHAM, S. A. 1991. Experimental evidence for pollination of Banksia species by non-flying mammals. Oecologia 87: 86-90.

D'ARCY, W. G., KEATING, R. C. \& BUCHMANN, S.L. 1996. The calcium oxalate package or so-called resorption tissue in some angiosperm anthers. In: The anther: form, function and phylogeny. (eds W. G. D' Arcy \& R. C. Keating), pp.159-191. Cambridge University Press, Cambridge.

DAFNI, A., BERNHARDT, P., SHMIDA, A., IVRI, Y., GREENBAUM, S., O'TOOLE, C. H. \& LOSITO, L. 1990. Redbowl-shaped flowers: convergence for beetle pollination in the mediterranean region. Israel Journal of Botany $39: 81-92$.

DE VRIES, P. J. 1979. Pollen-feeding rainforest Parides and Battus butterflies in Costa Rica. Biotropica 11:237-238

DOBSON, H. E. M. \& PENG, Y. 1997. Digestion of pollen components by larvae of the flower-specialist bee Chelostema florisomne (Hymenoptera: Megachilidae). Journal of Insect Physiology 43: 89-100.

DODSON, C. H. 1962. The importance of pollination in the evolution of the orchids of tropical America. Bulletin of the American Orchid Society 31: 525-534, $641-649,731-735$.

DOMBROW, H. 1997. New species of Hopliini from the Northern and Western Cape Province of the Republic of South Africa (Coleoptera: Scarabaeidae: Melolonthinae: Hoplini). Coleoptera 1: 137-160.

DOWNES, J. A. 1955. The food habits and description of Atrichopogan pollinivorus (Diptera: Ceratopogonidae). Transactions of the Royal Entomological Society of London 106: 439-453.

DUNKELD, F. V. \& BOUSH, G. M. 1969. Effect of starvation on the black carpenter beetle, Attagenus megatoma, infected with the eugregarine Pyxinia frenzeli. Journal of Invertebrate Pathology 14: 49-52.

DU TOIT, J. T. 1990. Giraffe feeding on Acacia flowers: predation or pollination? African Journal of Ecology 28: 63-68.

EVANS, A. V. \& BELLAMY, C. L. 1996. An inordinate fondness for beetles. Henry Holt \& Company, New York.

FAEGRI, K. \&VAN DER PIJL, L. 1966. The Principles of Pollination Ecology. Pergamon Press, Oxford. 
FARRELL, B. D. 1998. "Inordinate fondness" explained: why are there so many beetles? Science 281: 555-559.

FERRARI, S. F. \& STRIER, K. B. 1992. Exploitation of Mabea fistulifera nectar by marmosets (Callithrix flaviceps) and muriquis (Brachyteles arachnoides) in south-east Brazil. Joumal of Tropical Ecology 8: 225-239.

GESS, F. W. 1968. Insects found on Proteas. Journal of the Botanical Society of South Africa 54:29-33.

GILBERT, F. S. 1981. Foraging ecology of hoverflies: morphology of the mouthparts in relation to feeding on nectar and pollen in some common urban species. Ecological Entomology 6: 245-262.

GILBERT, L. E. 1972. Pollen feeding and reproductive biology of Heliconius butterflies. Proceedings of the National Academy of Sciences, United States of America 69: 1403-1407.

GOLDBLATT, P., BERNHARDT, P. \& MANNING, J. C. 1998. Pollination of petaloid geophytes by monkey beetles (Scarabaeidae: Rutelinae: Hopliini) in South Africa. Anmuls of the Missouri Botanical Garden 85: 215-230.

GOLDINGAY, R. L., CARTHEW, S. M. \& WHELAN, R. J. 1991. The importance of nonflying mammals in pollination. Oikos 61:79-87.

GOTTSBERGER, G. 1974. The structure and function of the primitive angiosperm flower. Acta Botanica Neerl. 23: 461-471.

GOTTSBERGER, G. 1977. Some aspects of beetle pollination in the evolution of flowering plants. Plant Systematics and Evolution, Supplementary 1: 211-226.

GOTTSBERGER, G. 1989a. Beetle pollination and flowering rhythm of Annona spp. (Annonaceae) in Rrazil. Plant Systematics and Evolution 167: 165-187.

GOTTSBERGER, G. 1989b. Comments on flower evolution and beetle pollination in the genera Annona and Rollina (Annonaceae). Plant Systematics and Evolution 167: 189-194.

GOTTSBERGER, G. 1990. Flowers and beetles in the South American tropics. Botanica Acta. 103:360-365.

GRANT, B. R. 1996. Pollen digestion by Darwin's finches and its importance for early breeding. Ecology 77: 489-499.

GRANT, V. 1950. The pollination of Cyclanthus occidentalis. American Journal of Botany 37: 294-297.

GROGAN, D. E. \& HUNT, J. H. 1979. Pollen proteases: their potential role in insect 
digestion. Insect Biochemistry 9: 309-313.

HARRY, O. G. 1967. The effect of a eugregarine Gregarina polymorpha on the mealworm larva of Tenebrio molitor. Journal of Protozoan Zoology 14(4): $539-547$.

HASLETT, J. R. 1983. A photographic account of pollen digestion by adult hoverflies. Physiological Entomology 8: 167-171.

HERRERA M., L. G. \& MARTINEZ DEL RIO, C. 1998. Pollen digestion by new world bats: effects of processing time and feeding habits. Ecology 79: $2828-2838$.

HOLLOWAY, B. A. 1976. Pollen-feeding in hover-flies (Diptera: Syrphidae). New Zealand Journal of Zoology 3: 339-350.

HOWELL, D. J. 1974. Bats and pollen: physiological aspects of the syndrome of chiropterophily. Comparative Biochemical Physiology 48A: 263-276.

JOHNSON, S.A., VAN TETS, I. G. \& NICOLSON, S. W. 1999. Sugar preferences and xylose metabolism of a mammal pollinator, the Namaqua Rock Mouse (Aethomys namaquensis). Physiological and Biochemical Zoology 72: 438444.

JOHNSON, S. D. \& STEINER, K. E. 2000. Generalization versus specialization in plant pollinator systems. Trends in Ecology and Evolution 15: 140-143.

KEVAN, P. G. \& BAKER, H. G. 1983. Insecta as flower visitors and pollinators. Annual Review of Entomology 28: 407-453.

KEVAN, P. G., CHALONER, W. G. \& SAVILE, D. B. O. 1975. Interrelationships of early terrestrial arthropods and plants. Palaeontology 18: 391-417.

KIRK, W. D. 1984. Pollen-feeding in thrips (Insecta: Thysanoptera). Journal of Zoology, London 204: 107-117.

KIRK, W. D. 1987. How much pollen can thrips destroy? Ecological Entomology 12: $31-40$.

KIRKMAN, M. 1998. Do embedding monkey beetles (Scarabaeidae: Hopliini) have a thermal advantage over their non-embedding counterparts. Honours Project. Zoology Department, University of Cape Town.

KNOX, R. N. 1979. Pollen and allergy. Studies in biology 107. Edward Arnold, London.

KROON, G.H., VAN PRAAGH, J. P. \& VELTHUIS, H. H. W. 1974. Osmotic shock as a prerequisite to pollen digestion in the alimentary tract of the worker 
honeybee. Journal of Apicultural Research 13:177-181.

LAW, B. S. 1992. Physiological factors affecting pollen use by Queensland Blossom bats, Syconycteris australis. Functional Ecology 6:257-264.

LEHANE, M. J., ALLINGHAM, P. \& WEGLICKI, P. 1996. Peritrophic matrix composition of the tsetse fly, Glossina morsitans morsitans. Cell Tissue Res. 283:375-384.

LEWIS, T. 1973. Thrips, their biology, ecology and economic importance. Academic Press, London.

LOUW, G. N. \& NICOLSON, S. W. 1983. Thermal, energetic and nutritional considerations in foraging and reproduction of the carpenter bee Xylocopa capitata. Journal of the Entomological Society of Southern Africa 46: 227 : 240 .

LOUW, S. 1987. Observations on the mating behaviour of Platychelus brevis Burmeister (Coleoptera: Scarabaeidae: Rutelinae). Joumal of the Entomological Society of Southern Africa 50: 258-259.

MANNING, J. \& GOLDBLATT, P. 1996. West Coast, South African Wild Flower Guide 7. Botanical Society of South Africa, Darling Wild Flower Society and National Botanical Institute, Claremont.

MARTINEZ DEL RIO, C. 1994. Nutritional ecology of fruit-eating and flowervisiting birds and bats. In: The digestive system in mammals: food, form amd function. (eds D. J. Chivers \& P. Langer), pp. 103-125. Cambridge University Press, Cambridge.

MILGROM, L. 1985. Spiders with a taste for pollen. New Scientist 21 March: p14.

MORELL, V. 1998. Earth's unbounded beetlemania explained. Science 281: $501-503$.

NICOLSON, S. W. 1990. Osmoregulation in a nectar-feeding insect, the carpenter bee Xylocopa capitata: water excess and ion conservation. Physiological Entomology 15: 433-440.

NICOLSON, S. W. 1994. Pollen feeding in the eucalypt nectar fly, Drosophila flavohirta. Physiological Entomology 19: 58-60.

OVERDORFF, D. J. 1992. Differential pattems in flower feeding by Eulemur fulvus rufus and Eulemur rubriventer in Madagascar. American Journal of Primatology 28:191-203. 
PATON, D.C. 1981. The significance of pollen in the diet of the New Holland Honeyeater, Phylidonyris novaehollandiae (Aves: Meliphagidae). Australian Journal of Zoology 29: 217-224.

PENG, Y.\& MARSTON, J. M. 1986. Filtering mechanism of the honey bee proventriculus. Physiological Entomology 11: 433-439.

PENG, Y., NARS, M. E., MARSTON, J. M. \& FANG, Y. 1985. The digestion of dandelion pollen by adult worker honeybees. Physiological Entomology $10: 75-82$.

PETERS, W. 1992. Peritrophic Membranes, Zoophysiology Series. Vol. 30. 238pp. Springer, Berlin.

PICKER, M. D. \& MIDGLEY, J. J. 1994. Observations on unusual mating and fossorial activity in the monkey beetle Hoplocnemis crassipes Olivier (Coleoptera: Scarabaeidae: Rutlinae). African Entomology 2: 181-188.

PICKER, M. D. \& MDGLEY, J. J. 1996. Pollination by monkey beetles (Coleoptera: Scarabaeidae: Hopliini): flower and colour preferences. African Entomology 4: $7-14$

PROCTOR, M., YEO, P.\& LACK, A. 1996. The Natural History of Pollination. Haper Collins, London.

RASWEILER, J. J. 1977. The care and management of bats as laboratory animals. In: Biology of bats. Vol. 3. (ed W. A. Wimsatt), pp. 519-617. Academic Press, New York.

REBELO, A. G. \& BREYTENBACH, G. J. 1987. Mammal pollination in the Cape flora. In: A preliminary synthesis of pollination biology in the Cape flora. (ed A. G. Rebelo), pp. 109-125. South African National Scientific Programmes Report No:141.

RICHARDS, A. G. \& RICHARDS, P. A. 1977. The peritrophic membranes of insects. Annual Review of Entomology 22: 219-240.

RICHARDSON, K.C. \& WOOLLER, R. D. 1990. Adaptations of the alimentary tract of some Australian lorikeets to a diet of pollen and nectar. Australian.Journal of Zoology 38: 581-586.

RICHARDSON, K.C., WOOLLER, R.D. \& COLLINS, B.G. 1986. Adaptations to a diet of nectar and pollen in the marsupial Tarsipes rostratus (Marsupialia: Tarsipedidae). J. Zool., Lond. 208: 285-297.

RICKSON, F. R., CRESTI, M. \& BEACH, J.H. 1990. Plant cells which aid in 
pollen digestion within a beetles guts. Oecologia $82: 424-426$.

RIEK, E. F. 1973. The insects of Australia. Melbourne University Press, Melbourne. SAMUELSON, G. A. 1994. Pollen consumption and digestion by leaf beetles. In:

Novel Aspects of the Biology of Chrysomelidae. (eds P. H. Jolivet, M. L.

Cox \& E. Pettipierre), pp. 179-183. Kluwer, Dordrecht.

SCHOLTZ, C. H. \& CHOWN, S. L. 1995. The evolution of habitat use and diet in the

Scarabaeoidea: a phylogenetic approach. In: Biology, Phylogeny and

Classification of Coleoptera: Papers Celebrating the $80^{\text {th }}$ Birthday of Roy A.

Crowson. Edited by J. Pakaluk \& S. A. Slipinski. Muzeum i Instytut Zoologii

PAN, Warszawa.

SCHWALBE, C. P. \& BAKER, J. E. 1976. Nutrient reserves in starving black carpet

beetle larvae infected with the eugregarine Pyxinia frenzeli. Journal of Invertebrate Pathology 28: 11-15.

SCOTT, H. G. \& STOJANOVICH, C.J. 1963. Digestion of juniper pollen by

Collembola. Florida Entomology 46: 189-191.

SHEEHAN, D. C. \& HRAPCHAK, B. B. 1980. Theory and practise of histotechnology. The C. V. Mosby Company, St. Louis.

SIMPSON B. B. \& NEFF, J.L. 1983. Evolution and diversity of floral rewards. In:

Handbook of experimental pollination biology. (eds C. E. Jones \& R. L.

Little), pp. 142-159. Van Nostrand Reinhold, New York.

SKAIFE, S. H. 1955. Dwellers in the darkness: an introduction to the study of termites. Pp. 84-86. Longmans, London.

SMART, J. \& HUGHES, N. F. 1973. The insect and the plant: progressive palaeoecological intergration. In: Insect/Plant Relationships. (ed H. F. Emden), pp. 143-155. Symposia of the Royal Entomological Society of London. No. 6.

SMTTH, D. S. 1968. Insect cells: structure and function. Oliver and Boyd, Edinburgh.

SMITH, R. B. \& MOMMSEN, T. P. 1984. Pollen feeding in an orb-weaving spider. Science 226: 1330-1332.

SNODGRASS, R. E. 1925. Anatomy and physiology of the honey bee. McGraw-Hill, New York.

SNODGRASS, R. E. 1935. Principles of insect morphology. McGraw-Hill, New York.

STANLEX, R. G. \& LINSKENS, H.F. 1974. Pollen: Biology Biochemistry 
Management. Springer-Verlag, New York.

STEINER, K. 1998a. The evolution of beetle pollination in a South African orchid. American Journal of Botany 85: 1180-1193.

STENER, K. 1998b. Beetle pollination of peacock moraeas (Iridaceae) in South Africa. Plant Sysematics and Evolution 209:47-65.

SUMNER, R. 1936. Relation of gregarines to growth and longevity in the mealworm, Tenebrio molitor. Annals of the Entomology Society of America 29:645648.

SUSSMAN, R. W. \& RAVEN, P. H. 1978. Pollination by lemurs and marsupials: an archaic coevolutionary system. Science 200: 731-736.

SZOLDERITS, M. R. \& CRAILSHEIM, K. 1993. A comparison of pollen consumption and digestion in honeybee (Apis mellifera carnica) drones and workers. Joumal of Insect Physiology 39: 877-881.

TANODA, Y. \& KAYA, H. K. 1992. Protozoan infections: Apicomplexa, Microspora. In: Insect Pathology. Academic Press, London.

TELLAM, R. L. 1996. The peritrophic matrix. In: Biology of the insect midgut. (eds M. J. Lehane \& P.F. Billingsley), pp. 86-114. Chapman \& Hall, London.

TERRA, W. R. \& FERREIRA, C. 1981. The physiological role of the peritrophic membrane and trehalase digestive enzymes in the midgut and excreta of starved Rhynchosciara. Journal of Insect Physiology 27: 325-331.

TERRA, W. R. 1990. Evoultion of digestive systems of insects. Annual review of Entomology 35:181-200.

TERRA, W. R. \& FERREIRA, C. 1994. Insect digestive enzymes: properties, compartmentalisation and function. Comparative Biochemical Physiology $1: 1-62$

THEN, L. B. 1974. Floral biology of Magnolia. American Journal of Botany 61 : $1037-1045$.

THIEN, L. B. 1980. Patterns of pollination in the primitive angiosperms. Biotropica 12: $1-13$.

TURNER, V. 1982. Marsupials as pollinators in Australia. In: Pollination and Evolution. (eds J. A. Armstrong, J. M. Powell \& A. J, Richards), pp. 55-65. Royal Botanic Gardens, Sydney.

TURNER, V. 1984, Banksia pollen as a protein source in the diet of two Australian 
marsupials: Cercatetus nanus and Tarsipes rostratus. Oikos 43:53-61.

VAN DER PIJL, L. 1960. Ecological aspects of flower evolution. I Phyletic evolution. Evolution 14: 403-416.

VAN TETS, 1. G. 1997. Extraction of nutrients from Protea pollen by African rodents. Belgian Journal of Zoology 127: 61-67.

VAN TETS, I. G. \& NICOLSON, S. W. 2000. Pollen and the nitrogen requirments of Lesser Double Collared Sunbird (Nectarinia chaybea). Auk, in press.

VAN TETS, I. G. \& WHELAN, R. J. 1997. Pollen in the diet of four flower feeding mammals. Ecography 20: 499-505.

VON HASER, A. 1998. Why do flowers in Namaqualand close? Flower closure in relation to the environment and pollen sensitivity to moisture. Honours Project, University of Cape Town.

WASER, N. M., CHITTKA, L., PRICE, M. V., WILLIAMS, N. M. \& OLLERTON, J. 1996. Generalization in pollination systems, and why it matters. Ecology 77 : 1043-1060.

WHITCOMB, W. \& WILSON, H. F. 1929. Mechanics of digestion of pollen by the adult honeybee and the relation of undigested parts to dysentry of bees. Wisconsin Agricultural Experiment Station Research Bulletin No. 92.

WHITEHEAD, V. B., GILIOMEE, J. H. \& REBELO, A.G. 1987. Insect pollination in the Cape flora. In: A preliminary synthesis of pollination biology in the Cape flora. (ed A. G. Rebelo), pp. 52-82. South African National Scientific Programmes Report No: 141.

WIENS, D. \& ROURKE, J. 1978. Rodent pollination in southem African Protea spp. Nature 276: 71-73.

WIENS, D., ROURKE, J., CASPER, B. B., RICKART, E. A., LAPINE, T. R, PETERSON, C. J. \& CHANNING, A. 1983. Nonflying mammal pollination of southern African proteas: a non-coevoled system. Annals of the Missouri Botanical Garden 70: 1-31.

YOON, C. K. 1998. A taste for flowers helped beetles conquer the world. The New York Times: Science Times July 28: 1-5.

ZAR, J.H. 1984. Biostatistical Analysis. Prentice-Hall, New Jersey. 